\title{
Spectrally Enhanced Lighting Program Implementation for Energy Savings:
}

Field Evaluation

\author{
Prepared by \\ Pacific Northwest National Laboratory
}

for

U.S. Department of Energy

Office of Energy Efficiency and Renewable Energy Building Technologies Program

August 2006 


\section{Pacific Northwest}

National Laboratory

Operated by Battelle for the

U.S. Department of Energy

\title{
Spectrally Enhanced Lighting Program Implementation for Energy Savings: Field Evaluation
}

\author{
KL Gordon \\ GP Sullivan \\ PR Armstrong \\ EE Richman \\ BD Matzke
}

August 2006

Prepared for the U.S. Department of Energy under Contract DE-AC05-76RL01830 


\title{
DISCLAIMER
}

This report was prepared as an account of work sponsored by an agency of the United States Government. Neither the United States Government nor any agency thereof, nor Battelle Memorial Institute, nor any of their employees, makes any warranty, express or implied, or assumes any legal liability or responsibility for the accuracy, completeness, or usefulness of any information, apparatus, product, or process disclosed, or represents that its use would not infringe privately owned rights. Reference herein to any specific commercial product, process, or service by trade name, trademark, manufacturer, or otherwise does not necessarily constitute or imply its endorsement, recommendation, or favoring by the United States Government or any agency thereof, or Battelle Memorial Institute. The views and opinions of authors expressed herein do not necessarily state or reflect those of the United States Government or any agency thereof.

\author{
PACIFIC NORTHWEST NATIONAL LABORATORY \\ operated by \\ BATTELLE \\ for the \\ UNITED STATES DEPARTMENT OF ENERGY \\ under Contract DE-AC05-76RL01830 \\ Printed in the United States of America \\ Available to DOE and DOE contractors from the \\ Office of Scientific and Technical Information, \\ P.O. Box 62, Oak Ridge, TN 37831-0062; \\ ph: (865) 576-8401 \\ fax: (865) 576-5728 \\ email: reports@adonis.osti.gov
}

\author{
Available to the public from the National Technical Information Service, \\ U.S. Department of Commerce, 5285 Port Royal Rd., Springfield, VA 22161 \\ ph: (800) 553-6847 \\ fax: $(703) 605-6900$ \\ email: orders@ntis.fedworld.gov \\ online ordering: http://www.ntis.gov/ordering.htm
}




\section{Spectrally Enhanced Lighting Program Implementation for Energy Savings:}

\section{Field Evaluation}

KL Gordon

GP Sullivan

PR Armstrong

EE Richman

BD Matzke

August, 2006

Prepared for

the U.S. Department of Energy

Under Contract DE-AC05-76RLO1830

Pacific Northwest National Laboratory

Richland, Washington 99352 


\section{Executive Summary}

This report provides results from an evaluation of lighting retrofits at three office buildings in California in 2005. Field measurements were conducted by Pacific Northwest National Laboratory (PNNL) for the U.S. Department of Energy (DOE) Building Technologies Program as part of the Spectrally-Enhanced Lighting Program: Implementation for Energy Savings (SELPIES).

The SELPIES demonstrations were developed to validate the performance of a lighting design strategy for commercial office buildings based on the use of "spectrally enhanced" fluorescent lamps. The basis for the approach is research conducted during the 1990s indicating that fluorescent lamps with relatively more radiant energy in the shorter (blue) wavelengths of the visible spectrum will be perceived by the human eye as brighter, compared to lamps with less energy in these wavelengths.

The theory behind spectrally enhanced lighting is that, for the same amount of light output (measured with a standard illuminance meter), lamps with a higher correlated color temperature (CCT) will appear brighter than those with lower CCT. Thus, energy can be saved because the actual light output of the higher CCT lamps can be decreased, while maintaining equivalent perceived brightness and visual acuity relative to lower CCT lamps. Energy savings are achieved by using lower wattage lamps and/or lower ballast factor ballasts. In the SELPIES demonstrations, existing fluorescent lamps, from 3000 to 4100 Kelvin, were replaced with lamps of 5000 Kelvin. Normal ballast-factor ballasts (0.88) were replaced with new electronic ballasts with ballast factors ranging from 0.60 to 0.77 .

The demonstrations were designed to decrease lighting power loads in the three buildings by $22 \%$ $50 \%$, depending on the existing installed lamps and ballasts. The project designers hypothesized that this reduction in electrical loads could be achieved by the change to higher CCT lamps without decreasing occupant satisfaction with the lighting. During the period from August through December 2005, PNNL performed field measurements and occupant surveys before and after the lighting retrofits were completed. PNNL measured the following: overhead lighting electrical loads, light levels in the workspace, task lighting use, and occupant ratings of satisfaction with the lighting. The analysis compared pre-retrofit to post-retrofit conditions in these four areas.

Electrical loads $(\mathrm{kW})$ and consumption $(\mathrm{kWh})$ by the overhead lighting equipment were measured by installing data logger meters on the lighting circuits at the lighting control panel. Data were collected for at least two weeks under the pre-retrofit or baseline condition (in which existing lamps were replaced with identical new lamps and the fixtures were cleaned) and for at least two weeks following the retrofit with the new higher CCT lamps and new ballasts. The logging meters were configured to record average overhead lighting loads (in $\mathrm{kW}$ ) in five-minute intervals 24 hours per day during the monitoring periods. In addition, connected load measurements were taken on a sample of fixtures in each building during the baseline period and in the post-retrofit period.

Pre-retrofit and post-retrofit illuminance measurements were taken at representative spaces in each building before and after retrofit. The instrument used for all measurements was a combined photopic/scotopic meter. The human eye has two types of photoreceptor cells, known by their shape as "cones" and "rods." The photopic luminous efficiency function describes the sensitivity of the coneshaped photoreceptor cells to all the wavelengths in the visible spectrum. The rod-shaped photoreceptor 
cells have a different sensitivity curve, called the scotopic luminous efficiency function. Standard light meters are calibrated to the photopic response. Use of a photopic/scotopic meter allowed for measurement of the scotopic illuminance levels and calculation of the scotopic to photopic (S/P) ratio. The S/P ratio provides an easily referenced indicator of relative blue content in the light source. Most light sources have $\mathrm{S} / \mathrm{P}$ ratios ranging from 0.8 to 2.5 , with the higher values containing more energy in the blue wavelengths of the visible spectrum.

Pre- and post-retrofit task lighting use was monitored to assess whether people compensated for the lower overhead light levels by using their task lights more frequently. In all three buildings, undercabinet mounted task lighting fixtures of 15-40 watts were present. The frequency of task lighting use was monitored with portable data loggers installed in a sample of task lights in each building. Data were collected for about two weeks in both the pre- and post-retrofit periods. In addition to monitoring task lighting use in a sample of work spaces, two questions regarding task lighting use were included on the occupant survey. The first asked whether the occupant had a desk/task light in their workspace. If they indicated the presence of a desk/task light, a subsequent question asked the respondent to choose a frequency among the following choices: Never, Less than half the time, About half the time, More than half the time, or Always.

A web-based occupant survey collected occupant ratings of satisfaction with the lighting prior to and following the retrofits. The project designers hypothesized that there would not be a statistically significant change in occupant ratings of satisfaction with the lighting after the retrofit. The survey asked three questions about lighting satisfaction, as well as several other questions on thermal comfort and office furnishings. The survey was conducted on-line and took less than five minutes to complete. Fulltime staff in each building were asked to complete the survey three weeks after the baseline condition was established, and again three weeks after the retrofit was completed, to allow for adaptation to the new lighting conditions.

PNNL's evaluation found that connected loads due to overhead lighting in the three buildings decreased by $20 \%-46 \%$ following the retrofit. Horizontal photopic light levels decreased by $15 \%-31 \%$. Task lighting use did not change significantly, as indicated by metered use or in terms of occupants' reported use. Finally, occupant ratings of satisfaction with the lighting did not change significantly following the retrofits in any of the three buildings. Specific results found in the three buildings are summarized in the table below. 
Table S.1. Summary of SELPIES Field Evaluation Results by Building

\begin{tabular}{|c|c|c|c|c|c|c|}
\hline & \multicolumn{2}{|c|}{ Building A } & \multicolumn{2}{|c|}{ Building B } & \multicolumn{2}{|c|}{ Building C } \\
\hline \multicolumn{7}{|l|}{ Energy Measurements } \\
\hline Change in connected load $(\mathrm{kW})$ & \multicolumn{2}{|c|}{$-45.6 \%$} & \multicolumn{2}{|c|}{$-19.8 \%$} & \multicolumn{2}{|c|}{$-20.5 \%$} \\
\hline Est. annual energy savings (kWh) & \multicolumn{2}{|c|}{44,000} & \multicolumn{2}{|c|}{60,000} & \multicolumn{2}{|c|}{37,000} \\
\hline \multicolumn{7}{|l|}{ Light Level Measurements } \\
\hline Change in horizontal photopic illuminance & \multicolumn{2}{|c|}{$-20 \%$} & \multicolumn{2}{|c|}{$-31 \%$} & \multicolumn{2}{|c|}{$-15 \%$} \\
\hline Change in $\mathrm{S} / \mathrm{P}$ ratio & \multicolumn{2}{|c|}{$+40 \%$} & \multicolumn{2}{|c|}{$+46 \%$} & \multicolumn{2}{|c|}{$+19 \%$} \\
\hline \multicolumn{7}{|l|}{ Task Lighting Measurements } \\
\hline Change in task lighting use & \multicolumn{2}{|c|}{$\begin{array}{l}-3.9 \% \\
\text { (Not statistically } \\
\text { significant) }\end{array}$} & \multicolumn{2}{|c|}{$\begin{array}{l}+2.7 \% \\
\text { (Not statistically } \\
\text { significant) }\end{array}$} & \multicolumn{2}{|c|}{$\begin{array}{c}-1.5 \% \\
\text { (Not statistically } \\
\text { significant) }\end{array}$} \\
\hline Occupant Satisfaction Measurements & Pre & Post & Pre & Post & Pre & Post \\
\hline \multirow{2}{*}{$\begin{array}{l}\text { How satisfied are you with the amount of light in } \\
\text { your workspace? (mean scores) } \\
1=\text { very dissatisfied; } 7=\text { very satisfied }\end{array}$} & 5.15 & 5.23 & 5.24 & 5.26 & 5.49 & 5.56 \\
\hline & \multicolumn{2}{|c|}{$\begin{array}{l}\text { Not statistically } \\
\text { significant }\end{array}$} & \multicolumn{2}{|c|}{$\begin{array}{l}\text { Not statistically } \\
\text { significant }\end{array}$} & \multicolumn{2}{|c|}{$\begin{array}{c}\text { Not statistically } \\
\text { significant }\end{array}$} \\
\hline \multirow{2}{*}{$\begin{array}{l}\text { How satisfied are you with your visual comfort } \\
\text { under this lighting? (mean scores) } \\
\text { 1=very dissatisfied; } 7=\text { very satisfied }\end{array}$} & 4.90 & 5.10 & 5.04 & 5.06 & 5.29 & 5.48 \\
\hline & \multicolumn{2}{|c|}{$\begin{array}{l}\text { Not statistically } \\
\text { significant }\end{array}$} & \multicolumn{2}{|c|}{$\begin{array}{l}\text { Not statistically } \\
\text { significant }\end{array}$} & \multicolumn{2}{|c|}{$\begin{array}{c}\text { Not statistically } \\
\text { significant }\end{array}$} \\
\hline \multirow{2}{*}{$\begin{array}{l}\text { Overall, does the lighting quality enhance or } \\
\text { interfere with your ability to get your job done? } \\
\text { (mean scores) } \quad 1=\text { interferes; } 7=\text { enhances }\end{array}$} & 4.62 & 5.03 & 4.88 & 5.03 & 5.26 & 5.28 \\
\hline & \multicolumn{2}{|c|}{$\begin{array}{l}\text { Statistically } \\
\text { significant }\end{array}$} & \multicolumn{2}{|c|}{$\begin{array}{l}\text { Not statistically } \\
\text { significant }\end{array}$} & \multicolumn{2}{|c|}{$\begin{array}{c}\text { Not statistically } \\
\text { significant }\end{array}$} \\
\hline
\end{tabular}




\section{Acknowledgments}

This work was conducted for the US Department of Energy, Building Technologies Program, Lighting Research and Development program, managed by Dr. James Brodrick. The authors acknowledge Jim's oversight and advice during the course of the study.

The authors further acknowledge Brad Gustafson of DOE's Federal Energy Management Program (FEMP) for his critical assistance in securing two of the three demonstration sites for the project. FEMP provided supplementary funding to enable participation by these federal facilities.

We are grateful for the cooperation of the facility management staff in the three demonstration buildings, including the following individuals: Rhonda Ross, Lex Christiansen, Mark Silva, Joe Garatti, Lenny Lethaby, Warren DeBoer, Jim Lewis, Joel Salvador, Tom Santoianni, and Paul Kistler. In addition, we thank all of the building occupants who took time to complete the pre- and post-retrofit surveys.

We thank Pacific Gas \& Electric Company's Pacific Energy Center for the loan of 100 portable data loggers used in monitoring task lighting use in the buildings.

We thank PNNL staff members Kathi Ruiz, for her assistance in making follow-up survey calls to the building occupants, and Terri Gilbride, for her conscientious and comprehensive editing of this report.

Finally, the authors acknowledge Brian Liebel, of AfterImage + Space, the principal investigator of the Spectrally-Enhanced Lighting Program: Implementation for Energy Savings (SELPIES), for his cooperation in all aspects of the evaluation. 


\section{Contents}

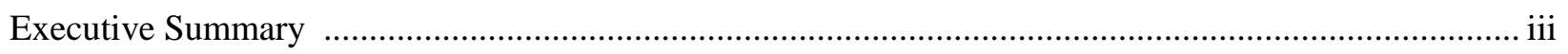

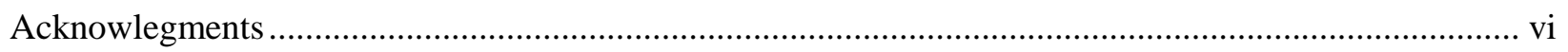

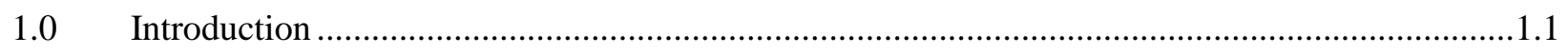

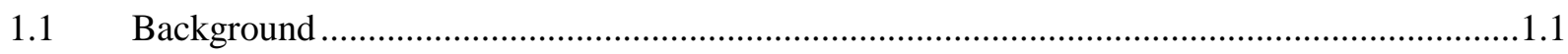

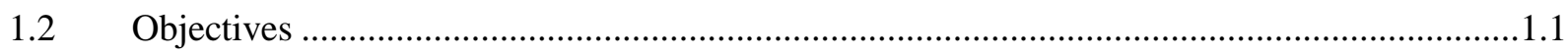

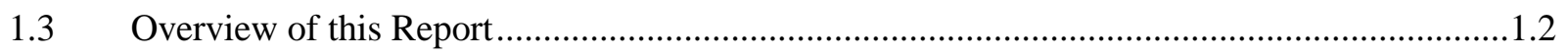

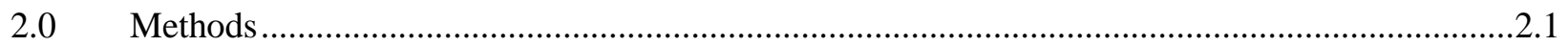

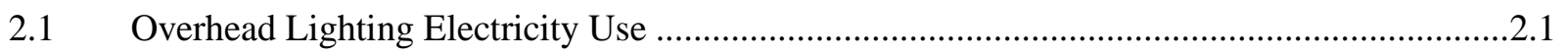

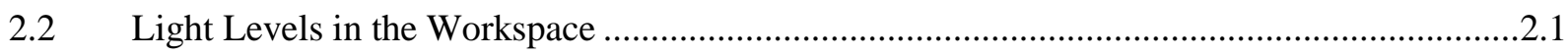

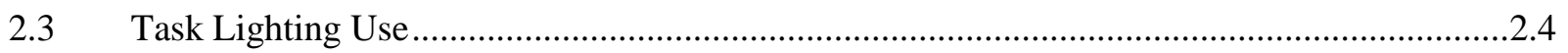

2.4 Occupant Ratings of Satisfaction with the Lighting .........................................................

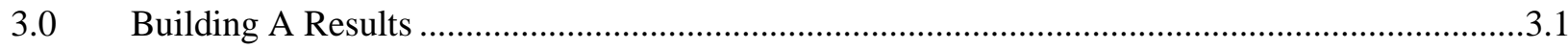

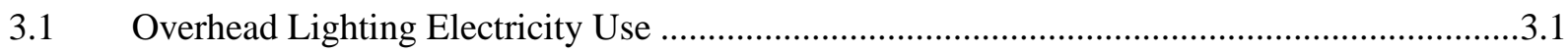

3.1.1 Pre- and Post-Retrofit Measurements............................................................................ 3.1

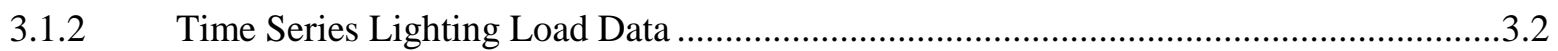

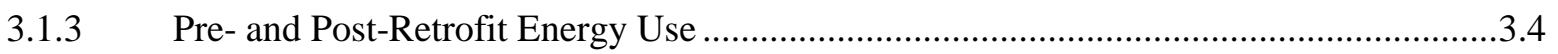

3.1.4 Connected Load Measurements ..........................................................................................

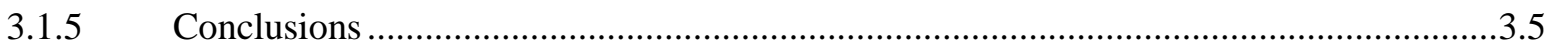

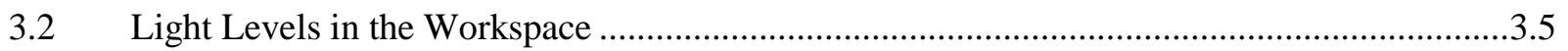

3.2.1 Pre- and Post-Retrofit Measurements...............................................................................

3.2.2 Statistical Analysis of Light-Level Measurements.........................................................10

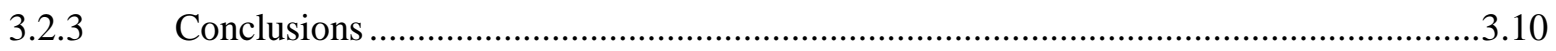

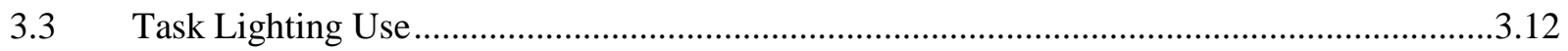

3.3.1 Pre- and Post-Retrofit Measurements...........................................................................13

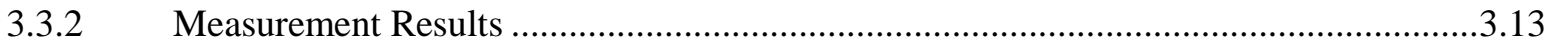

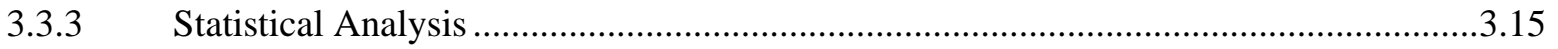

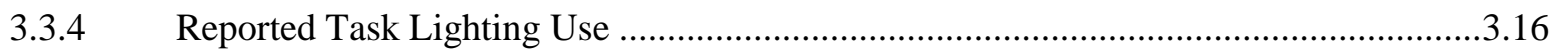

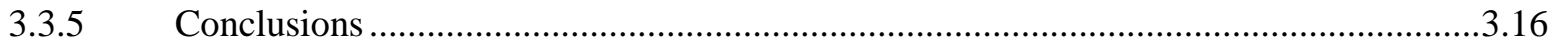

3.4 Occupant Ratings of Satisfaction with the Lighting ............................................................

3.4.1 Pre- and Post-Retrofit Measurements..........................................................................17

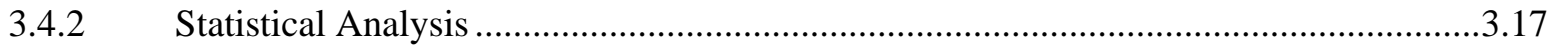

3.4.3 Variables and their Impacts on Responses ..................................................................19 


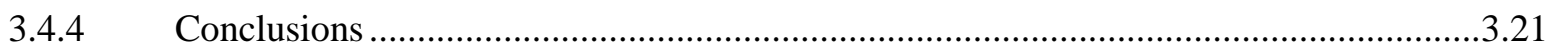

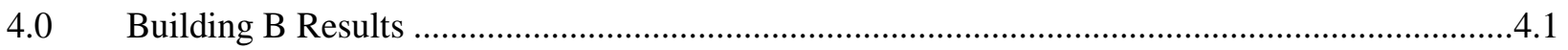

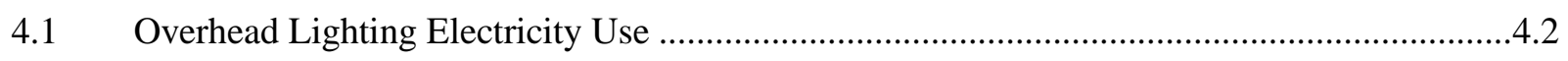

4.1.1 Pre- and Post-Retrofit Measurements..........................................................................

4.1.2 Time Series Lighting Load Data ............................................................................ 4.2

4.1.3 Pre- and Post-Retrofit Energy Use ......................................................................... 4.5

4.1.4 Connected Load Measurements ............................................................................... 4.6

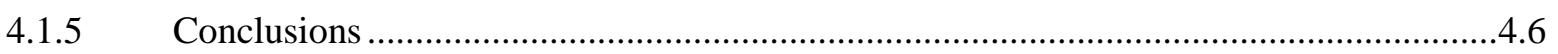

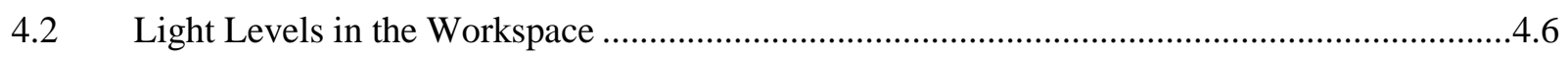

4.2.1 Pre- and Post-Retrofit Measurements......................................................................... 4.6

4.2.2 Statistical Analysis of Measurements...................................................................11

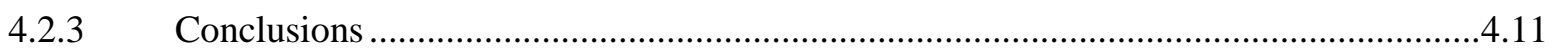

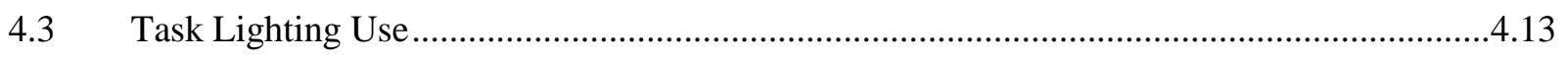

4.3.1 Pre- and Post-Retrofit Measurements........................................................................13

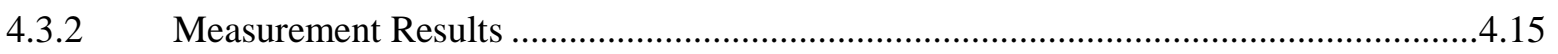

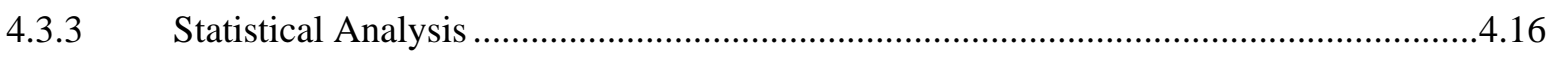

4.3.4 Reported Task Lighting Use .............................................................................

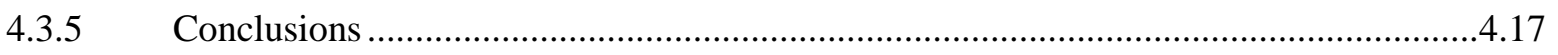

4.4 Occupant Ratings of Satisfaction with the Lighting .........................................................4.17

4.4.1 Pre- and Post-Retrofit Measurements........................................................................ 4.18

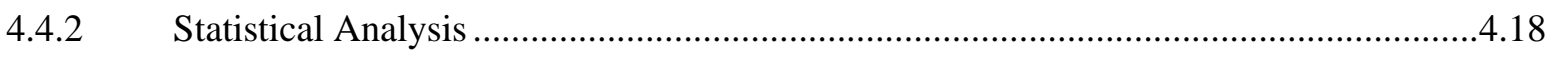

4.4.3 Variables and their Impacts on Responses ............................................................20

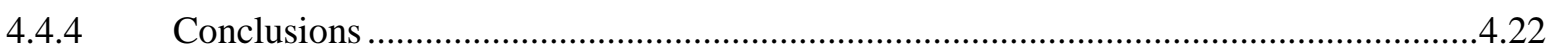

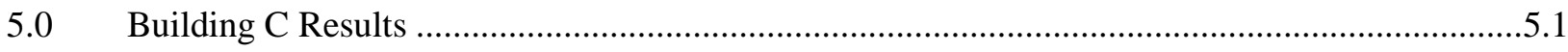

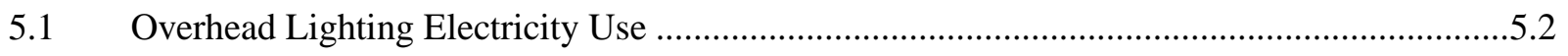

5.1.1 Pre- and Post-Retrofit Measurements.........................................................................

5.1.2 Time Series Lighting Load Data ................................................................................

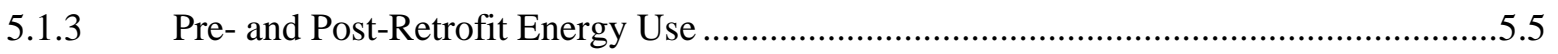

5.1.4 Connected Load Measurements ..................................................................................

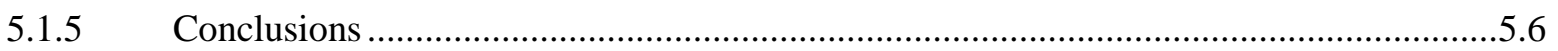

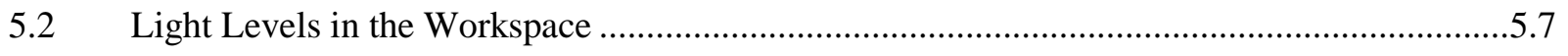

5.2.1 Pre- and Post-Retrofit Measurements........................................................................

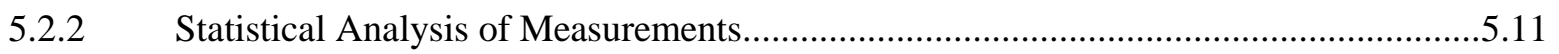

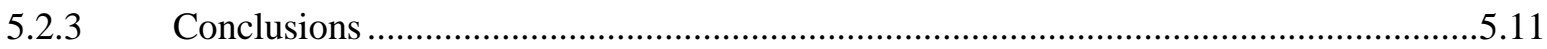

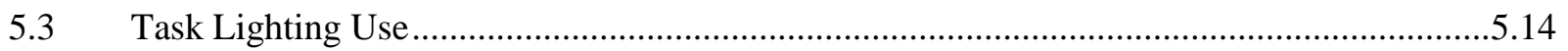


5.3.1 Pre- and Post-Retrofit Measurements......................................................................

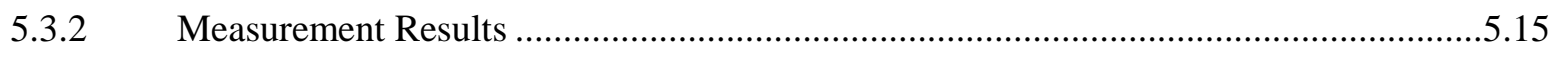

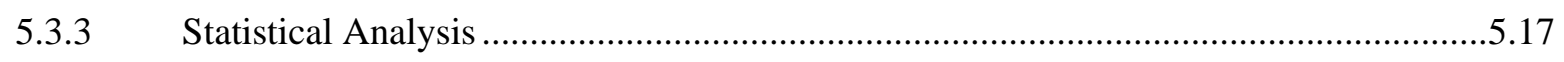

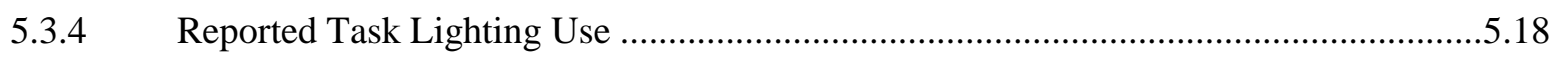

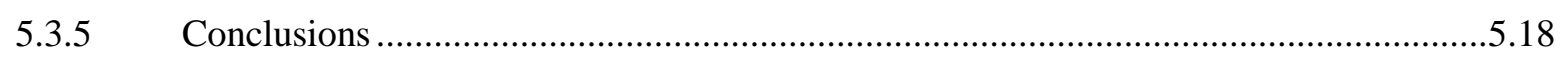

5.4 Occupant Ratings of Satisfaction with the Lighting ............................................................18

5.4.1 Pre- and Post-Retrofit Measurements...........................................................................19

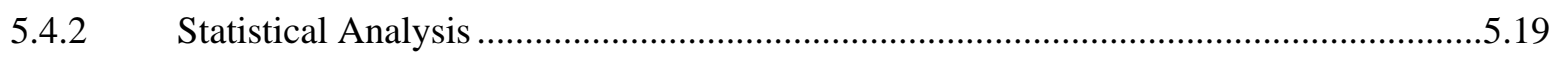

5.4.3 Variables and their Impacts on Responses .................................................................2.

5.4.4 Daylight Availability vs. Occupant Survey Responses ................................................5.22

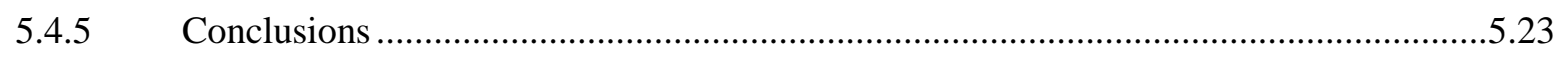

Appendix A - End-Use Logger Description and Configurations $\quad$..................................................1

Appendix B - Occupant Lighting Satisfaction Survey Instrument .................................................... B.1

Appendix C - Overhead Light Level Measurement Data.................................................................

Appendix D - Task Lighting Data Logger Specifications for the HOBO ${ }^{\circledR}$ Data Loggers ...................... D.1 


\section{Figures}

Figure 2.1. Illuminance measurements were taken at 36 " from the wall at 30 " above the floor for horizontal measurements and at 46" above the floor for vertical measurements.

Figure 2.2. Illuminance Meter in Position to Measure (A) Horizontal Measurements and (B) Vertical Measurements.

Figure 3.1. End Use Metering Loggers Used to Measure Current, Power, and Apparent Power in Building A.

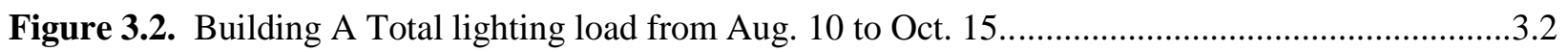

Figure 3.3. Building A Pre-Retrofit Weekday Load Profiles for Aug. 10 - Aug. 29, 2005 ....................3.2

Figure 3.4. Building A Post-Retrofit Weekday Load Profiles for Sept. 12 - Oct. 7, 2005 .....................3.3

Figure 3.5. Building A Mean Pre- and Post-Retrofit Workday Load Profiles. ..........................................

Figure 3.6. Building A - Pre-Retrofit Scotopic/Photopic Ratio Comparison ............................................

Figure 3.7. Building A - Post-Retrofit Scotopic/Photopic Ratio Comparison........................................... 3.8

Figure 3.8. Building A - Pre-Retrofit Vertical vs. Horizontal Comparison (Photopic)...........................3.9

Figure 3.9. Building A - Post-Retrofit Vertical vs. Horizontal Comparison (Photopic) ........................3.10

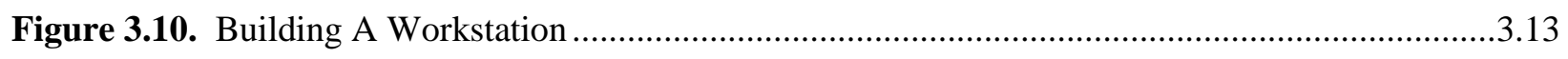

Figure 3.11. Building A Workstation Tasklight ...............................................................................

Figure 3.12. Building A - Task Light Usage as a Percentage of Business Hours Before and After Retrofit.

Figure 3.13. Building A - Task Lighting Logger Difference in Usage, Before and After Retrofit

Figure 4.1. Building B Open Office Area

Figure 4.2. Building B - Distribution Panel with Three-Phase Lighting Riser Logger Installed in Right-Hand Compartment.

Figure 4.3. Building B Lighting Riser Load, Oct. 13 to Nov. 23 ........................................................ 4.3

Figure 4.4. Building B Pre-Retrofit Weekday Load Profiles for Oct. 13 -Nov. 4, 2005 .......................4.3

Figure 4.5. Building B Post-Retrofit Weekday Load Profiles for Nov. 7 -Dec. 6, 2005 .......................4.4

Figure 4.6. Building B Mean Pre- and Post-Retrofit Workday Load Profiles.........................................4.5

Figure 4.7. Building B - Pre-Retrofit Scotopic/Photopic Ratio Comparison .......................................4.8

Figure 4.8. Building B Post-Retrofit Scotopic/Photopic Ratio Comparison .........................................4.9

Figure 4.9. Building B Pre-Retrofit Vertical vs. Horizontal Comparison (Photopic) ..........................4.10

Figure 4.10. Building B Post-Retrofit Vertical vs. Horizontal Comparison (Photopic).......................4.11

Figure 4.11. Building B - Typical Work Station with Task Light Off ..............................................4.14

Figure 4.12. Building B - Typical Work Station with Task Light On ...............................................4.14

Figure 4.13. Building B - Task Light Usage as a Percent of Business Hours Before and After Retrofit. 
Figure 4.14. Building B - Task Lighting Logger Differences in Usage Before and After Retrofit

Figure 5.1. Building C Open Office Area, Second Floor, East Wing, Looking East from the Foyer.

Figure 5.2. Building C Open Office Area, Second Floor, East Wing, Looking South from the North Wall

Figure 5.3. Building C - One of Two End-Use Logger Installations, Second Floor, Panel L2A............5.3

Figure 5.4. Building C Second-Floor Lighting Load, Sept. 26 - Nov. 23 ................................................

Figure 5.5. Building C Second Floor Pre-Retrofit Weekday Load Profiles, Sept 26 - Oct. 17, 2005 .....5.4

Figure 5.6. Building C Second Floor Post-Retrofit Weekday Load Profiles, Oct. 31 - Nov. 22, 2005 ...5.4

Figure 5.7. Building C Second Floor Mean Pre- and Post-Retrofit Weekday Load Profiles ...................5.5

Figure 5.8. Building C - Pre-Retrofit Scotopic/Photopic Ratio Comparison ..........................................5.8

Figure 5.9. Building $C$ - Post-Retrofit Scotopic/Photopic Ratio Comparison........................................5.9

Figure 5.10. Building $C$ - Pre-Retrofit Vertical vs. Horizontal Comparison (Photopic) ........................5.10

Figure 5.11. Building $C$ - Post-Retrofit Vertical vs. Horizontal Comparison (Photopic) ......................5.11

Figure 5.12. Building $C$ - Workstation within Open Plan Office Area ...............................................5.14

Figure 5.1.3. Building C Cubicle Workstation ..................................................................................15

Figure 5.14. Building C - Task Light Usage as a Percent of Business Hours Before and

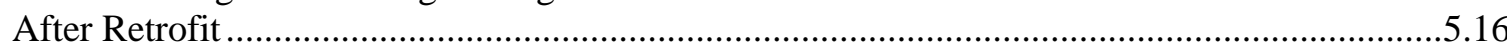

Figure 5.15. Building B Task Lighting Logger Differences in Usage Before and After Retrofit

\section{Tables}

Table 3.1. Building A - Average Pre-and Post Retrofit Lighting Loads

Table 3.2. Building A - Average Pre-Retrofit to Post-Retrofit Light Level and S/P Ratio Changes ........3.6

Table 3.3. Building A - Horizontal and Vertical Photopic and Scotopic Measured Data Analysis Results

Table 3.4. Building A - S/P Ratio Analysis Results

Table 3.5. Building A - Comparison of Pre- and Post-Retrofit Task Lighting Usage in Percent of Hours.

Table 3.6. Building A - Comparison of Occupant Responses to Question about Frequency of Task Lighting Use, Pre- and Post-Retrofit.

Table 3.7. Comparison of Survey Responses from Building A Workspaces With and Without Daylight

Table 4.1. Building B - Average Weekly, Weekday, and Work Hour Lighting Loads .4 .5 
Table 4.2. Building B - Average Pre- to Post-Retrofit Lighting Levels and S/P Ratio Changes

Table 4.3. Building B - Horizontal and Vertical Photopic and Scotopic Measured Data Analysis Results

Table 4.4. Building B - S/P Ratio Analysis Results

Table 4.5. Building B - Comparison of Pre- and Post-Retrofit Task Lighting in Percent of Hours

Table 4.6. Building B - Comparison of Occupant Responses to Question about Frequency of Task Lighting Use, Pre- and Post-Retrofit

Table 4.7. Comparison of Survey Responses from Building B Workspaces With and Without Daylight.....

Table 5.1. Building C Second Floor - Average Pre- and Post-Retrofit Loads.

Table 5.2. Building $C$ Average Pre- to Post-Retrofit Light Level and S/P Ratio Changes

Table 5.3. Building C Horizontal and Vertical Photopic and Scotopic Measured Data Analysis Results

Table 5.4. Building C S/P Ratio Analysis Results....

Table 5.5. Building C Comparison of Pre- and Post-Retrofit Task Lighting Usage in Percent of Hours.

Table 5.6. Building C Comparison of Occupant Responses to Question about Frequency of Task Lighting Use, Pre- and Post-Retrofit

Table 5.7. Comparison of Survey Responses from Building C Workspaces With and Without Daylight 


\subsection{Introduction}

This report summarizes measurements made by Pacific Northwest National Laboratory (PNNL) before and after lighting retrofits in three office buildings in California. Measurements were made during the period from August through December 2005.

\subsection{Background}

The Spectrally-Enhanced Lighting Program: Implementation for Energy Savings (SELPIES) was developed to validate the performance of a particular lighting design strategy for commercial office buildings. The basis for the approach is research conducted during the 1990s indicating that fluorescent lamps with relatively more radiant energy in the shorter (blue) wavelengths of the visible spectrum will be perceived by the human eye as brighter, compared to lamps with less energy in these wavelengths.

The color appearance of light sources is stated in correlated color temperature. CCT indicates whether a light source appears more yellow/gold/orange or more blue, in terms of the range of available shades of "white." CCT is given in degrees on the Kelvin (absolute temperature) scale and refers to the appearance of a theoretical black body heated to high temperatures. As the metal gets hotter, it turns red, orange, yellow, white, and finally blue. The CCT of a light source is the temperature (in degrees K) at which the heated theoretical black body matches the color of the light source in question.

Lamps with more blue content have a higher CCT. The theory behind spectrally enhanced lighting is that, for the same amount of light output (measured with a standard illuminance meter), lamps with a higher CCT will appear brighter than those with lower CCT. Thus, energy can be saved because the actual light output of the higher CCT lamps can be decreased, while maintaining equivalent perceived brightness and visual acuity relative to lower CCT lamps. Energy savings are achieved by using lower wattage lamps and/or lower ballast factor ballasts. Ballast factor is the relative light output of a fluorescent lamp operated on a given ballast, relative to the same lamp on a reference ballast. Ballast factor can be used to decrease light output with a corresponding decrease in energy loads. Normal ballast factor for electronic ballasts used to operate T8 lamps is 0.88 .

In the SELPIES demonstrations, existing fluorescent lamps, from 3000 to 4100 Kelvin, were replaced with lamps of 5000 Kelvin. Ballasts were replaced with new electronic ballasts with ballast factors of 0.60 to 0.77 .

\subsection{Objectives}

The objective of PNNL's monitoring tasks was to gather data necessary to compare pre-retrofit and post-retrofit conditions in the three buildings in the following four areas:

- overhead lighting electricity use

- light levels in the workspace

- frequency of task lighting use

- occupant ratings of satisfaction with the lighting. 


\subsection{Overview of this Report}

The report is organized as follows. Chapter 2 describes methodology. Chapters 3, 4, and 5 describe measurement results at Building A, a 57,000-sq ft office building located in Santa Rosa, California, in which 1,700 T12 lamps were replaced; Building B, a 119,000-sq ft office building located in Vallejo, California, in which 2,800 T8 lamps were replaced; and Building C, a 67,000-sq ft office building located in Oxnard, California, in which 2,300 T8 lamps were replaced. Appendix A provides specifications for the data loggers and the configuration of each logger used to measure current, power, and apparent power from the ceiling light fixtures. Appendix B provides the occupant satisfaction survey instrument. Appendix $\mathrm{C}$ provides the light level measurements and scotopic to photopic (S/P) ratios. Appendix D provides the specifications for the portable data loggers used to monitor task lighting. 


\subsection{Methods}

PNNL conducted measurements before and after existing lamps and ballasts in overhead lighting fixtures in each building were replaced with new lamps and electronic ballasts. The new lamps had a correlated color temperature (CCT) of 5000 Kelvin, color rendering index (CRI) of 85, and equivalent or lower wattages than the lamps they replaced (exact wattage varied by building). The new ballasts had a lower ballast factor than the ballasts being replaced. The new lamps are referred to in this report as 850 lamps ( 8 references a CRI in the 80 s and 50 refers to a CCT of 5000 Kelvin). No fixtures were replaced or moved; only the lamps and ballasts were replaced.

The demonstrations were designed to decrease lighting power loads in the three buildings by $22 \%$ $50 \%$, depending on the energy usage of the existing installed lamps and ballasts. The project designers hypothesized that this reduction in electrical loads could be achieved by replacing the existing lamps with higher CCT lamps without decreasing occupant satisfaction with the lighting.

The measurement tasks were carried out using the equipment and methodologies described below. Results of these measurements are provided in Chapters 3, 4, and 5 below.

\subsection{Overhead Lighting Electricity Use}

Two energy measures are of interest: connected load for overhead lighting in the building and total energy use due to the overhead lighting. The full change in energy consumption cannot be measured directly because energy use at any given time is subject to variations in building operation. If all other things are kept constant, energy use is directly proportional to connected load and connected load can be measured directly and, moreover, very precisely. We therefore report both the change in connected load as well as our observations of energy use patterns before and after the retrofits.

Electrical loads $(\mathrm{kW})$ and consumption $(\mathrm{kWh})$ by the overhead lighting equipment were measured by installing Synergistic C180 data logger meters on the lighting circuits at the lighting control panel. The loggers were programmed to measure current, power, and apparent power on each circuit as documented in Appendix A. Because light fixtures exhibit small load variations (related to and generally smaller than the lumen depreciation effect) over their lifetime, each existing lamp was replaced with a new lamp of the same wattage and type to establish an accurate baseline prior to retrofit with the higher CCT lamps. At this time the fixtures were also cleaned. The goal was to obtain as accurate a baseline as possible. The monitoring equipment was installed prior to the baselining and cleaning. Data were collected for at least two weeks under the baseline condition (with the replaced old lamps installed in cleaned fixtures) and for at least two weeks following the retrofit with the new higher CCT lamps and new ballasts. The logging meters were configured to record average overhead lighting loads (in $\mathrm{kW}$ ) in five-minute intervals 24 hours per day during the monitoring periods.

Two methods were used to estimate the energy savings resulting from the lighting retrofits. First, we compared the average electrical load on the overhead lighting circuits in the pre-retrofit and post-retrofit time periods (two to three weeks each). This tells us actual load from the overhead lighting circuits in each building during the measurement periods. Multiplying the difference in average load $(\mathrm{kW})$ by the total number of hours in a year $(8,760$ hours) provides one estimate of annual kilowatt-hour $(\mathrm{kWh})$ 
savings. What are the limitations of this estimate? Most importantly, the average $\mathrm{kW}$ data represent a specific time period of 2-3 weeks in the baseline condition and 2-3 weeks in the post-retrofit condition. Over the course of a year, lighting use in any building fluctuates due to seasonal changes, scheduling changes, staff moves, and a variety of other reasons. The timing of two of the SELPIES projects (Buildings B and C) happened to coincide with the change from Daylight Saving Time to standard time at the end of October. Because the hours of electric lighting use are typically lower in the summer, and increase as the days shorten and clocks are set back in the fall, an energy savings estimate based only on the difference between measured pre-retrofit and post-retrofit average load during the data collection periods could underestimate actual savings over a full year.

To provide another estimate of annual energy savings, we also used a second method: measuring connected loads on a sample of fixtures or circuits in each building. Connected load was measured using a Fluke 43B Power Quality Analyzer (see Appendix A, Section A.8 for specifications). The measured percent reduction in connected load was multiplied by the pre-retrofit average $\mathrm{kW}$ load and then by 8,760 hours/year to yield a second annual savings estimate. While still based on the 2-3 week snapshot of the average pre-retrofit overhead lighting load, this estimate reflects the actual reduction in connected load, which is more reliable than the pre- to post-retrofit comparison. The $\mathrm{kWh}$ savings estimates based on connected load for Buildings B and C differ from the estimates based on average pre/post-retrofit $\mathrm{kW}$ difference by a factor of about 1.5 , primarily due to the seasonal time change that occurred between the pre- and post-retrofit periods. We feel the best estimate of annual energy savings is the one based on the measured connected load reduction.

\subsection{Light Levels in the Workspace}

Pre-retrofit and post-retrofit illuminance measurements were taken at representative spaces in each building to assess the lighted characteristics of the test areas before and after retrofit. Repeatable measurements were taken at a point 36" from one cubicle or office wall and 36" from the adjoining perpendicular wall as shown in Figure 2.1. Horizontal measurements were taken on a horizontal plane (the desktop) at 30" above the floor (approximately desk height) and vertical measurements were taken in the vertical plane (with the illuminance meter head facing the office or cubicle wall) at 46" above the floor (approximately eye height when seated) to represent a typical occupant's viewing level (see Figure 2.2). The direction of the vertical measurement was chosen to represent what was considered to be the most common viewing direction of the occupant during their work day, based on location of work and reference materials in the workspace.

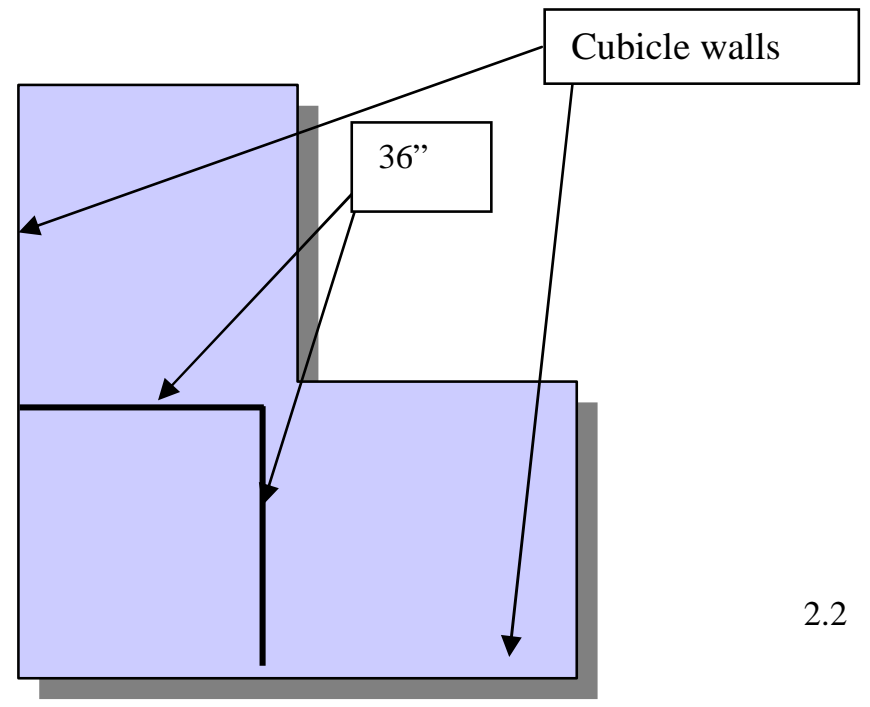

Figure 2.1. Illuminance measurements were taken at 36" from the cubicle wall at 30" above the floor for horizontal measurements and at 46" above the floor for vertical measurements. 


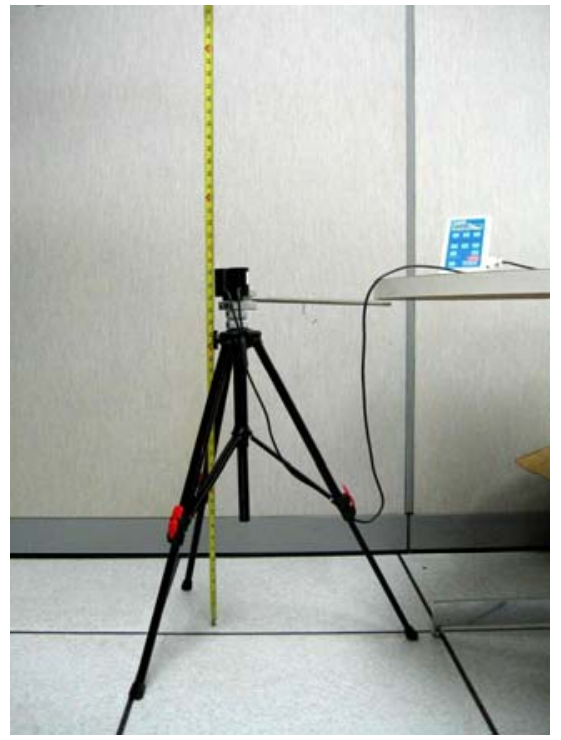

(A)

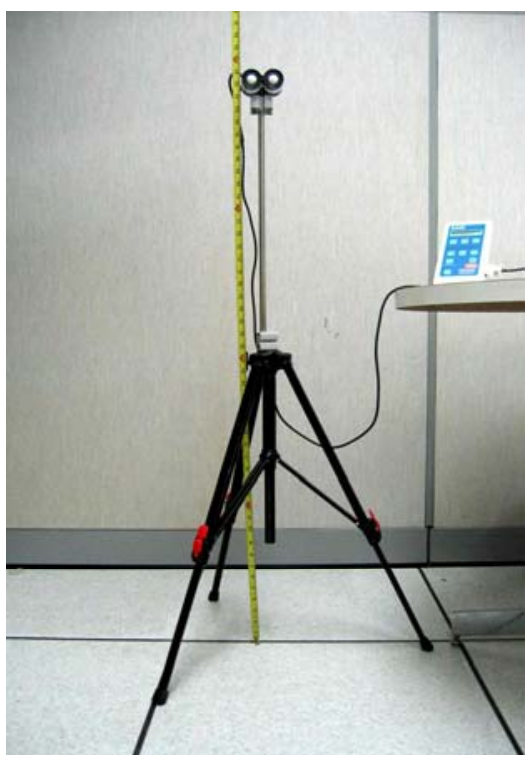

(B)

Figure 2.2. Illuminance Meter in Position to Take (A) Horizontal Measurements and (B) Vertical Measurements

Identical measurement locations, heights, and viewing direction were used for both the pre-retrofit and post-retrofit measurements. The instrument used for all measurements was a newly purchased and calibrated Solor Light Co., Inc. SL3103-001 combined photopic/scotopic (see note below) meter (s/n 9610, calibrated 7-26-05) with detector heads pmA2131/ pmA2130. All readings were taken in lux (1 lux $=0.1$ footcandles) with overhead lights on but no task lights on. Daylighting effects were minimized in two ways: 1) by selecting windowless private offices and cubicles and aisle locations that were well away from windows, and 2) by taking measurements after dark.

\subsubsection{Note on Photopic and Scotopic}

In this report, the terms photopic and scotopic are used primarily in describing the illuminance meter employed to measure workstation light levels. Standard illuminance meters are calibrated to the photopic luminous efficiency function, a curve determined by physical research and codified by the International Commission on Illumination (Commission Internationale de l'Eclairage or CIE). The human eye has two types of photoreceptor cells, known by their shape as "cones" and "rods." The photopic luminous efficiency function describes the sensitivity of the cone-shaped photoreceptor cells to all the wavelengths in the visible spectrum. The rod-shaped photoreceptor cells have a different sensitivity curve, called the scotopic luminous efficiency function. The illuminance meter used in this project has two receptor heads: one calibrated to the photopic curve and one calibrated to the scotopic.

The measured photopic and scotopic illuminance levels taken in the demonstration buildings are presented in this report both as absolute levels in standard metric units (lux) and as a ratio of scotopic to photopic (S/P ratio). The $\mathrm{S} / \mathrm{P}$ ratio provides an easily referenced indicator of relative blue content in the light source. Most light sources have S/P ratios ranging from 0.8 to 2.5, with the higher values containing more energy in the blue wavelengths of the visible spectrum. 


\subsection{Task Lighting Use}

The evaluation of pre- and post-retrofit task lighting use was deemed necessary to assess the extent of increased or decreased task light use attributable to changes in overhead lighting levels. The importance of this evaluation lies in the need to assess the potential for "take back" of the energy savings achieved with the overhead lighting by the potential increased use of task lighting. Task lights were all single lamp fixtures of various types. Nominal fixture wattages ranged from 15 to 40 watts.

The frequency and duration of task lighting use was monitored with Onset Computer Hobo® portable data loggers installed on or in the task lighting fixtures mounted beneath the shelves of the modular office furniture. A sample of task lights in each building was monitored. The data loggers recorded when a task light was turned on and the duration of the "on" condition.

The data loggers were set to track light level (lumens per square foot or footcandles) at 5- or 10minute intervals (depending on the exact data logger used in each building). Data were collected for about two weeks in both the pre- and post-retrofit periods. In all cases, the post-retrofit data were collected after the three-week adaptation period to allow for occupant adjustment to the new overhead lighting.

In addition to monitoring task lighting use in a sample of work spaces, two questions regarding task lighting use were included on the pre- and post-retrofit occupant survey, which is further described in Section 2.4 below. Question 7 on the survey asked the following:

Which of the following controls do you have for the lighting in your workspace? (check all that apply)

$\begin{array}{ll}\square & \text { Light switch } \\ \square & \text { Light dimmer } \\ \square & \text { Windows, blinds or shades } \\ \square & \text { Desk (task) light } \\ \square & \text { Bi-level switching (separate switches operating lights independently) } \\ \square & \text { Automatic occupancy sensor } \\ \square & \text { None of the above } \\ \square & \text { Other: }\end{array}$

If the respondent checked the Desk (task) light option, they were asked the following additional question:

How often do you use your Desk (Task) light(s) when you are working?

Never

Less that half of the time

About half of the time

More than half of the time

Always 


\subsection{Occupant Ratings of Satisfaction with the Lighting}

Web-based occupant surveys were conducted to assess occupant ratings of satisfaction with the lighting in their workspaces prior to and following retrofit. The project designers hypothesized that there would not be a statistically significant change in occupant ratings of satisfaction with the lighting after the retrofit.

Occupants were given three weeks to adjust to the cleaned and relamped fixtures before the preretrofit survey. Occupants were asked about their level of satisfaction with various aspects of their work environment, including office furniture, thermal comfort, and lighting. Similarly, the post-retrofit survey was administered after a three-week adaptation period following completion of the lighting retrofit in each building.

The survey instrument is based largely on the Indoor Environmental Quality survey developed by the Center for the Built Environment (CBE) at the University of California, Berkeley. This survey has been administered in more than 60 buildings to date and the questions have been pre-tested by the CBE using the cognitive interviewing method. ${ }^{1}$ The CBE survey addresses a range of indoor environmental issues including thermal comfort, office furnishings, maintenance, air quality, and lighting.

PNNL extracted the lighting and several other questions from the CBE survey for use in the SELPIES evaluation. Two questions that do not appear in the CBE survey were added to this survey: 1) type of computer monitor used, and 2) frequency of task lighting use. The full survey, including discussion of the survey questions, is provided in Appendix B.

The survey instrument and the plan for collecting information from building occupants was reviewed and approved by PNNL's Institutional Review Board as required for all studies involving human subjects.

\footnotetext{
${ }^{1}$ Zagreus, L., Huizenga, C., E. Arens and D. Lehrer, 2004. "Listening to the Occupants: A Web-based Indoor Environmental Quality Survey.” Indoor Air 2004; 14 (Suppl 8): pp. 65-74. December.
} 


\subsection{Building A Results}

This chapter provides results of pre- and post-retrofit measurements in Building A, a 57,000-sq ft, one-story office building located in Santa Rosa, California. Approximately 1,700 overhead lamps were replaced in this building. The original overhead lighting was provided by Philips F34T12/SPEC35/RS/EW lamps with magnetic rapid start ballasts (ballast factor 0.88), installed in predominantly 2x4-foot, 3-lamp fixtures. The building includes 30 enclosed offices, 103 cubicles, six small conference rooms, one large conference room, a training room, a transient work room, a customer service room, and three hallways. Lamps in all fixtures were replaced with new Philips F32T8/ADV850/XEW lamps. Ballasts were replaced with electronic instant start ballasts with a ballast factor of 0.77 . Results of PNNL's evaluations of lighting energy use consumption, light levels, task lighting use, and occupant satisfaction for Building A are described below.

The measured connected load for the pre-retrofit T12 lamps with standard magnetic ballasts was 37.7 W/lamp. The measured connected load for the post-retrofit T8 lamps with low power factor ballasts was 20.5 W/lamp. These measurements are consistent with the nominal (rated) fixture loads of the pre- and post-retrofit technologies. This change corresponds to a $45.6 \%$ reduction in connected load.

\subsection{Overhead Lighting Electricity Use}

\subsubsection{Pre- and Post-Retrofit Measurements}

The fixtures affected by the retrofit are powered from eighteen 277 -volt dedicated lighting circuits. Two end-use metering loggers were installed to monitor these circuits. One of the loggers is shown in Figure 3.1; the other logger installation is essentially identical. The pre-retrofit study period was August 10 to September 2, 2005, and the post-retrofit period was September 12 to October 15, 2005.

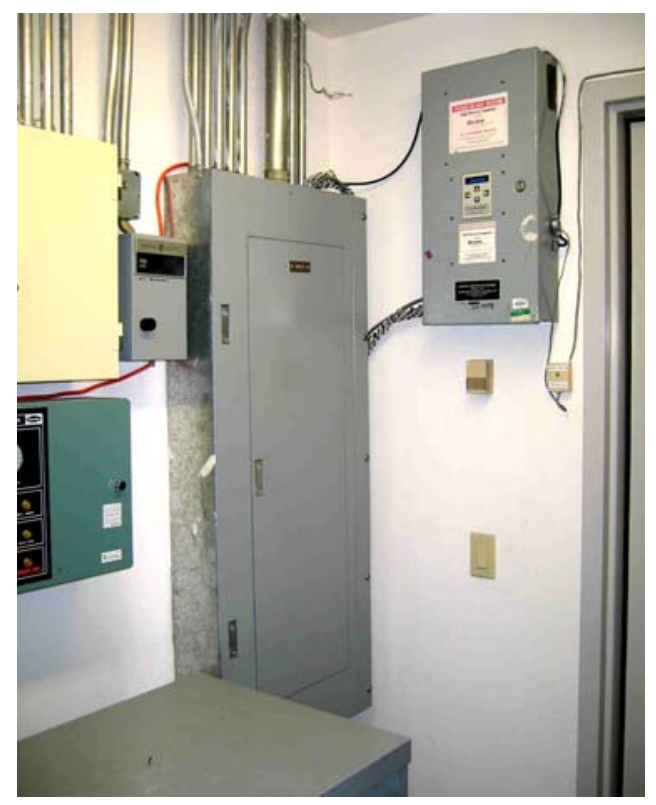

Figure 3.1. End Use Metering Logger. The box to the right of the control panel is one of two end use metering loggers used to measure current, power, and apparent power in Building A. 


\subsubsection{Time Series Lighting Load Data}

The time series data streams from the two loggers were merged into a single time series of total lighting power (sum of all circuits) shown in Figure 3.2.

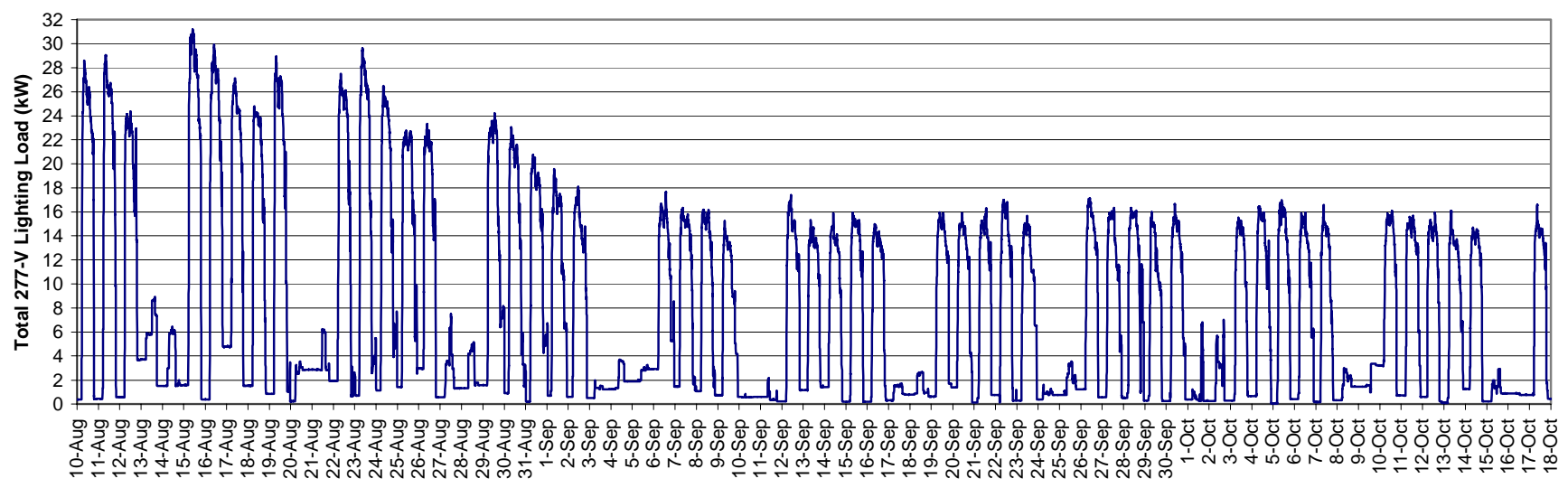

Figure 3.2. Building A total lighting load from Aug. 10 to Oct. 15. Retrofit activity took place Sept. 2-11, 2005

Daily lighting load profiles for pre-retrofit weekdays (Aug. 10-29) are shown in Figure 3.3 and daily lighting load profiles for post-retrofit weekdays (Sept. 12-Oct. 7) are shown in Figure 3.4. Each line represents a different day's profile in Figures 3.3 and 3.4.

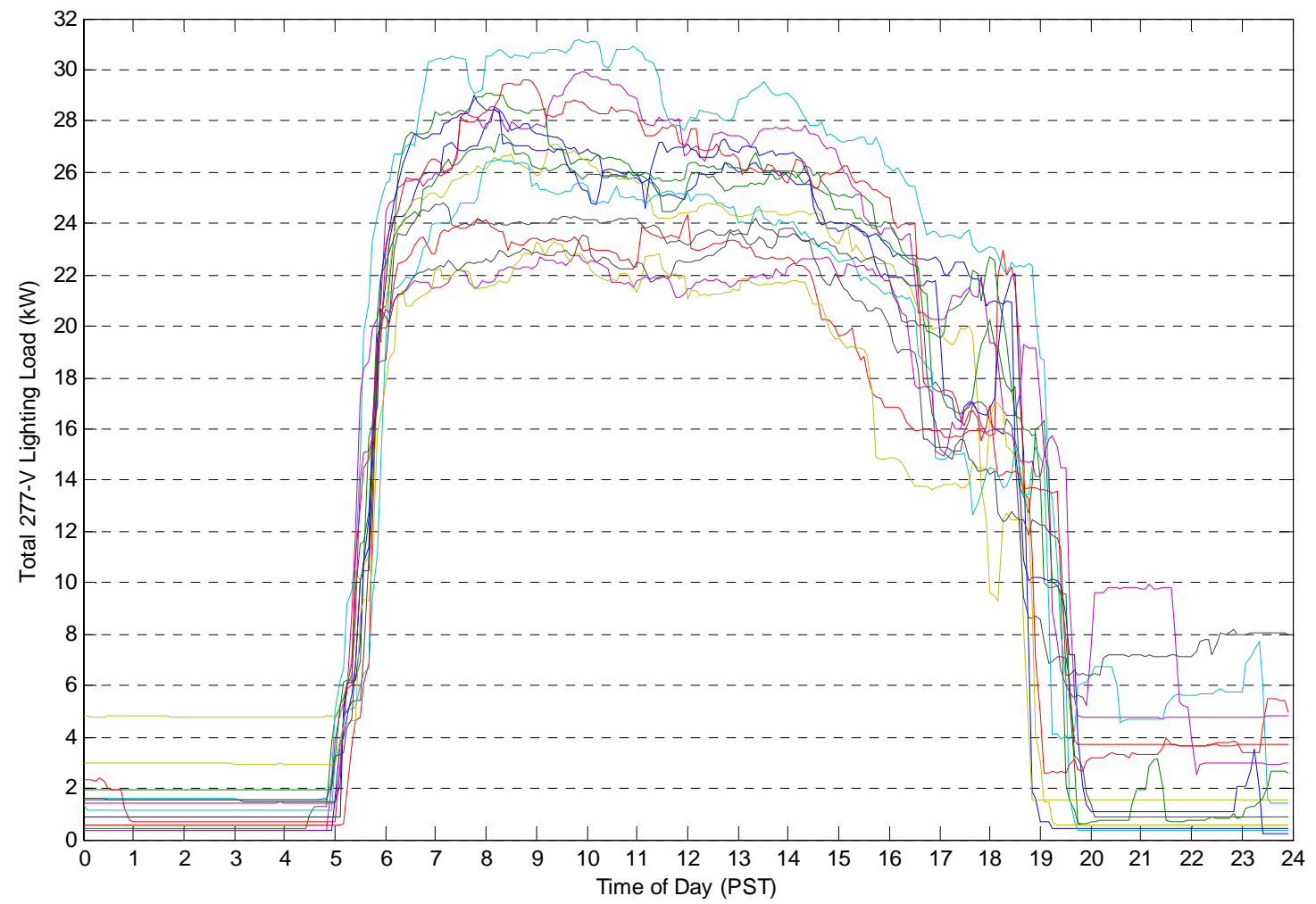

Figure 3.3. Building A Pre-Retrofit Weekday Load Profiles for Aug. 10 - Aug. 29, 2005 


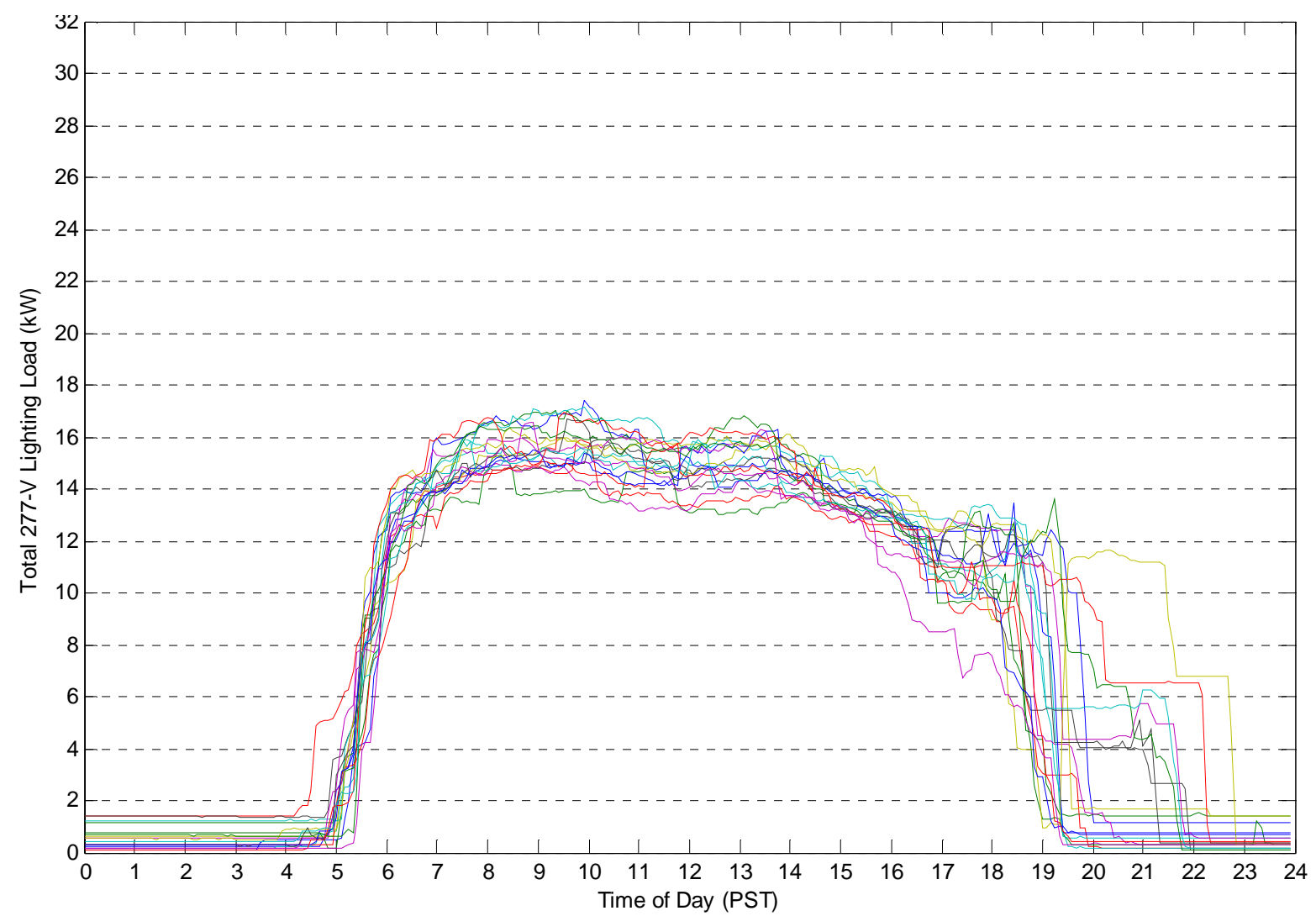

Figure 3.4. Building A Post-Retrofit Weekday Load Profiles for Sept. 12 - Oct. 7, 2005

Figures 3.3 and 3.4 show load variations of up to $25 \%$ (+/- 12.5\%) during working hours among days. Equally significant are variations in the duration of lighting hours. One can see that the time for turning off lights at the end of each day varies considerably and that the number of fixtures left on at night (as indicated by the load trajectory) also varies. Friday workhour loads are somewhat lower than the loads on other weekdays.

Figure 3.5 shows a comparison of the average pre-retrofit load to average post-retrofit load for the periods measured. This graph indicates a $40.9 \%$ drop in average daily lighting load after the retrofit. 


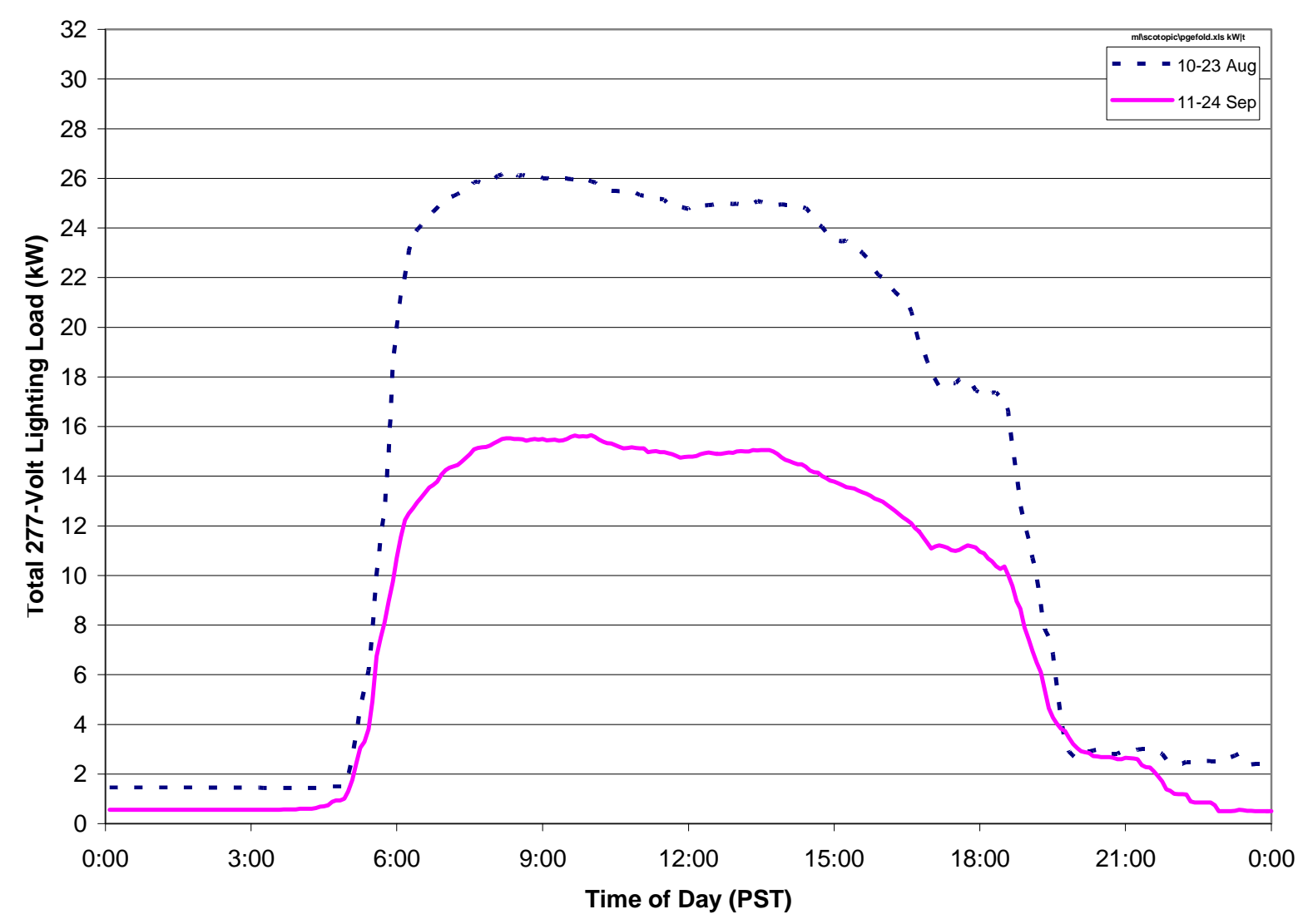

Figure 3.5. Building A Mean Pre- and Post-Retrofit Workday Load Profiles

\subsubsection{Pre- and Post-Retrofit Energy Use}

Average weekly, weekday, and workhours lighting loads were measured during the two typical preretrofit weeks of August 10-23 and during the two typical post-retrofit weeks of September 11-24. There were no holidays in either of these periods. The average weekly, weekday, and workhours lighting loads, expressed as average $\mathrm{kW}$, are shown in Table 3.1.

Table 3.1. Building A Average Pre-and Post Retrofit Lighting Loads

\begin{tabular}{|l|ccc|}
\hline & Weekly $(24 \times 7)$ & Weekday & Workhours \\
\hline pre-ret (average $\mathrm{kW})$ & 11.21 & 14.04 & 24.85 \\
post-ret (average $\mathrm{kW})$ & 6.21 & 8.30 & 14.66 \\
Ratio (post/pre) & 0.554 & 0.591 & 0.590 \\
Change (average kW) & 5.00 & 5.74 & 10.19 \\
Change (\% reduction) & $44.6 \%$ & $40.9 \%$ & $41.0 \%$ \\
\hline
\end{tabular}

The average weekly load in $\mathrm{kW}$ is the average load for all hours in the week ( $24 \times 7=168$ hours); the average weekday load is the average load for the week days ( $12 \times 5=60$ hours), and the work hours load is the average load for the work hours ( 9 x $5=45$ hours per week). The annual savings based on 
these observations is $11.21-6.21=5.00$ average $\mathrm{kW}$ or $44.6 \%$. The extrapolation of these numbers to annual energy savings is not entirely reliable because of seasonal affects and other day-to-day changes in building operation. However, we can roughly project savings of $8,760 \mathrm{hr} / \mathrm{yr} * 5.00$ average $\mathrm{kW}=43,800$ $\mathrm{kWh} / \mathrm{yr}$.

\subsubsection{Connected Load Measurements}

The energy-use measurements are subject to operational changes; e.g., longer hours of lighting use as hours of daylight drop in the Fall. A more reliable estimate of annual project energy savings is based on reduction in connected load, which can be measured directly. The reduction in connected load equals preretrofit connected load minus average post-retrofit connected load.

The pre-retrofit connected load, based on four banks of switched fixtures of 40 to 120 lamps per switch, was $37.7 \mathrm{~W} / \mathrm{lamp}$, ranging from 37.6 to $37.8 \mathrm{~W} / \mathrm{lamp}$.

It was not possible to measure the post-retrofit connected load from the switch banks because the number of fixtures on each switch was changed slightly during the retrofit electrical work. The postretrofit connected load, based on five groups of private office and conference room fixtures, was 20.5 W/lamp, ranging from 20.1 to $21.0 \mathrm{~W} / \mathrm{lamp}$.

Thus, $37.7 \mathrm{~W} / \mathrm{lamp}-20.5 \mathrm{~W} / \mathrm{lamp}=17.2 \mathrm{~W} / \mathrm{lamp}$, which is a $45.6 \%$ reduction in connected load.

The pre-retrofit weekly $\mathrm{kW}(11.21 \mathrm{~kW})$ multiplied by hours in a year ( $8760 \mathrm{hrs})$ multiplied by the observed reduction in connected load (0.456) yields a total project savings of $44,780 \mathrm{kWh} / \mathrm{yr}$.

\subsubsection{Conclusions}

Connected load decreased $45.6 \%$. We estimate annual energy savings are approximately 44,000 $\mathrm{kWh} / \mathrm{yr}$. The weekly average lighting energy savings $(44.6 \%)$ are consistent with the connected load reduction of $45.6 \%$ given the observed variations.

\subsection{Light Levels in the Workspace}

\subsubsection{Pre- and Post-Retrofit Measurements}

Pre- and post-retrofit light level readings were taken in 23 locations in Building A, including 20 offices, two conference rooms, and one hallway location. Pre-retrofit light level readings were made on August 2, 2005, from 5:30 pm to 8:30 pm. Vertical measurements were made within the 5:30 pm to 7:30 pm timeframe and horizontal measurements were made between 7:30 and 8:30 pm. To avoid daylighting affects, the earliest light level readings (vertical beginning at 5:30 pm) were taken starting with the interior spaces of the building where daylight was negligible.

However, toward the end of the vertical measurements time period (approaching 7:30 pm), when the locations near windows were being measured, there was the possibility of some daylight as the sun was not completely set at this time. A brief analysis of the pre- to post-retrofit vertical and horizontal photopic measurements for the three locations near windows compared to the averages for locations not near windows (no potential for daylight effect) shows that there was some potential effect. (See Appendix

$\mathrm{C}$ which contains detailed light level data for all three buildings.) Two of the three near-window locations 
show measurements of $2 \%$ to $8 \%$ higher than the average for non-window locations, indicating the potential for some daylight effect. The third location shows differences of $+12 \%$ to $+26 \%$ over the nonwindow location average. Because these three locations were the only ones out of the data set with potential daylight effects, the overall effect is considered minimal.

Post-retrofit light level readings were made on September 28, 2005, between 6:00 pm and 11:00 pm, which was after sundown to avoid any daylighting effects. Three non-office locations (two conference room and a hallway) were measured to provide control measurements that were not expected to be affected by occupant changes to spaces (changing articles on walls). These included one hallway measurement and two locations in a conference room. The individual measurement values and their associated S/P ratios can be found in Appendix C in Tables C.1 and C.2.

Although these data represent individual spaces, their averages can provide a useful comparison of the resulting change in light levels between pre- and post-retrofit conditions. As discussed in the next section on statistical analysis of these data, we are confident that these averages shown in Table 3.2 accurately represent the overall change in the test spaces.

Table 3.2. Building A - Average Pre-Retrofit to Post-Retrofit Light Level and S/P Ratio Changes

\begin{tabular}{|c|c|c|c|c|c|}
\hline \multicolumn{2}{|c|}{ Photopic (lux and \% change) } & \multicolumn{2}{c|}{ Scotopic (lux and \% change) } & \multicolumn{2}{c|}{ S/P ratio } \\
\hline Vertical & Horizontal & Vertical & Horizontal & Vertical & Horizontal \\
\hline$-42(-25 \%)$ & $-92(-20 \%)$ & $+5(+2 \%)$ & $+76(+13 \%)$ & $+0.47(+37 \%)$ & $+0.52(+40 \%)$ \\
\hline
\end{tabular}

Because of the nature of field measurements, including manual recording and measuring, it is always possible to experience recording errors or other unexpected anomalies in the measurements. Lighting equipment retrofit activities, maintenance, or normal business operation changes can also lead to differences between pre- and post-retrofit conditions that were not expected and might affect measurement values. This might include the addition or removal of lamps, furniture changes or moves, or other occupant changes to their workspace. Because of these possibilities, comparison plots were made of the scotopic versus photopic readings to visually identify S/P ratio outliers that might be mismeasurements or effects from retrofit variations. Figures 3.6 and 3.7 below show these comparisons. For uniform lighting conditions, the plotted points shown in the figures would be expected to form a uniform line with a consistent slope indicating similar S/P ratios for all locations. Those that fall far from this expected line could be considered outliers and potentially suspect.

As expected, the slope represented by the lines in the plots is steeper for the post-retrofit ratios, confirming the increased scotopic content of the post-retrofit lamps. Both charts show fairly uniform slopes for the plotted data, indicating consistent data with few outliers. The data for any outliers in the dataset were carefully considered to determine if they could be specifically identified as bad data points. In these cases the values that were considered outside of the expected values were either considered within the realm of possible data recording or effects form retrofit differences. Because they are so few in number and so small in magnitude, they have a negligible effect on the results. 


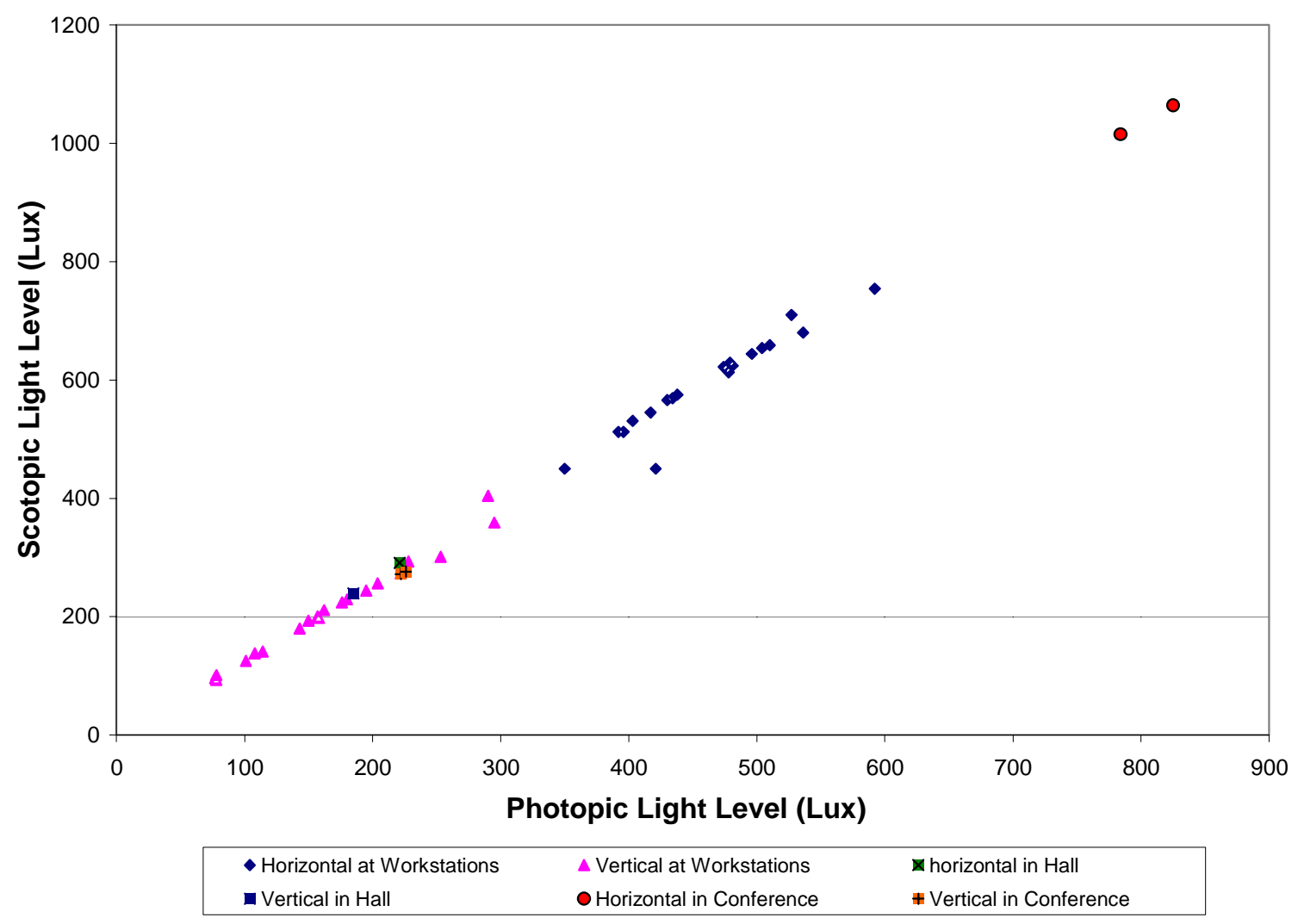

Figure 3.6. Building A - Pre-Retrofit Scotopic/Photopic Ratio Comparison 


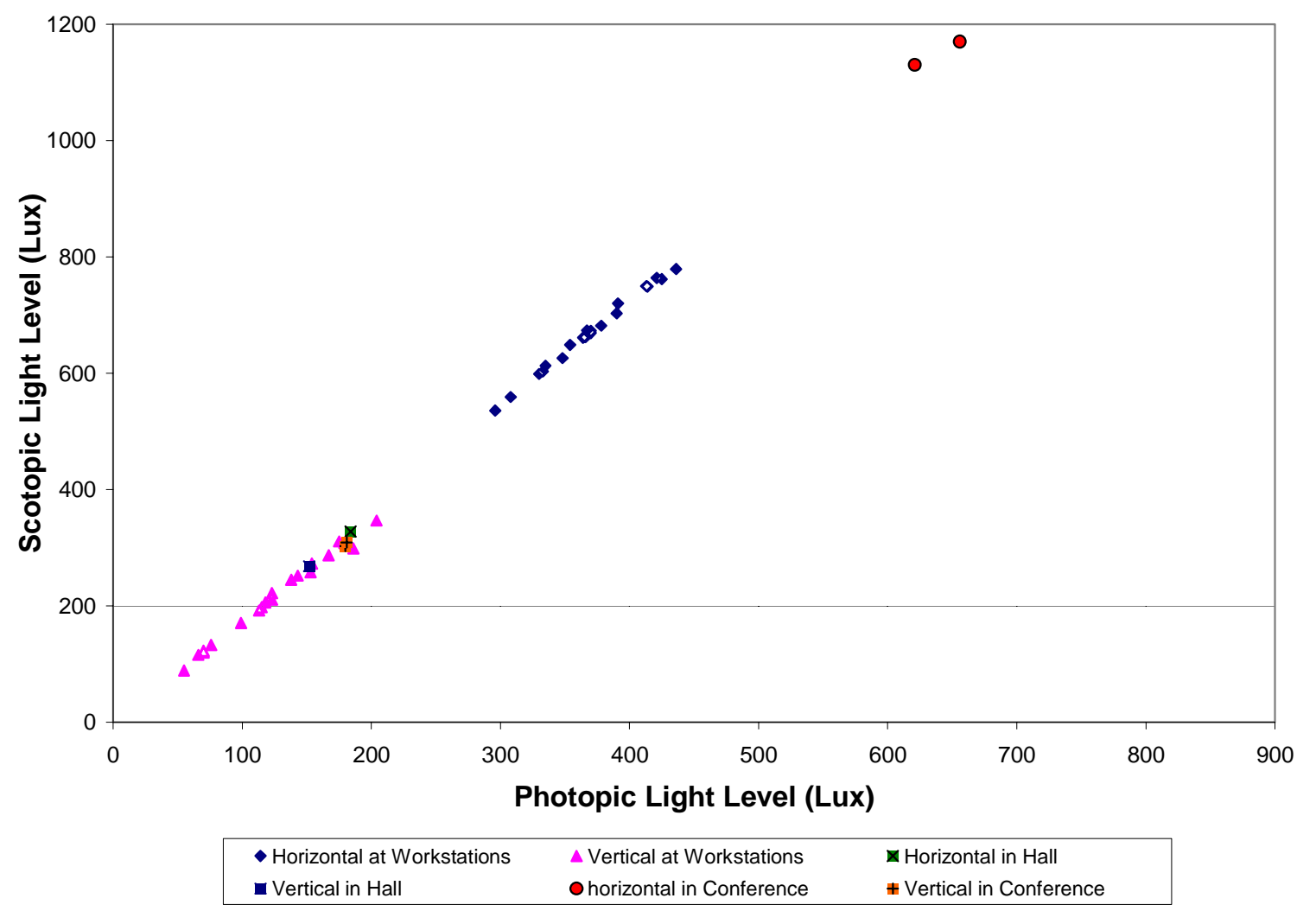

Figure 3.7. Building A - Post-Retrofit Scotopic/Photopic Ratio Comparison

One of the major variables affecting the light level measurements is the varied workspace environment and changing character of the occupied spaces. Workspaces are oriented in different ways in relation to overhead lighting fixtures and partition walls. Materials surrounding desk spaces and posted on walls (personal and business related) are also varied and can have an effect on the horizontal and vertical illuminance readings between spaces and in particular between time periods. This tends to reduce the consistency of the comparison between illuminance values within a specific set of measurements and between pre- and post-retrofit sets. As averaged data, these effects are less noticeable but it is useful to understand this variability. Figures 3.8 and 3.9 present ratios of horizontal to vertical measurements for each location. The cloud of data points shows the extent of the variability. 


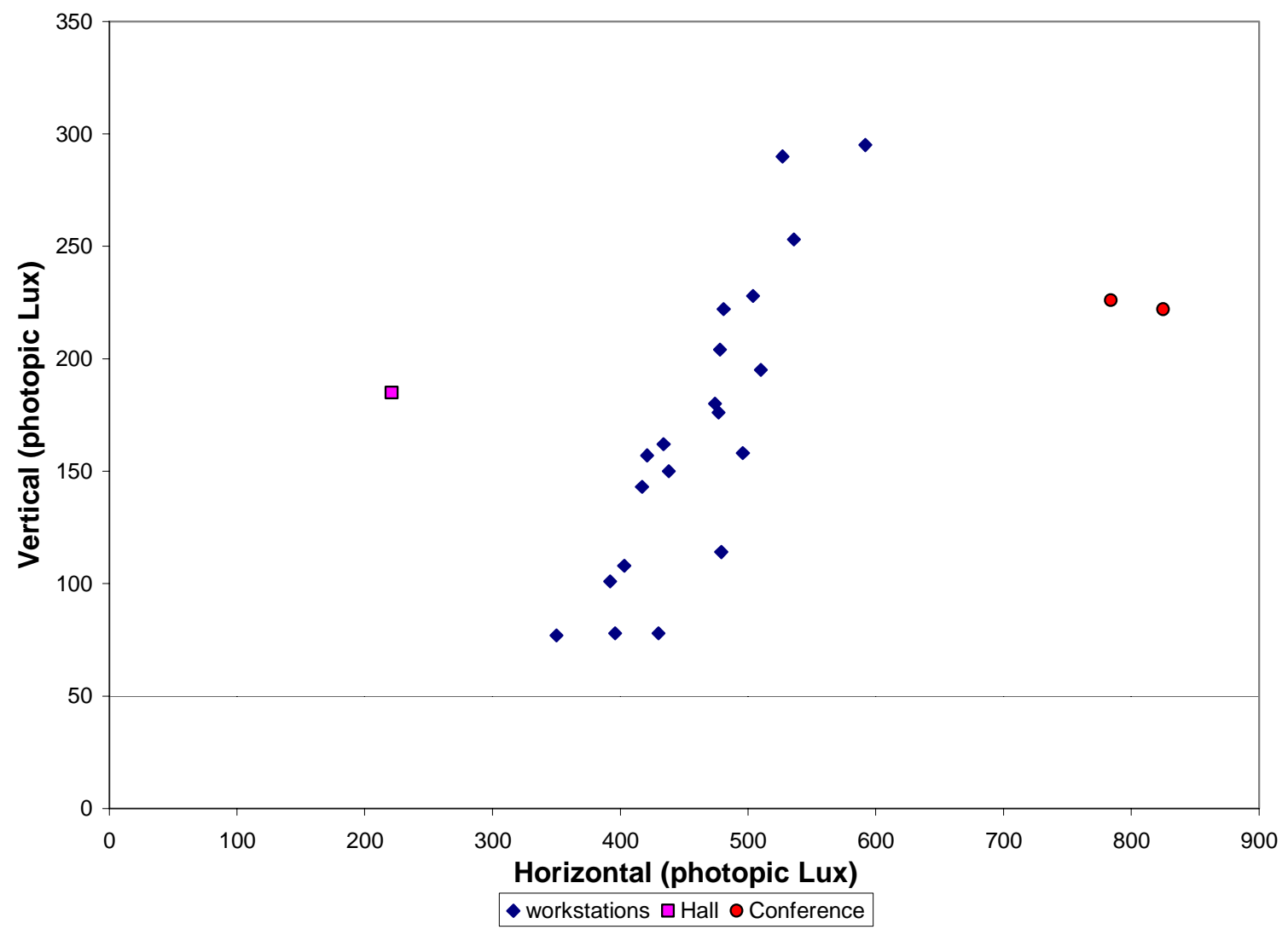

Figure 3.8. Building A - Pre-Retrofit Vertical vs. Horizontal Comparison (Photopic) 


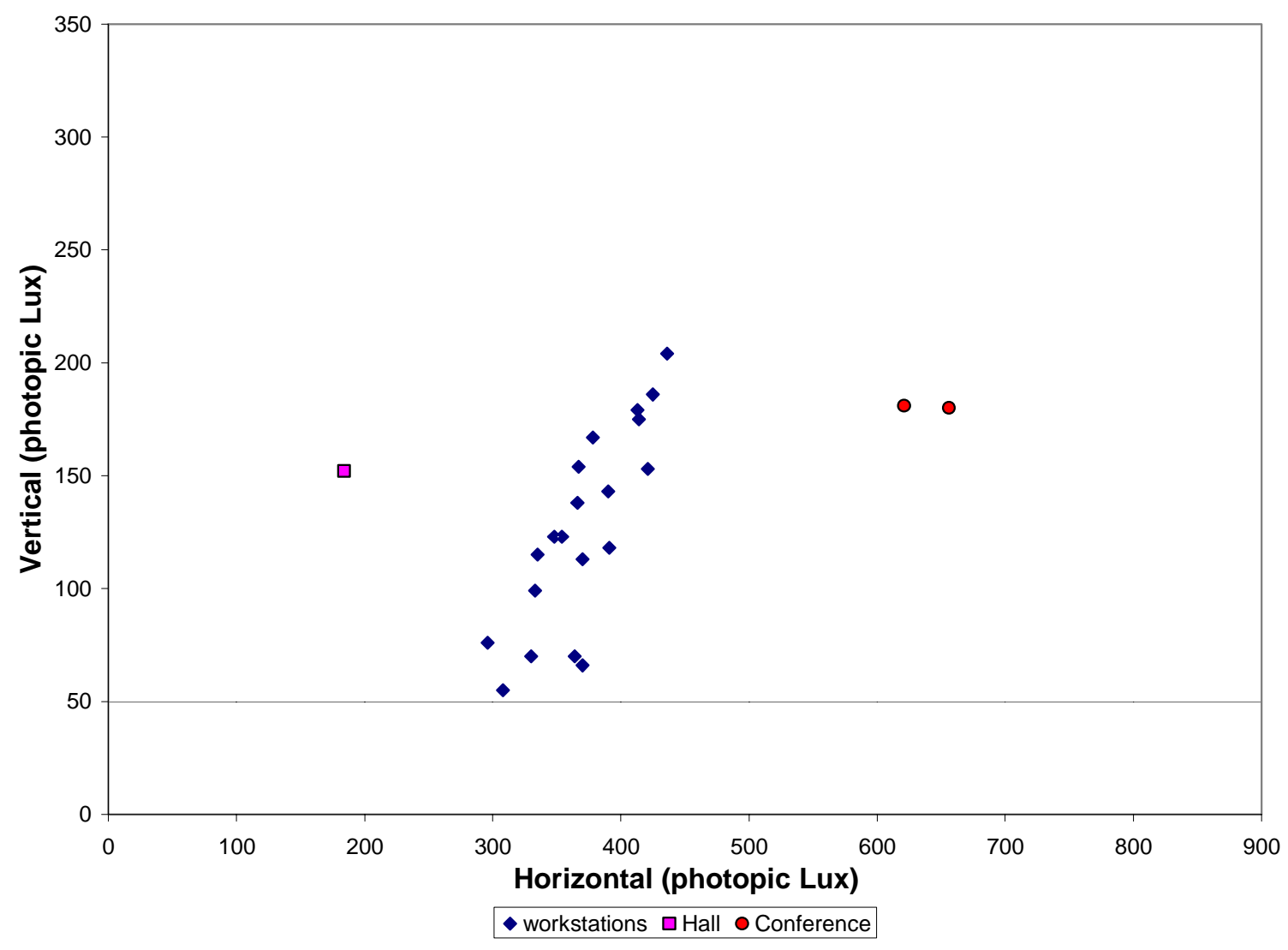

Figure 3.9. Building A - Post-Retrofit Vertical vs. Horizontal Comparison (Photopic)

\subsubsection{Statistical Analysis of Light Level Measurements}

While each of the 23 measurement locations is unique, their collective values form a measured comparison of the lighting of the building before and after the retrofit. The measured values for each location are given in Appendix C, Tables C.1 and C.2. Average values are also given in the detailed tables. They show that, as expected, the S/P ratio increased with the retrofit lighting. The minimums and maximums from Tables C.1 and C.2 show more variability than might be expected given a complete and consistent replacement of all overhead lighting in the measured spaces. However, variables exist in all real-world occupied spaces that affect light level measurements and their comparison. The variability in minimum and maximum values is most likely due to the type of fixtures used in the building. Parabolic fixtures are highly directional and have a sharp cut-off angle. For this reason, illuminance values can differ significantly in open plan offices, depending on the location of the fixture relative to cubicle walls and the height of those walls. Other potential variables that could impact variability in pre- and postretrofit illuminance measurements including the following:

- Material (letters, drawings, pictures, etc.) on the wall that the sensor is aimed toward for the vertical measurements may change over time, which could affect vertical readings if lighter materials are replaced with darker materials or vice versa.

- Equipment close to the horizontal measurement point (particularly computer monitors) may be moved, added, or removed, which would affect the horizontal readings. 
- Nearby bookcase contents, plants, notebooks, and other equipment may change quantity or location, causing differences primarily in the horizontal measurements.

To ensure that the variability experienced with these measurements did not adversely affect the usability of the averages as comparison results, a statistical analysis was completed for the 20 sets of office location measurements. The two conference locations (room 179) were not expected to be affected by any of these variables and, because of the uncluttered nature of the spaces, their values were extreme compared to office locations; therefore, they were excluded from this statistical analysis. The hallway location (193A) was similarly expected to be unaffected and was also excluded.

\subsubsection{Horizontal Measured Data Analysis}

Because the differences of post-retrofit minus pre-retrofit measurements look approximately normally distributed for the horizontal measurements, the two-sided paired t-test is highly appropriate and the derived confidence intervals should be good approximations. Additional analysis using the Wilcoxon Signed Rank test takes into account whether or not the measurement increased or decreased, as well as the magnitude of the change. Results of the analysis are shown in Table 3.3. These results indicate high confidence that the average overall decrease in horizontal photopic light level is 92 lux, with a $95 \%$ confidence interval of $+/-14$ lux and the average overall increase in horizontal scotopic light level is 76 lux with a $95 \%$ confidence interval of $+/-22$ lux.

Table 3.3. Building A - Horizontal and Vertical Photopic and Scotopic Measured Data Analysis Results

\begin{tabular}{|c|c|c|c|c|}
\hline & \multicolumn{2}{|c|}{ Horizontal } & \multicolumn{2}{|c|}{ Vertical } \\
\hline & Photopic & Scotopic & Photopic & Scotopic \\
\hline Mean Before Retrofit (lux) & 461.75 & 595.95 & 168.45 & 212.95 \\
\hline Mean After Retrofit (lux) & 370.45 & 671.65 & 126.35 & 218.05 \\
\hline 2-Sided paired t-test, $\mathrm{p}$-value & $0.0000^{(a)}$ & 0.0000 & 0.0000 & 0.5106 \\
\hline $\begin{array}{l}\text { Wilcoxon Signed Rank test, p- } \\
\text { value }\end{array}$ & 0.0001 & 0.0001 & 0.0001 & 0.0761 \\
\hline Change in light level & -92 lux & $+76 \operatorname{lux}$ & $-42 \operatorname{lux}$ & $+5^{(\mathrm{b})}$ \\
\hline $95 \%$ confidence interval & $+/-14 \operatorname{lux}$ & $+/-22 \operatorname{lux}$ & $+/-13 \operatorname{lux}$ & NA \\
\hline \multicolumn{5}{|c|}{$\begin{array}{l}\text { (a) The very small }(0.0000,0.0001) \mathrm{p} \text {-values indicate that there is essentially no chance that the } \\
\text { observed change in light level is due to random variation. }\end{array}$} \\
\hline
\end{tabular}

\subsubsection{Vertical Measured Data Analysis}

For the vertical measurements, differences look less normal, but not so extreme that the two-sided paired t-test cannot be applied. However, the same conclusions were also reached using non-parametric tests (Wilcoxon Signed Rank and Sign tests). These results indicate high confidence that the average overall decrease in vertical photopic light level is 42 lux with a 95\% confidence interval of $+/-13$ lux. 
Applying this test and assuming a normal distribution, there is no statistically solid evidence that the vertical scotopic measurements increased or decreased as a whole. The additional Wilcoxon Signed Rank test that takes into account the magnitude of the change shows a p-value of 0.0761 , which is still not statistically significant at the 5\% level. However, looking at the measurement data itself, there were 12 increases, 7 decreases, and 1 with no change. Of the 19 samples that had a change, the 4 smallest changes were negative, and 9 of the largest 11 changes were positive. Results of the analysis are shown in Table 3.3. These results indicate no statistical evidence of a change in vertical scotopic light levels but do indicate a trend toward an overall increase of 5 lux.

\subsubsection{S/P Ratio Analysis}

A statistical analysis of the resulting $\mathrm{S} / \mathrm{P}$ ratios derived from the raw measurement data was also completed. Because the S/P ratios are not expected to be dependent on variations of the locations, all 23 locations were included and are represented in the results, which are shown in Table 3.4.

Table 3.4. Building A - S/P Ratio Analysis Results

\begin{tabular}{|l|c|c|}
\hline & Vertical & Horizontal \\
\hline Mean Before Retrofit & 1.26 & 1.29 \\
\hline Mean After Retrofit & 1.73 & 1.81 \\
\hline 2-Sided paired t-test, p-value $=$ & 0.0000 & 0.0000 \\
\hline Wilcoxon Signed Rank test, p-value= & 0.0001 & 0.0001 \\
\hline Change in S/P ratio & 0.47 & 0.52 \\
\hline 95\% confidence interval & $+/-0.02$ & $+/-0.03$ \\
\hline
\end{tabular}

These results indicate high confidence that the average overall increase in vertical $\mathrm{S} / \mathrm{P}$ ratio is 0.47 with a $95 \%$ confidence interval of $+/-0.02$ and the average overall increase in horizontal S/P ratio is 0.52 with a $95 \%$ confidence interval of $+/-0.03$.

\subsubsection{Conclusions}

The light level measurements taken in a sample of workstations in Building A indicate that horizontal photopic light levels decreased by $20 \%$ following the retrofit. Horizontal scotopic light levels increased by $13 \%$, and the S/P ratio increased by $40 \%$.

\subsection{Task Lighting Use}

PNNL monitored task lighting use in a sample of 45 workstations in Building A. As part of our evaluation we sought to determine whether office occupants used their task lights more, less, or the same amount after the ceiling lighting was retrofitted. We hoped to determine if a "take-back" of energy savings was occurring, i.e., whether occupants were turning on the task lighting more often after the ceiling lighting was changed. 


\subsubsection{Pre- and Post-Retrofit Measurements}

To assess pre- and post-retrofit task lighting use, individual data loggers were deployed at a sample of the building's workstations. Figure 3.10 and 3.11 show one style of task light and workstation/cubicle present in Building A. The lighting data loggers used were Onset Computer Hobo® H-8 models (see Appendix D for specifications). These were installed on or near 45 workstation task lights. The loggers were set to sense whether the task light was on or off by measuring the light intensity coming from the fixture at 10-minute intervals. Data were collected for more than two weeks in both the pre- and postretrofit periods. The post-retrofit data were collected after the three-week adaptation period to allow for occupant adjustment to the new overhead lighting.

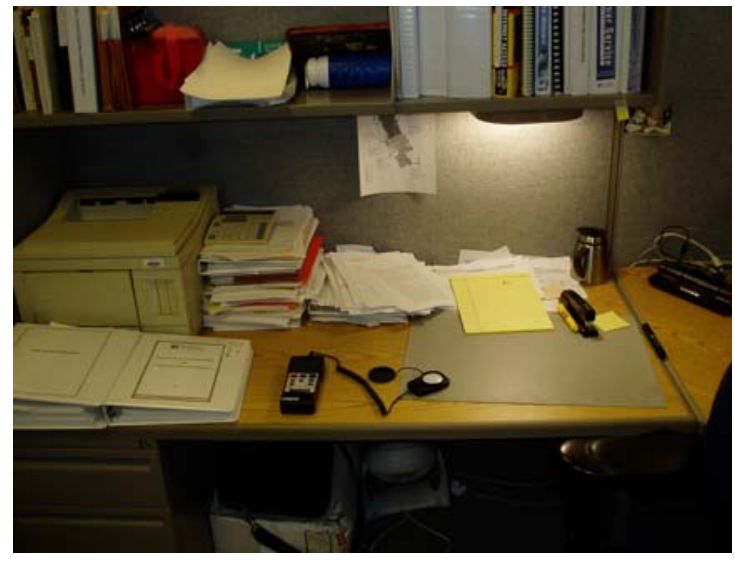

Figure 3.10. Building A Workstation

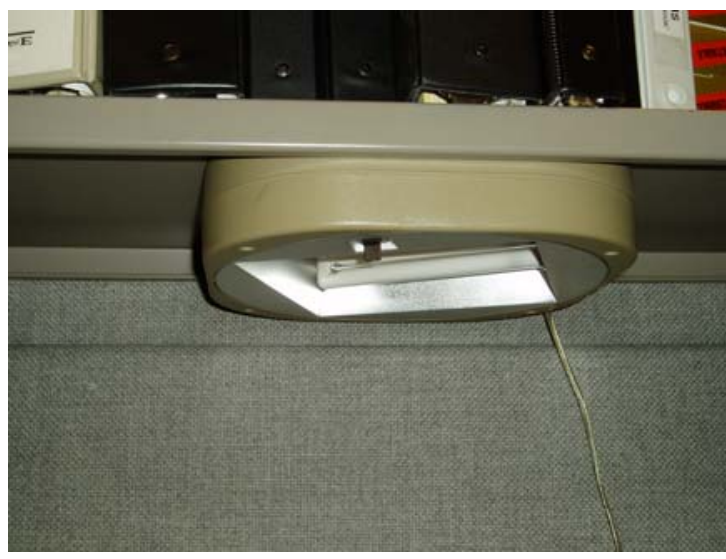

Figure 3.11. Building A Workstation Task Light

For the statistical testing, only those measurements collected Monday through Friday between 5:50 am and 7:10 pm were used, to capture the full range of normal business hours. Twelve business days were used before retrofit, and twelve business days were used after retrofit. In both cases, measurements started on a Friday and ended on a Monday.

\subsubsection{Measurement Results}

Based on data from 39 of the lighting data loggers ( 6 of the 45 loggers were either tampered with, had corrupt data, or were missing), there is no statistical evidence of task lighting usage change after the retrofit. The figures below show the percentage of task light use before and after the retrofit. The mean task lighting usage before the retrofit was $23.5 \%$ of the weekday business hours. The mean task lighting usage after the retrofit was 19.6\%. In absolute terms there was a reduction in task lighting usage (baseline to retrofit); however, statistically this difference is not significant (see Table 3.5).

Table 3.5. Building A - Comparison of Pre- and Post-Retrofit Task Lighting Usage in Percent of Hours

\begin{tabular}{|c|c|c|c|}
\hline & $\begin{array}{c}\text { Mean Task Light Usage } \\
\text { Pre-Retrofit }^{(a)}\end{array}$ & $\begin{array}{c}\text { Mean Task Light Usage } \\
\text { Post-Retrofit }\end{array}$ & $\begin{array}{c}\text { Statistically Significant } \\
\text { Change }^{(\mathrm{b})}\end{array}$ \\
\hline Building A & $23.5 \%$ & $19.6 \%$ & No \\
\hline
\end{tabular}

(a) Mean task light usage is defined as percentage of task light on-time from 5:50 am to 7:10 pm over 12 days before and 12 days after the retrofit period.

(b) Assumes normal distribution in application of the paired t-test to determine statistical significance. 


\section{Percent Usage Before Retrofit}

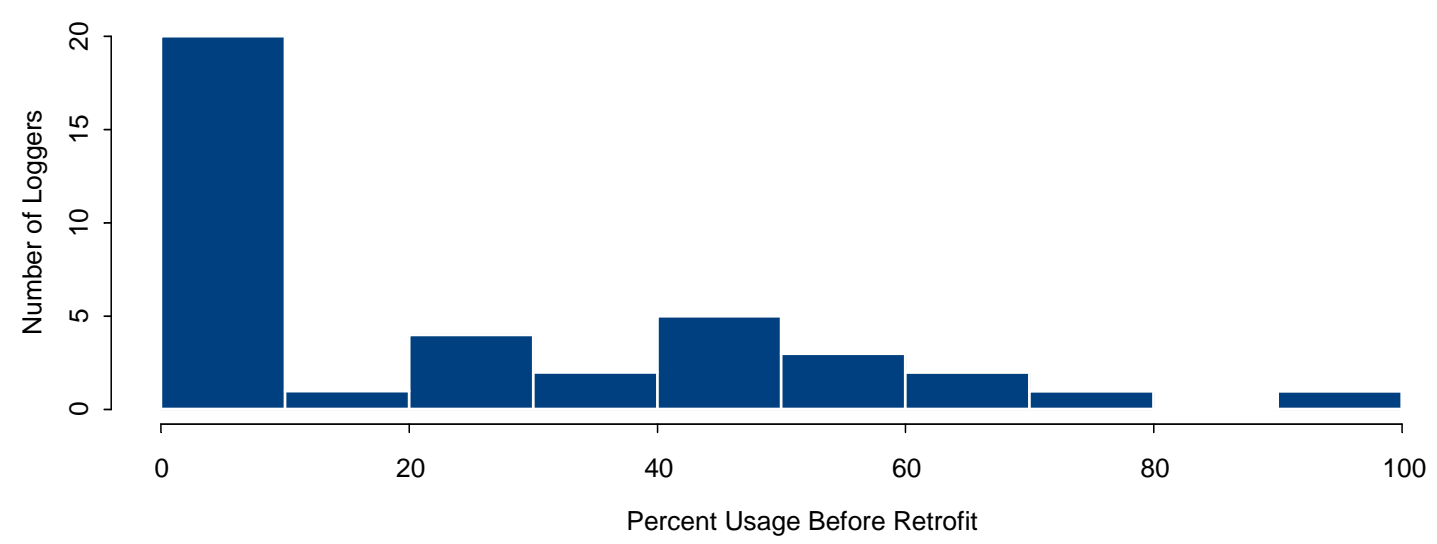

Percent Usage After Retrofit

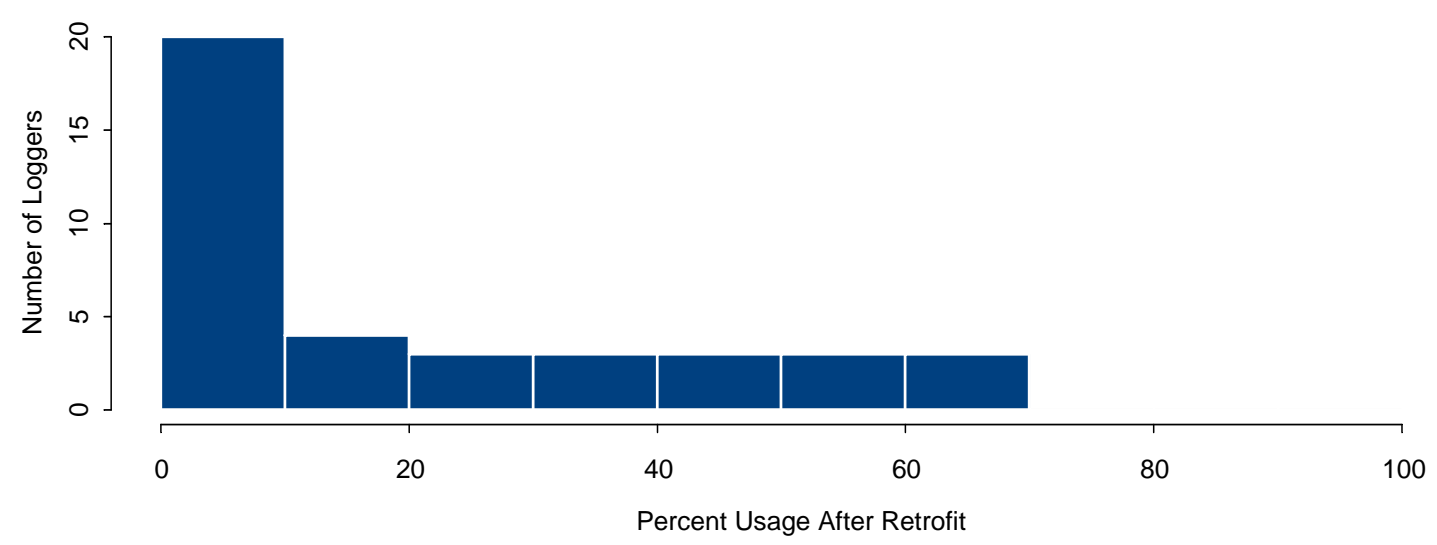

Figure 3.12. Building A - Task Light Usage as a Percentage of Business Hours Before and After Retrofit

Figure 3.12 shows the percentage of hours of the business day that each of the 39 task lights logged were used before and after retrofit. As can be seen, 20 of the task lights were almost never used before or after the retrofit. The plotted differences (post-retrofit - pre-retrofit) are shown in Figure 3.13, which indicate the data has an approximate normal distribution - with a small tail to the left. 


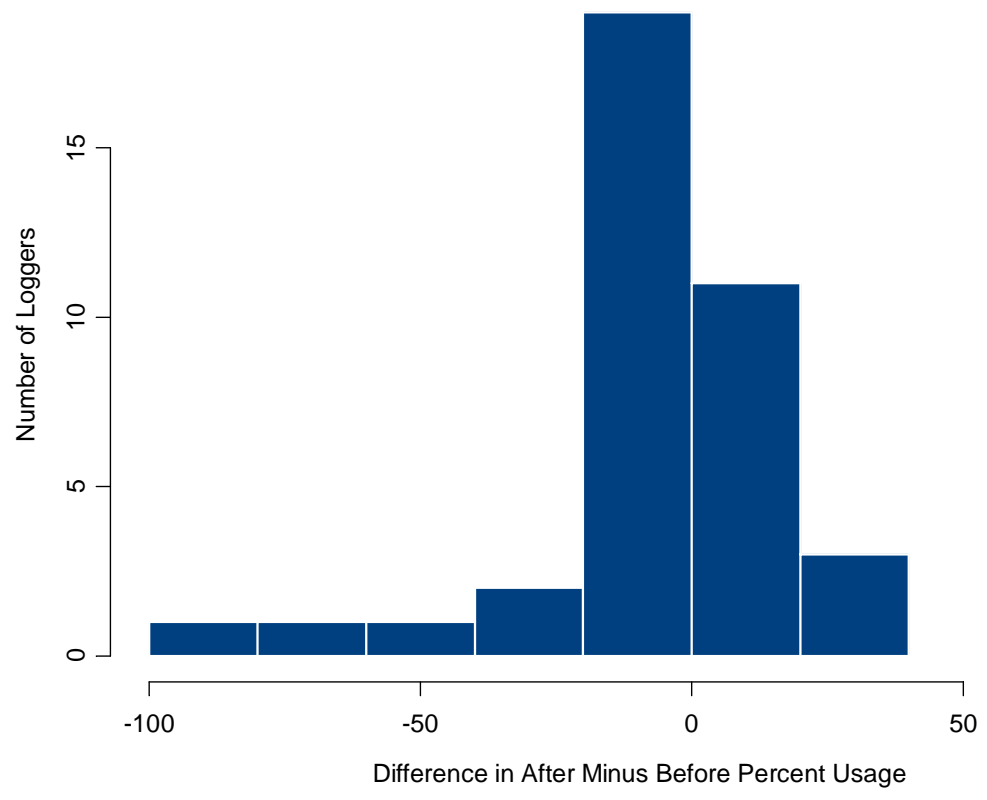

Figure 3.13. Building A - Task Lighting Logger Difference in Usage Before and After Retrofit

\subsubsection{Statistical Analysis}

Statistical analysis was conducted to determine whether the frequency of task lighting use after the retrofit was significantly different from before the retrofit. The results of the parametric and nonparametric tests used in the statistical analysis are given below.

\subsubsection{Paired t-test}

- Mean usage of task lighting was not significantly different after retrofit (19.6\%) when compared to before retrofit $(23.5 \%)$. Assuming the paired differences are normally distributed, the $95 \%$ confidence limit of the difference is $(-10.9 \%, 3.0 \%)$.

- $\quad$ P-value $=0.2564$

- Assuming normality, there is no significant difference.

\subsubsection{Wilcoxon Signed-Rank Test}

(Tests for differences in the ranks of the relative magnitude of the differences.)

- $\quad$ P-value $=0.7359$

- There is no evidence that usage increased or decreased after the retrofit.

\subsubsection{Sign Test}

- $\quad$-value $=1.0000$

- 14 had increased usage, 15 had decreased usage, 10 had no change. 


\subsubsection{Reported Task Lighting Use}

In addition to monitoring the frequency of task lighting use at a sample of 39 workstations, all 143 fulltime occupants of the building were asked about frequency of task lighting use as part of the online occupant survey; 63 occupants answered both the pre and post survey. In Building A, 22 survey respondents indicated on both the pre- and post-retrofit surveys that they had a desk/task light in their workspace. Of these, 3 respondents indicated more frequent desk/task light use after the retrofit than before the retrofit, 2 respondents indicated a decrease, and 17 reported no change in the frequency of desk/task lighting use. Overall, there was no statistically significant change in reported task lighting use following the retrofit. The 22 responses are plotted in Table 3.6, comparing the answers given before and after retrofit.

Table 3.6. Building A - Comparison of Occupant Responses to Question about Frequency of Task Lighting Use, Pre- and Post-Retrofit. Question: "How often do you use your Desk (Task) light(s) when you are working?" Note: Numbers along main diagonal represent the number of occupants who reported the same frequency of task lighting use both pre and post retrofit.

\begin{tabular}{|c|c|c|c|c|c|}
\hline Pre Post & Always & $\begin{array}{l}\text { More than } \\
\text { half of the } \\
\text { time }\end{array}$ & $\begin{array}{l}\text { About half of } \\
\text { the time }\end{array}$ & $\begin{array}{l}\text { Less than } \\
\text { half of the } \\
\text { time }\end{array}$ & Never \\
\hline Always & 10 & & & & \\
\hline $\begin{array}{l}\text { More than } \\
\text { half of the } \\
\text { time }\end{array}$ & 2 & & & 1 & \\
\hline $\begin{array}{l}\text { About half of } \\
\text { the time }\end{array}$ & & & 2 & 1 & \\
\hline $\begin{array}{l}\text { Less than half } \\
\text { of the time }\end{array}$ & & 1 & & 3 & \\
\hline Never & & & & & \\
\hline & & & & & 2 \\
\hline
\end{tabular}

\subsubsection{Conclusions}

Based on 10-minute light intensity data collected from 39 task lights over the course of four weeks (two weeks baseline and two weeks retrofit), there is no statistical evidence of task light usage change from before the retrofit to after the retrofit. Further, there was no statistically significant change in reported task lighting use by the occupants. Given these findings, there is no evidence of a take-back effect of increased task lighting use to adjust for photopic reductions in the overhead lighting levels.

\subsection{Occupant Ratings of Satisfaction with the Lighting}

Building A management provided a list of 179 names of employees to receive the occupant survey. Of these, 140 were in open plan offices (cubicles) and 39 were in enclosed offices. Twelve names were removed from the list because these staff had pre-tested the survey as part of the survey development 
phase. Another 24 names were removed because the staff were found to be telecommuters (working primarily from home), field staff (typically out of the office), or because they were on-leave during the entire period of the pre-retrofit survey. This left a population of 143 full-time staff, including 108 in open plan offices and 35 in enclosed offices, to participate in the pre-retrofit survey.

\subsubsection{Pre- and Post-Retrofit Measurements}

The pre-retrofit survey was administered the week of August 8, 2005. Building staff sent an email message to the 143 full-time staff inviting them to complete the survey. Follow-up phone calls were made to non-respondents during the week of August 15. By August 19, 101 responses had been received (71\% response rate).

Building occupants were notified after the pre-retrofit survey that the lighting would be retrofitted. Employees were not told that the lamp color would change.

Following a three-week adaptation period after the lighting retrofit, the post-retrofit survey was administered during the week of October 3, 2005. Full-time building occupants again received an email message from Building A staff inviting them to take the survey.

Follow-up phone calls were completed by PNNL staff during the week of October 14. A total of 63 paired (pre-retrofit and post-retrofit) responses were received. This represented a response rate of $44 \%$ of the eligible full-time building occupants.

\subsubsection{Statistical Analysis}

Occupants were asked several questions regarding work space satisfaction, including three questions specifically dealing with lighting (see Appendix B for survey instrument).

Results of the statistical analysis for each lighting question are provided below.

“How satisfied are you with the amount of light in your workspace?”

The scale was Very Dissatisfied $\bigcirc \bigcirc \bigcirc \bigcirc \bigcirc \bigcirc \bigcirc$ Very Satisfied

Responses were coded with $1=$ very dissatisfied, $7=$ very satisfied

- Mean Scores

○ Before: 5.15

○ After: 5.23

- Paired t-test

- $95 \%$ Confidence Interval of After minus Before

- $(-0.35,0.51)$

○ Post-retrofit scores were not significantly lower than pre-retrofit scores ( $\mathrm{p}$-value $=$ 0.6489)

- Post-retrofit scores were not significantly different from pre-retrofit scores ( $\mathrm{p}$-value $=$ 0.7022)

- No evidence that scores changed. 
- Wilcoxon Signed Rank Test

○ One-Sided p-value $=0.5691$

○ Two-Sided p-value $=0.8676$

○ No evidence that scores changed

- Sign Test

- 20 increases, 19 decreases, 22 unchanged

$\circ \quad$ One-Sided p-value $=0.6254$

○ Two-Sided p-value $=1.0000$

$\circ$ No evidence that scores changed.

"How satisfied are you with your visual comfort under this lighting?"

The scale was $\quad$ Very Dissatisfied $\bigcirc \bigcirc \bigcirc \bigcirc \bigcirc \bigcirc \bigcirc$ Very Satisfied

Responses were coded with $1=$ very dissatisfied, $7=$ very satisfied

- Mean Scores

○ Before: 4.90

○ After: 5.10

- Paired t-test

- $95 \%$ Confidence Interval of After minus Before

- $(-0.17,0.56)$

- Post-retrofit scores were not significantly lower than pre-retrofit scores ( $\mathrm{p}$-value $=$ 0.8556).

- Post- retrofit scores were not significantly different from pre-before retrofit scores ( $\mathrm{p}$ value $=0.2889$ ) .

○ No evidence that scores changed.

- Wilcoxon Signed Rank Test

$\circ \quad$ One-Sided p-value $=0.9148$

○ $\quad$ Two-Sided $\mathrm{p}$-value $=0.1728$

$\circ$ No evidence that scores changed.

- Sign Test

○ 23 increases, 14 decreases, 24 unchanged

$\circ \quad$ One-Sided p-value $=0.9506$

$\circ \quad$ Two-Sided p-value $=0.1877$

○ No Evidence that scores changed.

“Overall, does the lighting quality enhance or interfere with your ability to get your job done?”

The scale was Interferes $\bigcirc \bigcirc \bigcirc \bigcirc \bigcirc \bigcirc \bigcirc$ Enhances

Responses were coded with $1=$ interferes, $7=$ enhances 
- Mean Scores

○ Before: 4.62

○ After: 5.03

- Paired t-test

- $95 \%$ Confidence Interval of After minus Before

- $(0.04,0.78)$

- After retrofit scores were not significantly lower than before retrofit scores ( $\mathrm{p}$-value $=$ 0.9855).

- After retrofit scores were not significantly different from before retrofit scores ( $\mathrm{p}$-value = 0.0290).

○ There is evidence that scores increased.

- Wilcoxon Signed Rank Test

○ One-Sided p-value $=0.9904$

○ Two-Sided $\mathrm{p}$-value $=0.0196$

$\circ$ There is evidence that scores increased.

- Sign Test

○ 26 increases, 12 decreases, 23 unchanged

○ One-Sided p-value $=0.9931$

○ Two-Sided $\mathrm{p}$-value $=0.0336$

$\circ$ There is evidence that scores increased.

\subsubsection{Variables and their Impacts on Responses}

We analyzed the 63 paired (pre-retrofit and post-retrofit) survey responses to see how several variables may have influenced lighting satisfaction. Results are given below.

\subsubsection{Age}

Respondents were asked to indicate their age group as 30 or under, 31-50, or over 50. Respondent age group did not appear to be a factor for any questions on the survey. There was no statistically measurable difference in the answers given by respondents in any age group as compared to other age groups.

\subsubsection{Gender}

Respondent gender did not appear to be a factor for the lighting questions on the survey. However, for the third lighting question, "Overall, does the lighting quality enhance or interfere with your ability to get your job done?" the change in pre- to post-retrofit response among males was measurably different from the change in response among females. For males, the change in rating on this question was +0.74 , while for females it was -0.04 . Of the respondents, 35 identified themselves as male and 26 as female. The average pre-retrofit score for males on that question was 4.37; post-retrofit it was 5.11. For females, the pre-retrofit average was 4.96; post-retrofit was 4.92 . 


\subsubsection{Monitor Type}

Respondents were asked to indicate the type of computer monitor they used, choosing CRT with curved screen, CRT with flat screen, LCD flat screen, laptop, other, or "I do not use a computer in my workspace." In Building A, the number of respondents reporting each type of monitor was as follows (adds to more than the total survey responses because some may use more than one type of monitor in their workspace):

CRT with curved screen -34

CRT with flat screen -23

LCD flat screen - 2

Laptop - 9

Type of computer monitor did not appear to be a factor in any of the lighting question responses.

\subsubsection{Office Type}

\section{Pre-Retrofit:}

- When asked their satisfaction with the amount of light in their workspace, enclosed office respondents answered significantly higher (average rating 6.33) before retrofit than respondents in short cubicles (4.89).

- When asked about their visual comfort, enclosed office respondents answered significantly higher (6.33) before retrofit than respondents in short cubicles (4.57).

- When asked about the light and its affect on their ability to get their job done, enclosed office respondents answered significantly higher (6.00) before retrofit than respondents in short cubicles (4.18).

\section{Post-Retrofit:}

- When asked about their satisfaction with the amount of light in their workspace, enclosed office respondents answered significantly higher (6.33) after retrofit than respondents in short cubicles (4.75).

- When asked about their visual comfort, enclosed office respondents answered significantly higher (6.33) after retrofit than respondents in short cubicles (4.82).

- When asked about the light and its effect on their ability to get their job done, enclosed office respondents answered significantly higher (6.17) after retrofit than respondents in short cubicles (4.71).

\subsubsection{Daylighting Availability}

Seventeen of the 63 respondents had access to daylight in their office spaces, while 44 did not. Answers were broken out by daylight availability to see if it had any impact on answers (See Table 3.7). 
Table 3.7. Comparison of Survey Responses from Building A Workspaces With and Without Daylight

\begin{tabular}{|l|c|c|c|c|}
\hline Pre-Retrofit Ratings & $\begin{array}{c}\text { Sample } \\
\text { Size }\end{array}$ & Amount of Light & Visual Comfort & Impact on Job \\
\hline & \multicolumn{4}{|c|}{ Average score (scale 1 - 7) } \\
\hline Daylight & 17 & 5.71 & 5.24 & 4.94 \\
\hline No Daylight & 44 & 4.93 & 4.77 & 4.50 \\
\hline Post-Retrofit Ratings & 17 & 5.71 & 5.41 & 5.29 \\
\hline Daylight & 44 & 5.05 & 4.98 & 4.93 \\
\hline No Daylight & \multicolumn{5}{|l|}{} \\
\hline Change (post - pre) & 17 & 0.00 & 0.18 & 0.35 \\
\hline Daylight & 44 & 0.11 & 0.20 & 0.43 \\
\hline No Daylight &
\end{tabular}

There were no statistically significant differences when comparing the responses from respondents who had daylight as opposed to those who did not.

\subsubsection{Conclusions}

Statistical analysis of the pre-retrofit and post-retrofit responses from Building A occupants determined the following:

- Mean scores on two of the three lighting questions were not significantly different after retrofit compared to before retrofit. These questions were:

○ "How satisfied are you with the amount of light in your workspace?"

○ "How satisfied are you with your visual comfort under this lighting?"

- For one of the lighting questions, mean scores were statistically higher after retrofit. This question was:

○ "Overall, does the lighting quality enhance or interfere with your ability to get your job done?"

- Age was not a factor for any questions.

- Gender was not a factor for any of the lighting questions, but the change in rating among males for the "Overall, does the lighting quality enhance or interfere with your ability to get your job done?" differed measurably from the change in ratings by females.

- Monitor type was not a factor for any lighting questions.

- Respondents in short cubicles were less satisfied with their lighting than those in private offices both before and after retrofit.

- Reponses from occupants with daylight did not differ significantly from occupants without daylight. 


\subsection{Building B Results}

This chapter provides results of pre- and post-retrofit measurements in Building B, a 119,000 sq ft, four-story office building located in Vallejo, California. Approximately 2,800 overhead lamps were replaced in this building. The original overhead lighting was provided by General Electric F32T8/SP30/ECO lamps and electronic instant start ballasts with ballast factor of 0.88 . These were found in predominately 2x4-foot, 3-lamp fixtures, which lighted 20 enclosed offices (four shared), 122 cubicles, 15 conference rooms, 18 hallways, a library, and four training rooms (see Figure 4.1 for example of open office or cubicle area). Lamps in all fixtures were replaced with new GE F32T8/SPX50/ECO lamps. Ballasts were replaced with electronic programmed start ballasts with a ballast factor of 0.60 . Results of PNNL's evaluations of lighting energy use consumption, light levels, task lighting use, and occupant satisfaction ratings for Building $B$ are described below.

The measured connected load for the pre-retrofit T-8 lamps with standard electronic ballasts was 29.08 W/lamp. The measured connected load for the post-retrofit T-8 lamps with low-power factor ballast was $23.32 \mathrm{~W} / \mathrm{amp}$. These results are consistent with the nominal (rated) fixture loads of the preand post-retrofit technologies. The change corresponds to a $19.8 \%$ reduction in connected load.

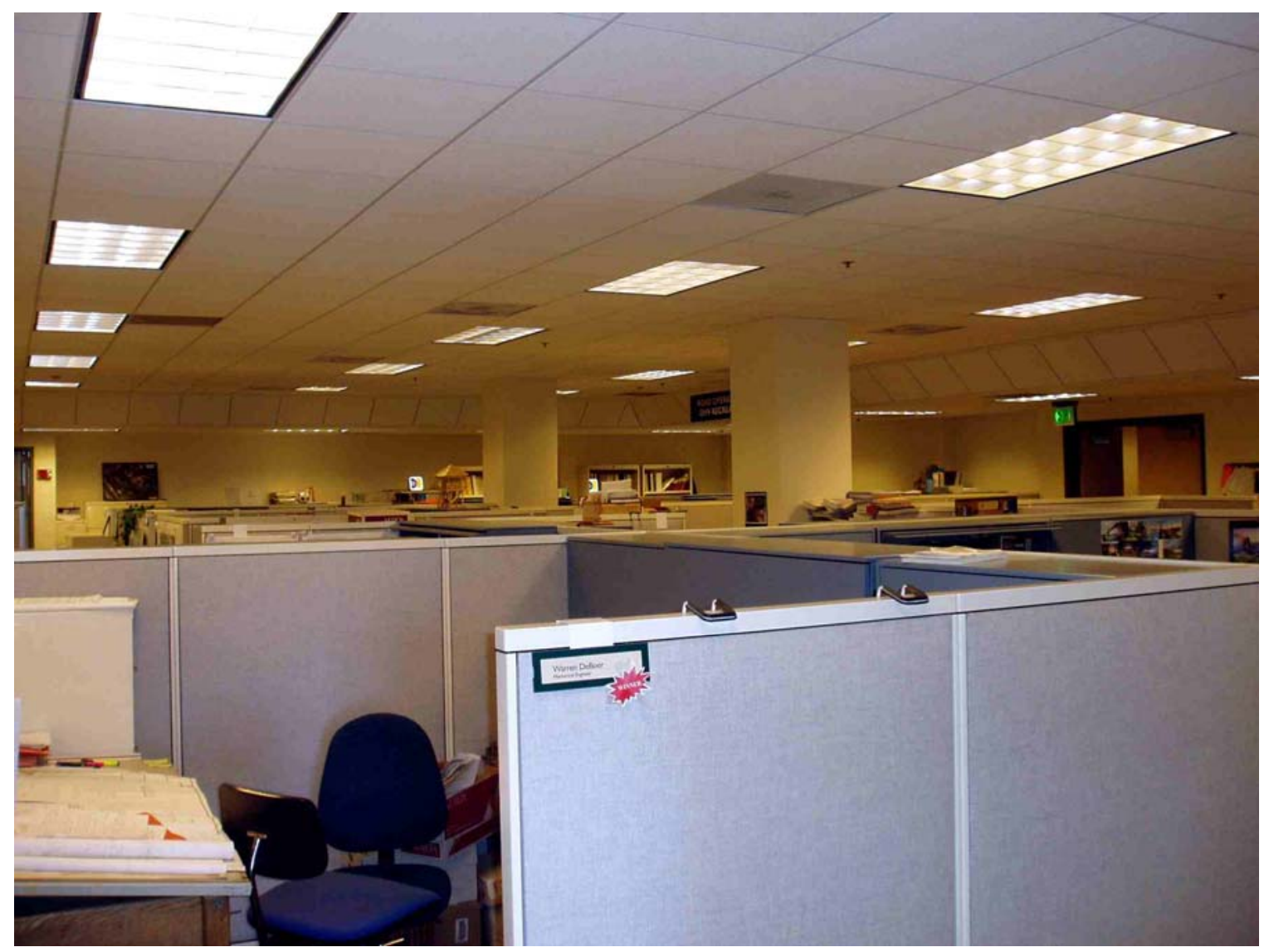

Figure 4.1. Building B Open Office Area 


\subsection{Overhead Lighting Electricity Use}

\subsubsection{Pre- and Post-Retrofit Measurements}

The fixtures affected by the retrofit are powered from three 277 -volt dedicated interior lighting panels on the second through fourth floors (one panel per floor) and a mixed lighting panel on the first floor. The first floor panel serves exterior and stairwell lighting as well as the overhead office lighting. Two loggers were installed to monitor lighting power. An end-use metering logger was installed at the first-floor lighting panel similar to the installation shown in Figure 3.1 for Building A. A four-wire threephase power logger was installed on the lighting riser circuit of the distribution panel in the main electrical room as shown in Figure 4.2. The total overhead lighting load is taken to be the riser load minus the exterior and stairwell loads. The pre-retrofit study period was October 13 - November 4, and the post-retrofit period was November 7 - December 6, 2005.

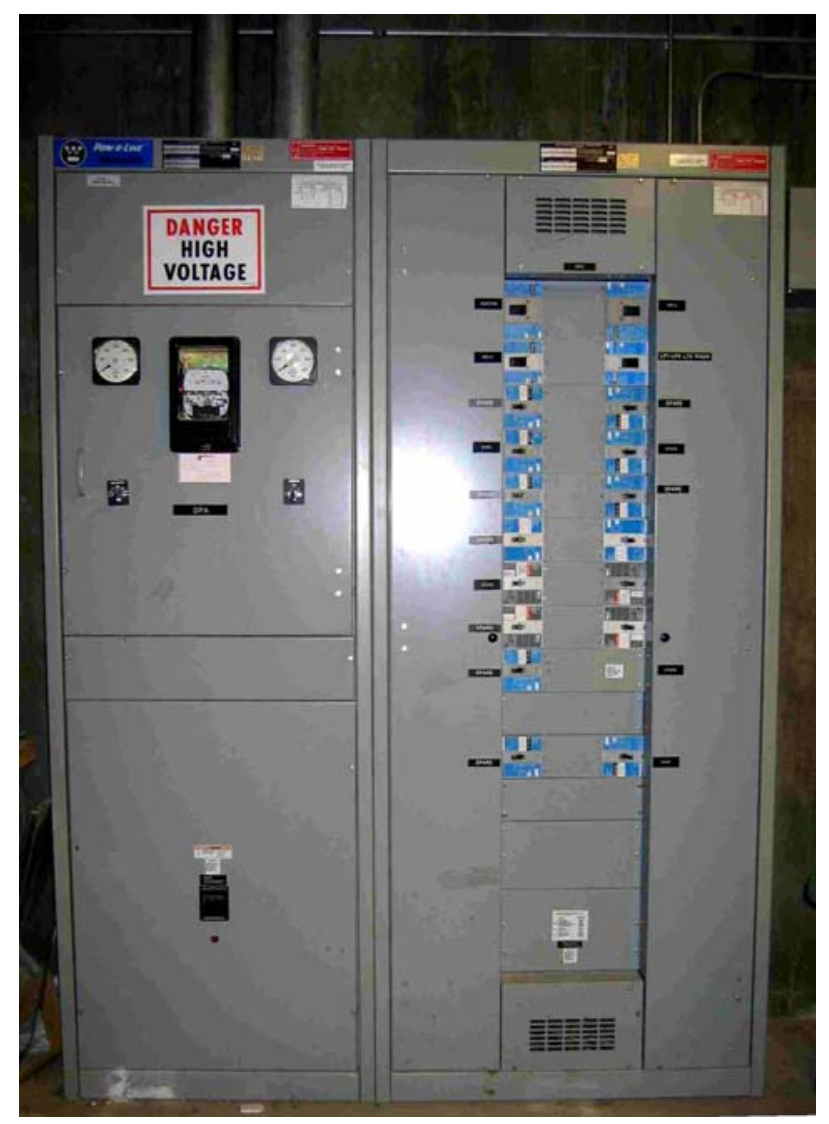

Figure 4.2. Building B - Distribution Panel with Three-Phase Lighting Riser Logger Installed in RightHand Compartment

\subsubsection{Time Series Lighting Load Data}

The time series data from the riser logger indicates total lighting power over the pre- and post-retrofit periods of the study as shown in Figure 4.3. 


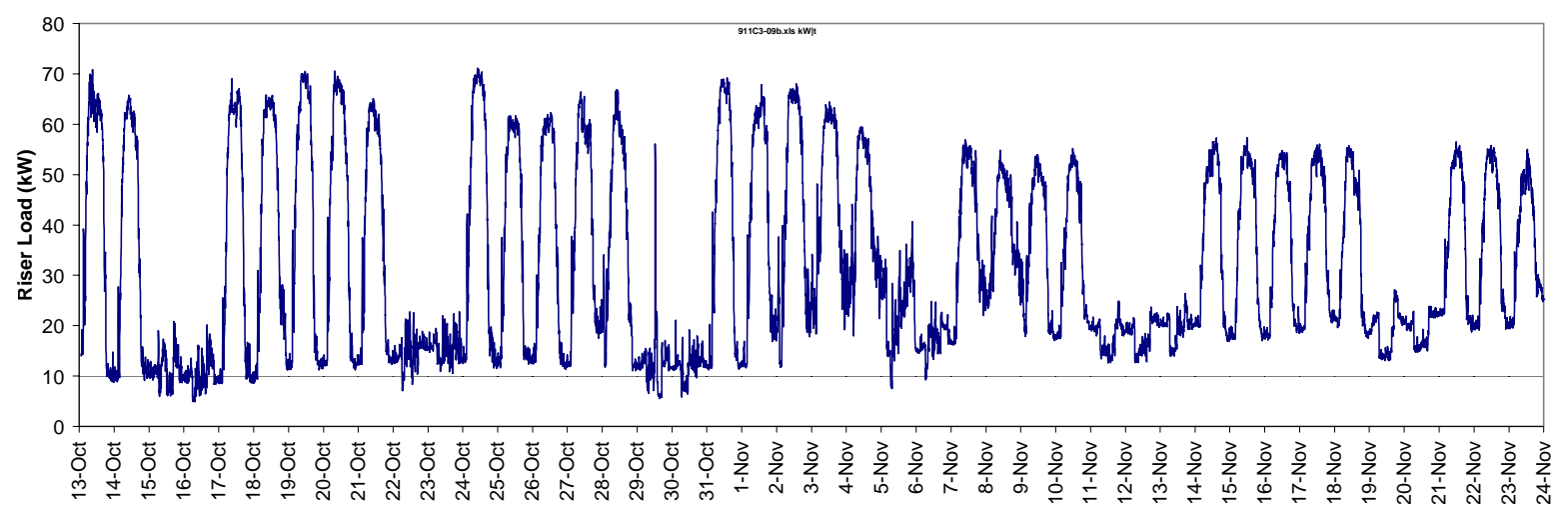

Figure 4.3. Building B Lighting Riser Load Oct. 13 to Nov. 23. Retrofit activity took place Nov. 3-6.

To better see the effects of varying building operations, the daily total lighting power profiles are shown for pre-retrofit weekdays in Figure 4.4 and for post-retrofit weekdays in Figure 4.5. Each daily load profile is a separate line in Figures 4.4 and 4.5.

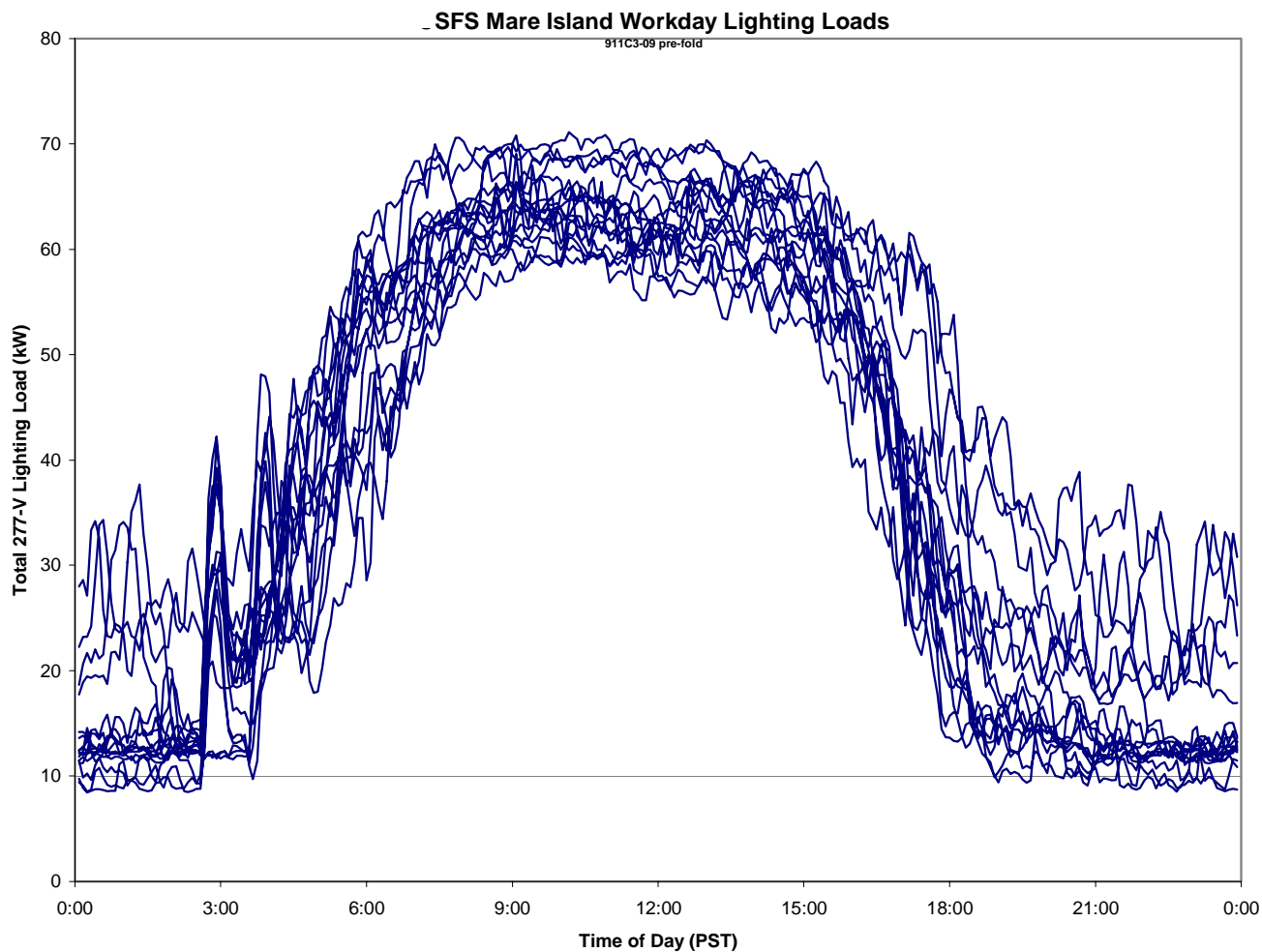

Figure 4.4. Building B Pre-Retrofit Weekday Load Profiles for Oct. 13-Nov. 4, 2005 


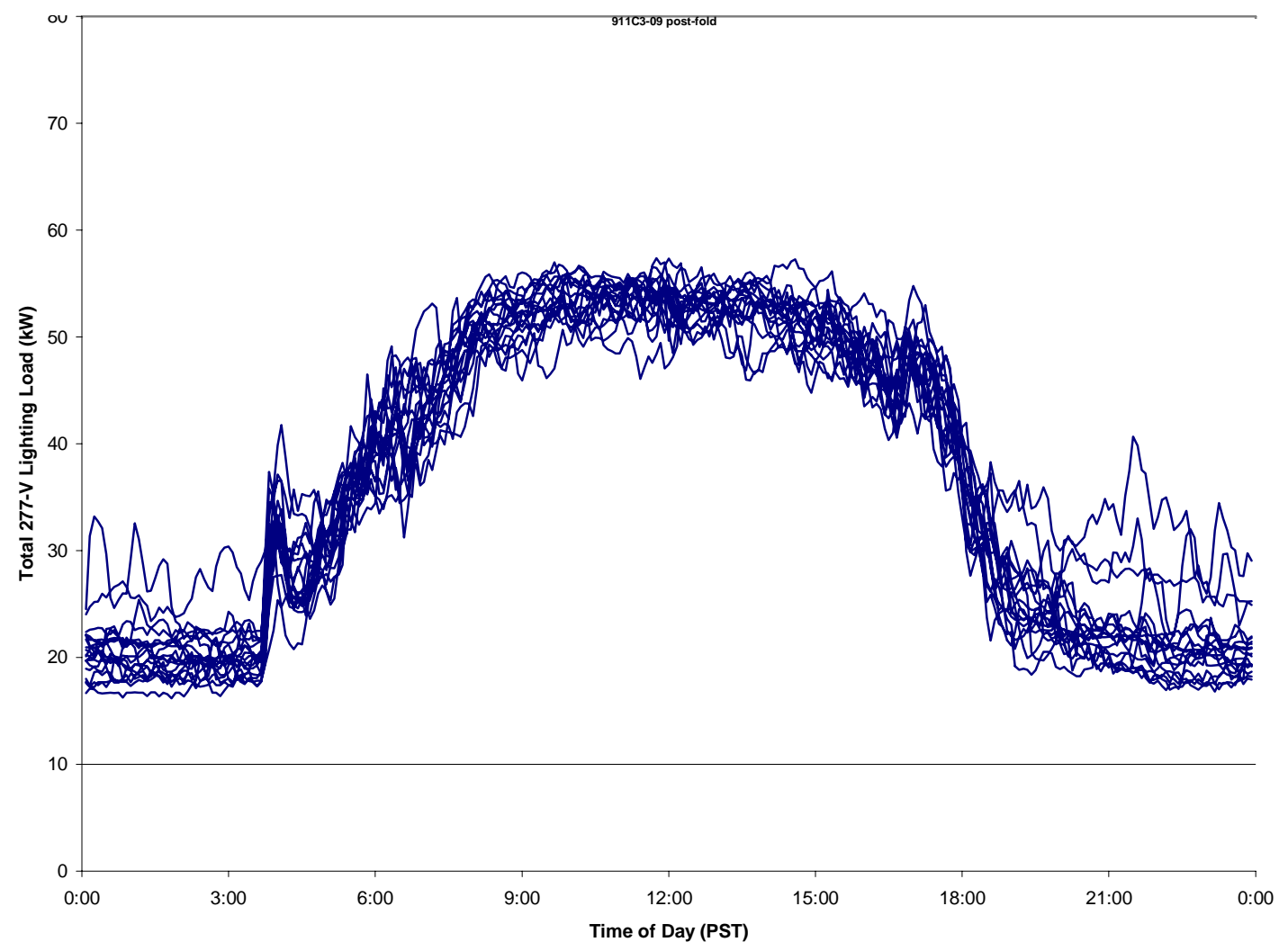

Figure 4.5. Building B Post-Retrofit Weekday Load Profiles for Nov. 7-Dec. 6, 2005

The mean daily profiles, after removing exterior lighting loads, are shown together in Figure 4.6. The two pre-retrofit profiles (Figures 4.3 and 4.4) show that a significant change in nighttime lighting use occurred with the change from daylight-savings to standard time on October 30 . We postulate that the seasonal onset of afternoon darkness results in more lights being left on. 


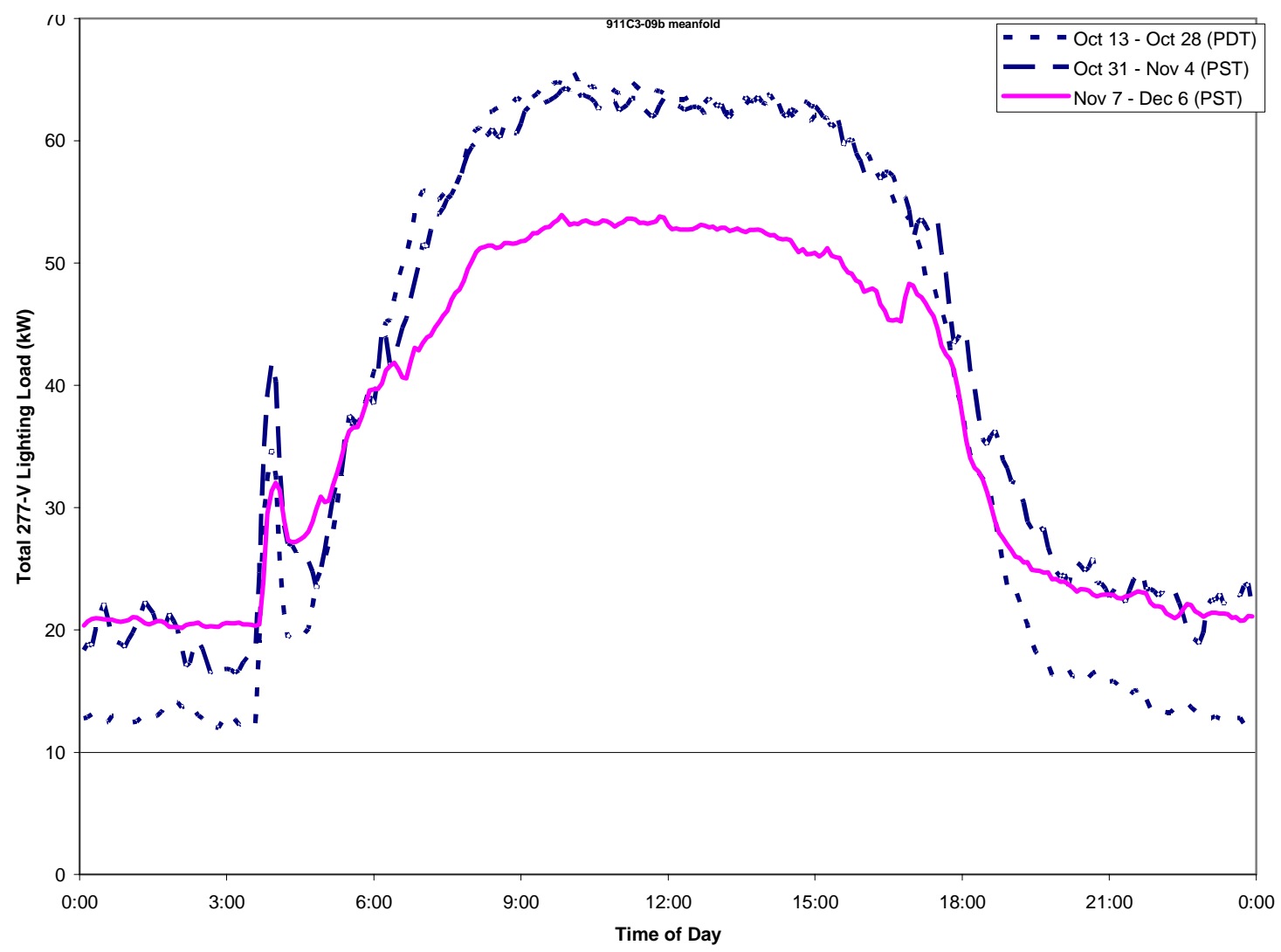

Figure 4.6. Building B Mean Pre- and Post-Retrofit Workday Load Profiles

There are variations of up to $20 \%(+/-10 \%)$ among normal workday profiles during the working hours and some Friday load profiles deviate by more than $10 \%$. Because the majority of overhead lighting is controlled by occupancy sensors in relatively small zones, there is not a well-defined "hat" profile. Significant variations occur from day to day over the entire daily profile. The morning "spike" between 03:30 and 04:00 is a result of air movement tripping some of the occupancy sensors and turning on the lights. The building manager confirmed that the HVAC controls are programmed to run the fans during this time period on each weekday morning. It is possible that occasional periods of additional night fan operation are triggering some of the same banks of lights on some nights.

\subsubsection{Pre- and Post-Retrofit Energy Use}

The pre-retrofit analysis period was October 16 through November 3 and the post-retrofit period was November 7 through December 6. The holidays, Veterans Day (Nov. 11) and Thanksgiving (November 23-25) were removed from the analysis. The average weekly, weekday, and workhour lighting loads, expressed as average $\mathrm{kW}$, are shown in Table 4.1. 
Table 4.1. Building B - Average Weekly, Weekday, and Work Hour Lighting Loads

\begin{tabular}{|l|ccc|}
\hline & Weekly $(24 \times 7)$ & Weekday & Workhours \\
\hline Pre-Retrofit (average kW) & 36.01 & 42.36 & 62.86 \\
Post-Retrofit (average kW) & 31.38 & 37.07 & 52.39 \\
Ratio & 0.872 & 0.875 & 0.834 \\
Change (average kW) & 4.62 & 5.29 & 10.46 \\
Change (\% reduction) & $12.8 \%$ & $12.5 \%$ & $16.6 \%$ \\
\hline
\end{tabular}

The average weekly load in $\mathrm{kW}$ is the average load for all hours in the week ( $24 \times 7=168$ hours); the average weekday load is the average load for the week days ( $12 \times 5=60$ hours), and the work hours load is the average load for the work hours ( 9 x $5=45$ hours per week). The annual savings based on these observations is 4.62 average $\mathrm{kW}$ or $12.8 \%$. The extrapolation of these numbers to annual energy savings is not entirely reliable because of seasonal effects. However, we can roughly project savings of $8760 \mathrm{hr} / \mathrm{yr} * 4.62$ average $\mathrm{kW}=40,500 \mathrm{kWh} / \mathrm{yr}$.

\subsubsection{Connected Load Measurements}

The most reliable estimate of annual project energy savings that can be obtained by short-term measurements is based on reduction in connected load, which can be measured directly. The reduction in connected load equals average pre-retrofit connected load minus average post-retrofit connected load.

The pre-retrofit connected load, based on five private offices and a small conference room, each with four 3-tube fixtures, was $29.08 \mathrm{~W} /$ lamp.

The post-retrofit connected load, based on the same five private offices and conference room, was 23.32 W/lamp.

Thus, $29.08 \mathrm{~W} / \mathrm{lamp}-23.32 \mathrm{~W} / \mathrm{lamp}=5.76 \mathrm{~W} / \mathrm{lamp}$, which is a $19.8 \%$ reduction in connected load.

The pre-retrofit weekly $\mathrm{kW}(36.01 \mathrm{~kW})$ multiplied by hours in a year ( $8760 \mathrm{hrs})$ multiplied by the observed reduction in connected load (0.198) yields an estimated total project savings of $62,460 \mathrm{kWh} / \mathrm{yr}$.

\subsubsection{Conclusions}

The lighting energy savings projected from end-use time-series data are less than the savings projected from connected load measurements. We attribute this mainly to the fact that post-retrofit days have fewer daylight hours than pre-retrofit days. The best estimate of long-term savings is $19.8 \%$, based on the reduction in connected load. We estimate annual energy savings at approximately $60,000 \mathrm{kWh} / \mathrm{yr}$.

\subsection{Light Levels in the Workspace}

\subsubsection{Pre- and Post-Retrofit Measurements}

All readings were taken after sundown in lux with overhead lights on but no task lights on. Preretrofit light level readings were made on October 18, 2005. Post-retrofit light level readings were made on December 17, 2005. In both cases, readings were begun after dark to avoid daylighting effects. In 
addition to 49 individual workstation readings, six locations in a typical office area walkway were taken to provide readings in an area with more static surroundings. These readings are expected to provide consistent measurements not affected by occupant changes or surrounding surface characteristic changes. The individual measurement values and their associated S/P ratios can be found in Appendix C.

Although these data represent individual spaces, their averages can provide a useful comparison of the resulting change in light levels between pre- and post-retrofit conditions. As discussed in the next section on statistical analysis of these data, there is fairly high confidence that these averages shown in Table 4.2 accurately represent the overall change in the test spaces.

Table 4.2. Building B - Average Pre- to Post-Retrofit Light Level and S/P Ratio Changes

\begin{tabular}{|c|c|c|c|c|c|}
\hline \multicolumn{2}{|c|}{ Photopic (lux and \%) } & \multicolumn{2}{c|}{ Scotopic (lux and \%) } & \multicolumn{2}{c|}{ S/P ratio } \\
\hline Vertical & Horizontal & Vertical & Horizontal & Vertical & Horizontal \\
\hline$-47(-31 \%)$ & $-147(-31 \%)$ & $-2(-1 \%)$ & $0(0 \%)$ & $+0.55(+44 \%)$ & $+0.59(+46 \%)$ \\
\hline
\end{tabular}

Because of the nature of field measurements including manual recording and measuring, it is always possible to experience recording errors or other unexpected anomalies in the measurements. Lighting equipment retrofit activities, maintenance, or normal business operation changes can also lead to differences between pre- and post-retrofit conditions that were not expected and might effect measurement values. This might include addition, or removal of lamps, furniture changes or moves, or other occupant changes to their workspace. Because of these possibilities, comparison plots were made of the scotopic versus photopic readings to visually identify S/P ratio outliers that might be mismeasurements or effects from retrofit variations. Figures 4.7 and 4.8 below show these comparisons. For uniform lighting conditions, the plotted points shown in the figures would be expected to form a uniform line with a consistent slope indicating similar S/P ratios for all locations. Those that fall far from this expected line could be considered outliers and potentially suspect.

As expected, the slope represented by the lines in the plots is steeper for the post-retrofit ratios, confirming the increased scotopic content of the post-retrofit lamps. Both charts show fairly uniform slopes for the plotted data, indicating consistent data with few outliers. The data for any outliers in the dataset were carefully considered to determine if they could be specifically identified as bad data points. In these cases, the values that were outside of the expected values were either considered within the realm of possible data recording or effects from retrofit differences. Because they are so few in number and so small in magnitude, they have a negligible effect on the results. 


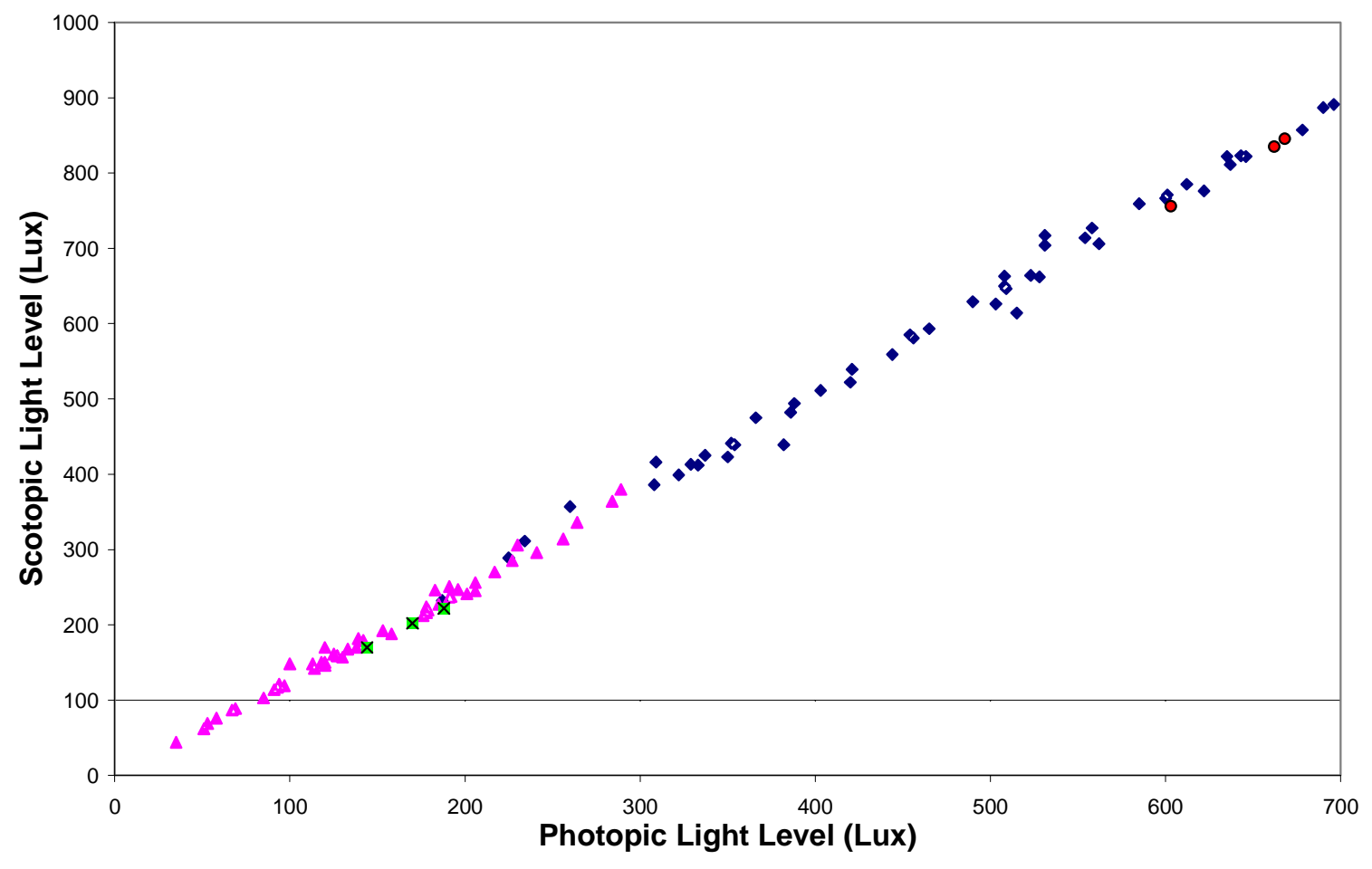

- Horizontal at Workstations $\Delta$ Vertical at Workstations $\bullet$ Horizontal in Aisle $\mathbf{x}$ Vertical in Aisle

Figure 4.7. Building B - Pre-Retrofit Scotopic/Photopic Ratio Comparison 


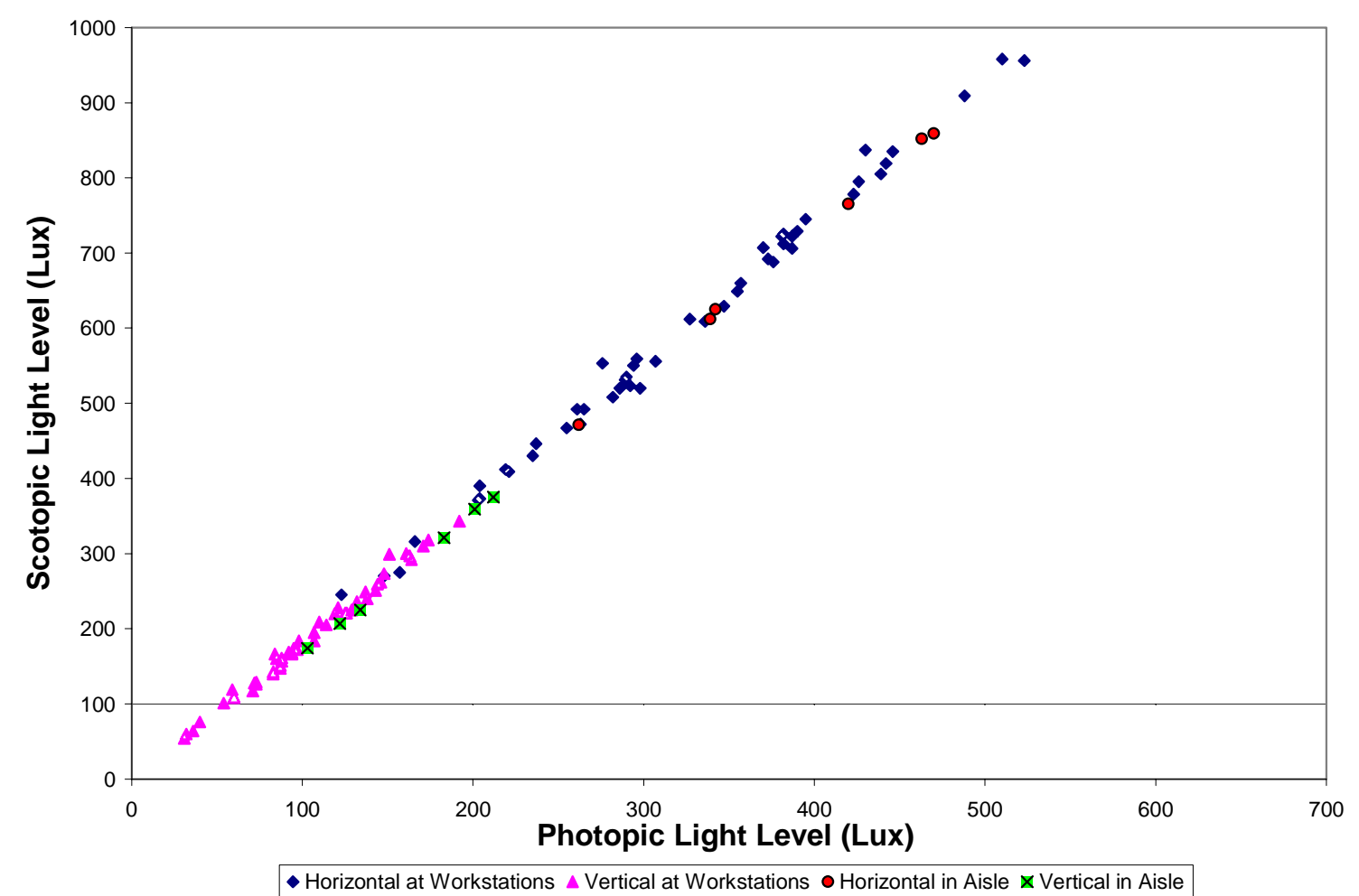

Figure 4.8. Building B - Post-Retrofit Scotopic/Photopic Ratio Comparison

One of the major variables affecting the light level measurements is the varied workspace environment and changing character of the occupied spaces. Workspaces are oriented in different ways in relation to overhead lighting fixtures and partition walls. Materials surrounding desk spaces and posted on walls (personal and business related) are also varied and can have an effect on the horizontal light level readings between spaces and in particular between time periods. This tends to reduce the consistency of the comparison between horizontal values within a specific set of measurements and between pre- and post-retrofit sets. As averaged data, these effects are less noticeable but it is useful to understand this variability. Figures 4.9 and 4.10 present ratios of horizontal to vertical measurements for each location. The cloud of data points shows the extent of the variability. 


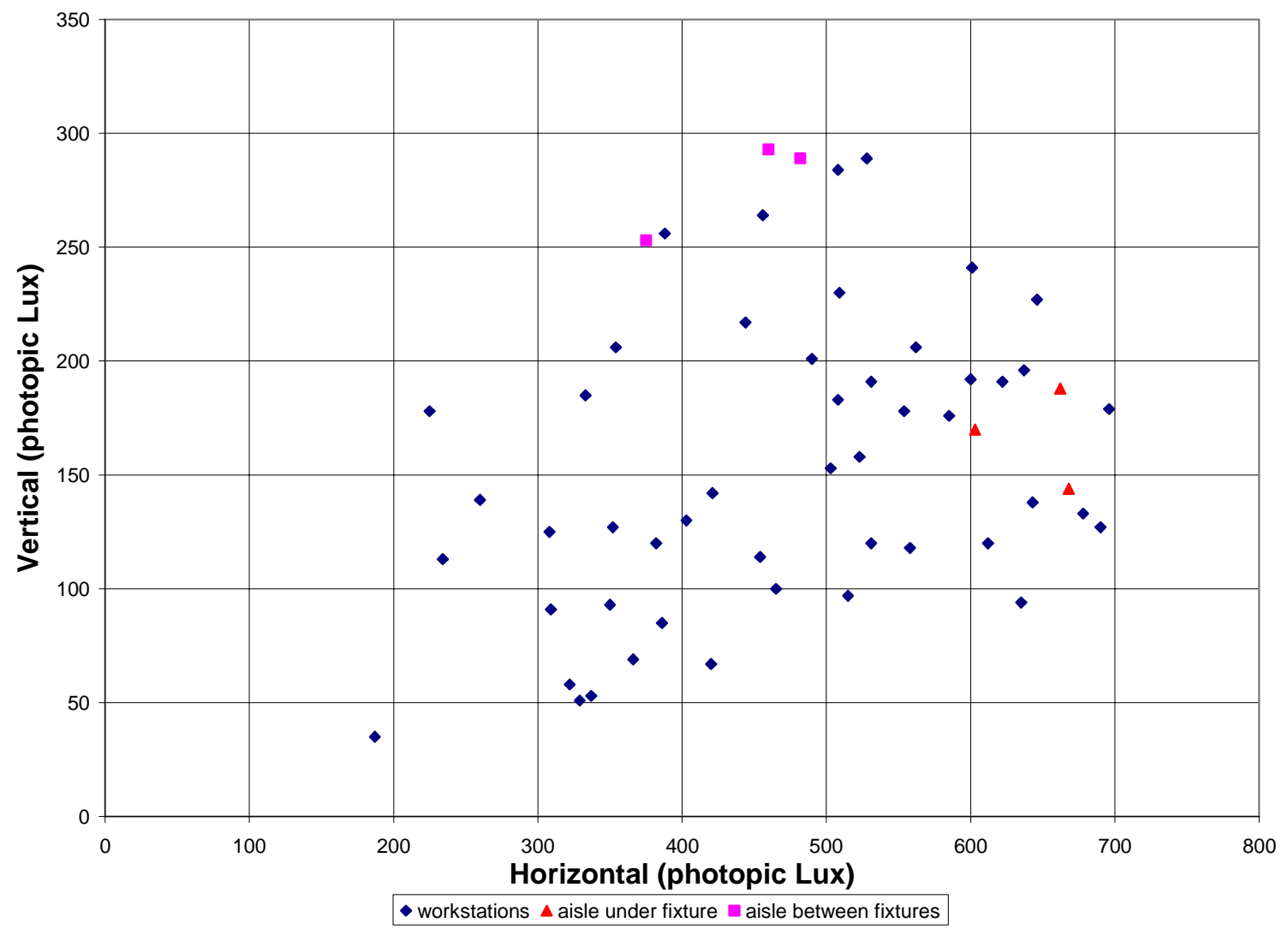

Figure 4.9. Building B - Pre-Retrofit Vertical vs. Horizontal Comparison (Photopic) 


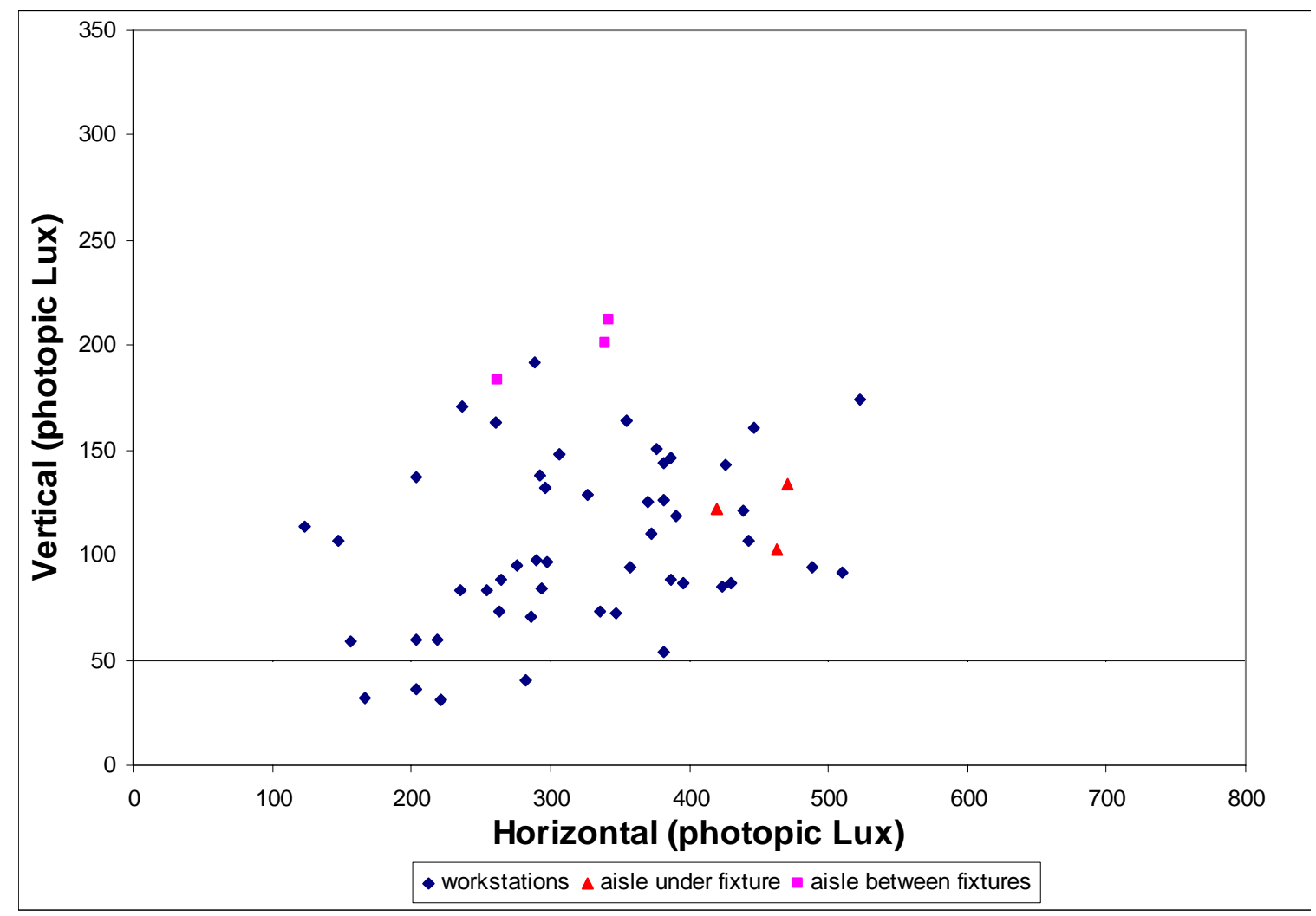

Figure 4.10. Building B - Post-Retrofit Vertical vs. Horizontal Comparison (Photopic)

\subsubsection{Statistical Analysis of Measurements}

While each of the 55 measurement locations is unique, their collective values form a measured comparison of the lighting of the building before and after the retrofit. The averages are shown in Tables C.3 and C.4. They show that, as expected, the $\mathrm{S} / \mathrm{P}$ ratio increased with the retrofit lighting. The minimums and maximums from Tables C.3 and C.4 show more variability than might be expected given a complete and consistent replacement of all overhead lighting in the measured spaces. However, variables exist in all real-world occupied spaces that affect light level measurements and their comparison. The variability in minimum and maximum values is most likely due to the type of fixtures used in the building. Parabolic fixtures are highly directional and have a sharp cut-off angle. For this reason, illuminance values can differ significantly in open plan offices, depending on the location of the fixture relative to cubicle walls and the height of those walls. Other potential variables that could impact variability in pre- and post-retrofit illuminance measurements including the following:

Material (letters, drawings, pictures, etc.) on the wall that the sensor is aimed toward for the vertical measurements may be changed over time by the occupant, affecting mostly vertical readings.

- Equipment close to the horizontal measurement point (particularly computer monitors) may be moved, added, or removed, affecting mostly horizontal readings.

- Nearby bookcase contents, plants, notebooks, and other equipment may change quantity or location, causing differences in mostly horizontal measurements. 
To ensure that the variability experienced with these measurements did not adversely affect the usability of the averages as comparison results, a statistical analysis was completed for the 49 sets of office location measurements. The open hallway locations (N370) were not expected to be affected by any of these variables and, because of the clean nature of the spaces, their values were extreme compared to office locations; therefore, they were excluded from this statistical analysis.

\subsubsection{Horizontal Measured Data Analysis}

Because the differences of post-retrofit minus pre-retrofit measurements look approximately normal for the horizontal measurements, the two-sided paired t-test is highly appropriate and the derived confidence intervals should be good approximations. Additional analysis using the Wilcoxon Signed Rank test takes into account whether or not the measurement increased or decreased, as well as the magnitude of the change. Results of the analysis are shown in Table 4.3. These results indicate high confidence that the average overall decrease in horizontal photopic light level is 147 lux with a $95 \%$ confidence interval of +/- 18 lux and that there was no overall change in horizontal scotopic light level. Looking at the measurement data itself, there were 25 increases, 23 decreases, and 1 with no change.

Table 4.3. Building B - Horizontal and Vertical Photopic and Scotopic Measured Data Analysis Results

\begin{tabular}{|l|l|l|l|l|}
\hline & \multicolumn{2}{|c|}{ Horizontal } & \multicolumn{2}{c|}{ Vertical } \\
\hline & Photopic & Scotopic & Photopic & Scotopic \\
\hline Mean Before Retrofit (lux) & 468.37 & 596.22 & 151.84 & 191.45 \\
\hline Mean After Retrofit (lux) & 321.29 & 596.20 & 104.86 & 189.51 \\
\hline 2-Sided paired t-test, p-value & $0.0000^{(a)}$ & 0.9986 & 0.0000 & 0.7525 \\
\hline Wilcoxon Signed Rank test, p-value & 0.0000 & 0.6154 & 0.0000 & 0.7202 \\
\hline Sign Test, p-value= & 0.0000 & 0.8854 & 0.0000 & 0.8854 \\
\hline Change in light level & -147 lux & $\sim 0$ lux & -47 lux & -2 lux \\
\hline 95\% confidence interval & $+/-18$ lux & NA & $+/-10$ lux & NA \\
\hline (a) The very smal (0.0000) p-van & &
\end{tabular}

(a) The very small (0.0000) p-values for the photopic measurements indicate that there is essentially no chance that the observed change in light level is due to random variation.

\subsubsection{Vertical Measured Data Analysis}

For the vertical measurements, differences look less normal, but aren't so extreme that the two-sided paired t-test can't be applied. However, the same conclusions were also reached using non-parametric tests (Wilcoxon Signed Rank and Sign tests). Vertical photopic measurements decreased in 47 of the office spaces and increased in 2 . These results indicate high confidence that the average overall decrease in vertical photopic light level is 47 lux with a 95\% confidence interval of $+/-10$ lux. Vertical scotopic measurements decreased in 25 of the office space, increased in 23 , and there was no change in 1 . These results indicate no statistical evidence of a change in vertical scotopic light levels. 


\subsubsection{S/P Ratio Data Analysis}

A statistical analysis of the resulting $\mathrm{S} / \mathrm{P}$ ratios derived from the raw measurement data was also completed as a further verification of the significance of the results. Differences in the S/P ratios are less normally distributed. However, conclusions are the same regardless of whether normality-based tests are used, or the non-parametric tests. The results are shown in Table 4.4.

Table 4.4. Building B - S/P Ratio Analysis Results

\begin{tabular}{|l|c|c|}
\hline & Vertical & Horizontal \\
\hline Mean Before Retrofit: & 1.26 & 1.27 \\
\hline Mean After Retrofit: & 1.81 & 1.86 \\
\hline 2-Sided paired t-test, p-value $=$ & 0.0000 & 0.0000 \\
\hline Wilcoxon Signed Rank test, p-value= & 0.0000 & 0.0000 \\
\hline Sign Test, p-value= & 0.0000 & 0.0000 \\
\hline Change in S/P ratio & +0.55 & +0.59 \\
\hline 95\% confidence interval & $+/-0.02$ & $+/-0.02$ \\
\hline
\end{tabular}

All 49 of the office spaces had an increase in vertical S/P ratio. These results indicate high confidence that the average overall increase in vertical $\mathrm{S} / \mathrm{P}$ ratio is 0.55 with a $95 \%$ confidence interval of $+/-0.02$.

All 49 of the office spaces had an increase in horizontal SP ratio. These results indicate high confidence that the average overall increase in horizontal S/P ratio is 0.59 with a $95 \%$ confidence interval of + /- 0.02 .

\subsubsection{Conclusions}

The light level measurements taken in a sample of workstations in Building B indicate that horizontal photopic light levels decreased by $31 \%$ following the retrofit. Horizontal scotopic light levels did not change, but the $\mathrm{S} / \mathrm{P}$ ratio increased by $46 \%$.

\subsection{Task Lighting Use}

PNNL monitored task lighting use in a sample of 37 workstations in Building B.

\subsubsection{Pre- and Post-Retrofit Measurements}

To assess pre- and post-retrofit task lighting use, individual lighting data loggers were deployed at a sample of the building's workstations. The photos below (Figures 4.11 and 4.12) show one workstation in Building B, both with task light turned off and turned on. Portable data loggers were installed on or near 37 workstation task lights. The loggers were set to track light level (lumens per square foot) at 10-minute intervals. Data were collected for more than two business weeks in both the pre- and post-retrofit periods. The post-retrofit data were collected after the three-week adaptation period to allow for occupant adjustment to the new overhead lighting. 
For statistical testing, only those measurements from Monday through Friday between 5:50 am and 7:10 pm were used, to represent the full range of normal business hours. Times after October 29 were adjusted for daylight savings. Ten business days were used before retrofit, and ten business days were used after retrofit. In both cases, measurements started on a Monday and ended on a Friday.

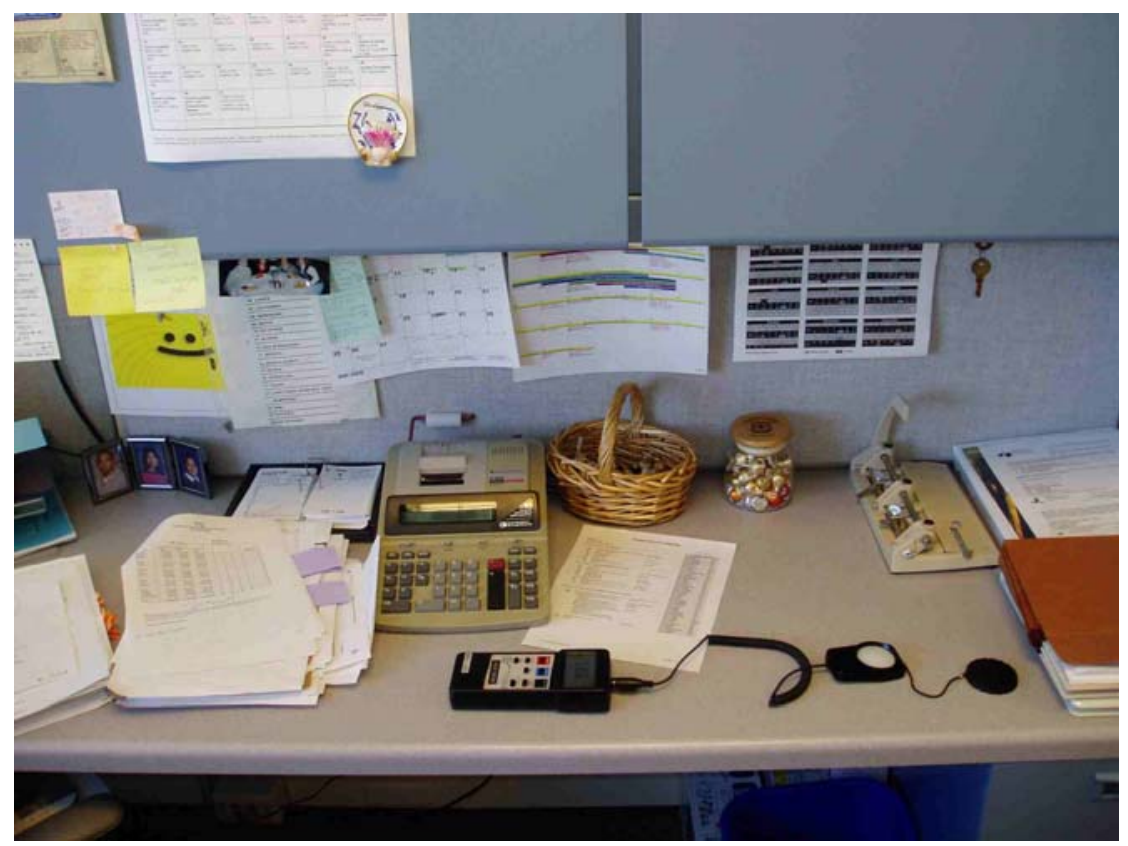

Figure 4.11. Building B - Typical Work Station with Task Light Off

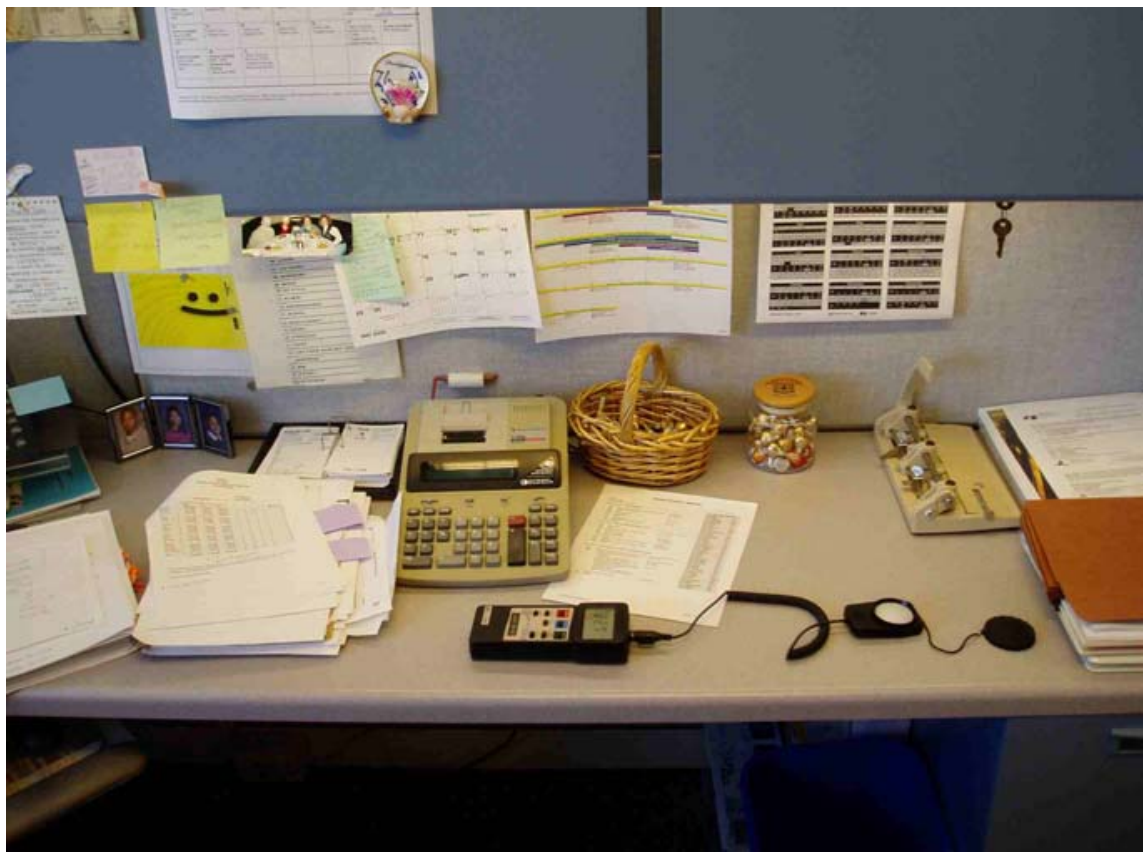

Figure 4.12. Building B - Typical Work Station with Task Light On 


\subsubsection{Measurement Results}

Based on data from the 37 lighting data loggers, there is no statistical evidence of task lighting usage change after the retrofit. The mean task lighting usage before the retrofit was $21.7 \%$ of weekday business hours. The mean task lighting usage after the retrofit was $24.4 \%$. In absolute terms there was an increase in task lighting usage (baseline to retrofit); however, statistically this difference is not significant (see Table 4.5).

Table 4.5. Building B - Comparison of Pre- and Post-Retrofit Task Lighting in Percent of Hours

\begin{tabular}{|l|c|c|c|}
\hline & $\begin{array}{c}\text { Mean Task Light } \\
\text { Usage Pre-Retrofit }^{(a)}\end{array}$ & $\begin{array}{c}\text { Mean Task Light Usage } \\
\text { Post-Retrofit }^{(a)}\end{array}$ & $\begin{array}{c}\text { Statistically } \\
\text { Significant Change }^{(\mathrm{b})}\end{array}$ \\
\hline Building B & $21.7 \%$ & $24.4 \%$ & No \\
\hline
\end{tabular}

(a) Mean task light usage defined as percentage of task light on-time from 5:50 am to 7:10 pm on 12 days during the pre- and post-retrofit period.

(b)Assumes normal distribution in application of the paired t-test to determine statistical significance.

Figure 4.13 below shows the percentage of work hours during which the monitored task lights were in use before and after the retrofit.

Percent Usage Before Retrofit

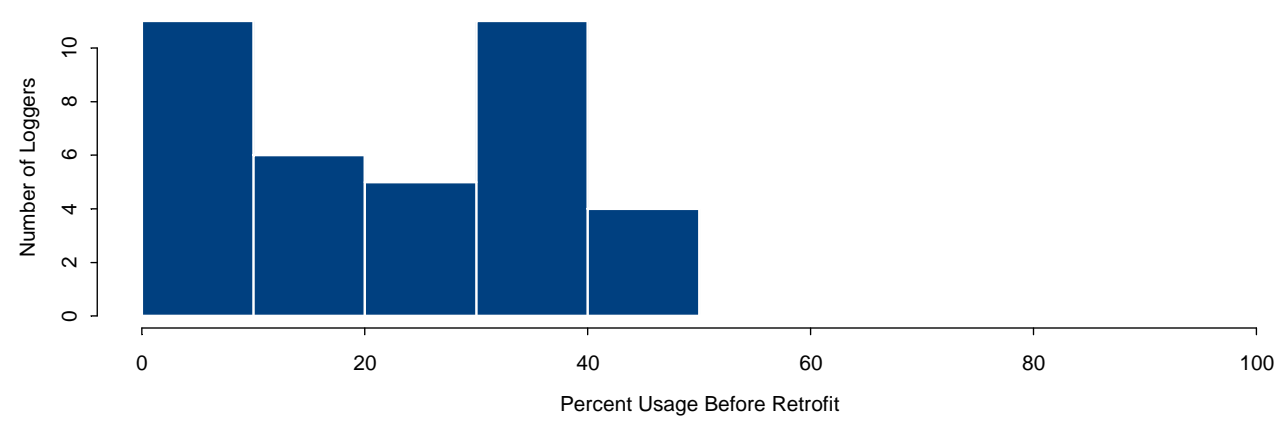

Percent Usage After Retrofit

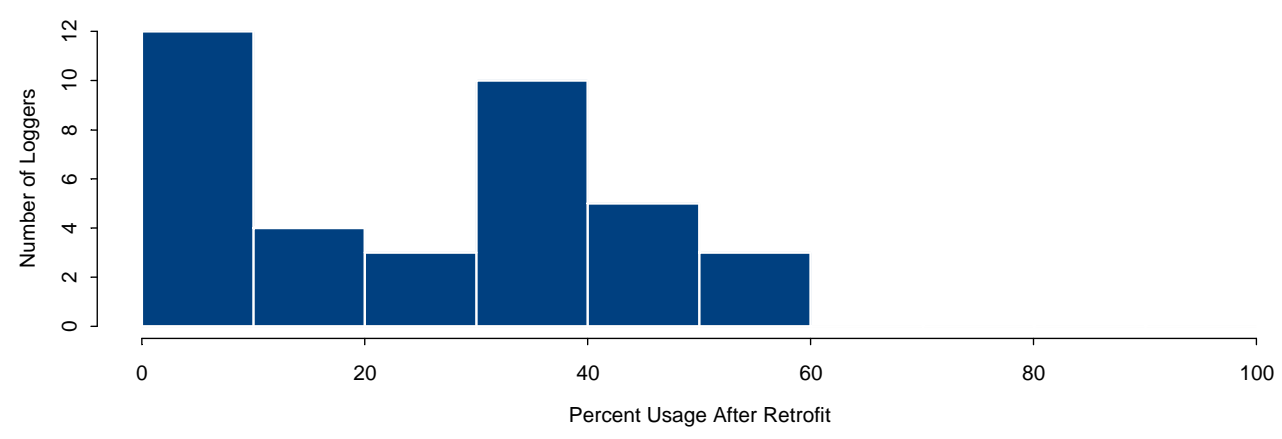

Figure 4.13. Building B - Task Light Usage as a Percent of Business Hours Before and After Retrofit 
Figure 4.14 is a difference usage chart representing the percentage usage for each logger before and after retrofit. The plotted differences show the data has an approximate normal distribution - with a small tail to the left.

\section{Differences in Usage}

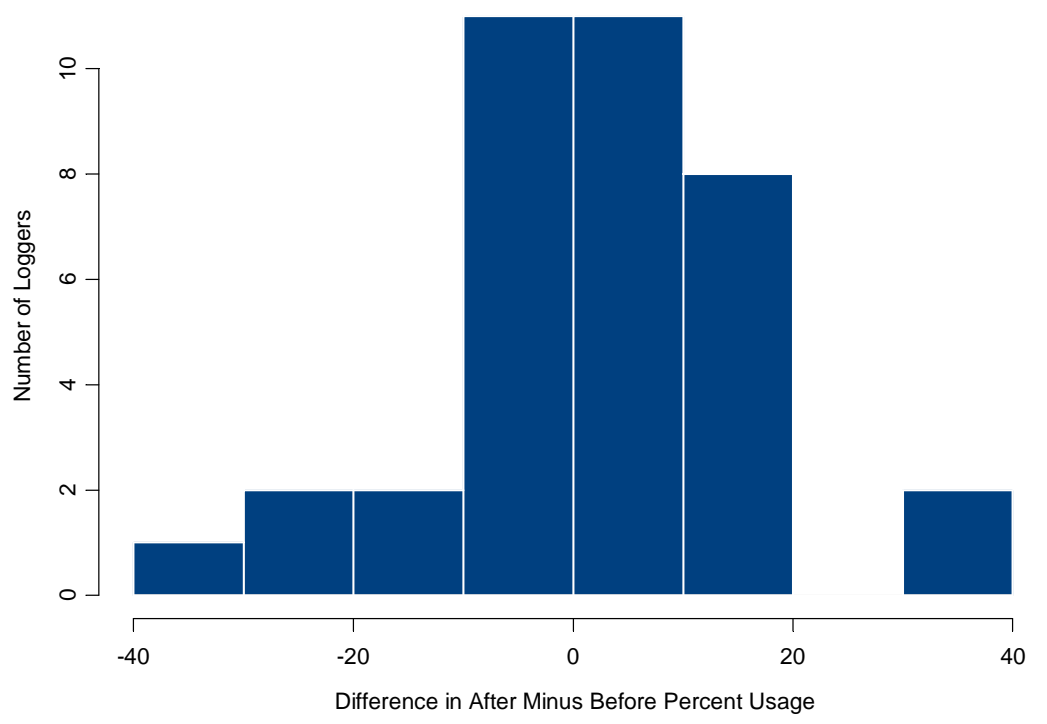

Figure 4.14. Building B - Task Lighting Logger Differences in Usage Before and After Retrofit

Assuming a normal distribution, a paired t-test was conducted. The resulting P-value is 0.2124 , indicating no significance in difference of usage from before to after retrofit.

\subsubsection{Statistical Analysis}

The results of the parametric and non-parametric tests used in the statistical analysis are given below.

\subsubsection{Paired T-Test}

- Mean usage of task lighting was not significantly different after retrofit (24.4\%) when compared to before retrofit (21.7\%). Assuming the paired differences are normally distributed, the $95 \%$ confidence limit of the difference is $(-1.6 \%, 7.0 \%)$

- However, out of 31 loggers that showed a change in usage, 21 showed an increase in usage while 10 showed a decrease in usage. This difference is significant within $95 \%$ confidence.

- Paired t-test

- $\quad$ P-value $=0.2124$

- Assuming normality, there is no significant difference.

\subsubsection{Wilcoxon Signed-Rank Test}

(Tests for differences in the ranks of the relative magnitude of the differences.)

- $\quad$ P-value $=0.0860$ 
- There is no strong evidence that usage increased or decreased after the retrofit.

\subsubsection{Sign Test}

- $\quad$ P-value $=0.0708$

- 21 had increased usage, 10 had decreased usage, 6 had no change.

- There is no strong evidence that more people had an increase in usage than a decrease.

\subsubsection{Reported Task Lighting Use}

In addition to monitoring the frequency of task lighting use at a sample of 37 workstations, all 256 fulltime occupants of the building were asked about frequency of task lighting use as part of the online occupant survey; 145 occupants answered both the pre- and post-retrofit surveys. In Building B, 80 survey respondents indicated on both the pre- and post-retrofit surveys that they had a desk/task light in their workspace. Of these, 12 respondents selected a response indicating more frequent desk/task light use after the retrofit than before the retrofit, 7 respondents indicated a decrease, and 61 reported no change in the frequency of desk/task lighting use. Overall, there was no statistically significant change in reported task lighting use following the retrofit. The number of responses to each possible answer is plotted in Table 4.6 below, comparing before and after retrofit.

Table 4.6. Building B - Comparison of Occupant Responses to Question about Frequency of Task Lighting Use, Pre- and Post-Retrofit. Question: "How often do you use your Desk (Task) light(s) when you are working?" NOTE: Numbers along main diagonal represent the number of occupants who reported the same frequency of task lighting use pre and post retrofit.

\begin{tabular}{|l|c|c|c|c|c|}
\hline \multicolumn{1}{|c|}{ Prest } & Always & $\begin{array}{c}\text { More than } \\
\text { half of the } \\
\text { time }\end{array}$ & $\begin{array}{c}\text { About half of } \\
\text { the time }\end{array}$ & $\begin{array}{c}\text { Less than } \\
\text { half of the } \\
\text { time }\end{array}$ & Never \\
\hline Always & 37 & 1 & & & 1 \\
\hline $\begin{array}{l}\text { More than } \\
\text { half of the } \\
\text { time }\end{array}$ & 5 & 4 & 1 & & 2 \\
\hline $\begin{array}{l}\text { About half of } \\
\text { the time }\end{array}$ & & 1 & 3 & 8 & 1 \\
\hline $\begin{array}{l}\text { Less than half } \\
\text { of the time }\end{array}$ & 2 & & & 1 & 10 \\
\hline Never & & & & & 1 \\
\hline
\end{tabular}

\subsubsection{Conclusions}

Based on 10-minute light intensity data collected from 37 task lights in Building B over the course of four weeks (two weeks baseline and two weeks retrofit), there is no statistical evidence of task light usage change from before the retrofit to after the retrofit. Further, there was no statistically significant change in reported task lighting use by the occupants. Given these findings, there is no evidence of a take back effect of increased task lighting use to adjust for photopic reductions in the overhead lighting levels. 


\subsection{Occupant Ratings of Satisfaction with the Lighting}

Building B management provided a list of 279 names of employees to receive the occupant survey. Of these, 260 were in open plan offices (cubicles) and 19 were in enclosed offices. A total of 23 names were removed because the staff were on-leave or on field assignment during the entire period of the preretrofit survey. This left a population of 256 full-time staff, including 239 in open plan offices and 17 in enclosed offices, to participate in the pre-retrofit survey.

\subsubsection{Pre- and Post-Retrofit Measurements}

The pre-retrofit survey was administered the week of October 10, 2005, following a three-week adaptation period after the baseline lamp change-out and fixture cleaning. Building staff sent an email message to all full-time staff in the building inviting them to complete the survey.

The survey was sent to 256 full-time staff occupying the building. Follow-up phone calls were made to non-respondents during the week of October 17. By October 21, 214 responses had been received (84\% response rate).

Building occupants were notified after the pre-retrofit survey that the lighting would be retrofitted. Employees were not told that the lamp color would change.

Following a three-week adaptation period after the lighting retrofit, the post-retrofit survey was administered during the week of November 28, 2005. Full-time building occupants again received an email message from Building B staff inviting them to take the survey.

Follow-up phone calls were completed by PNNL staff during the week of December 5. A total of 145 paired (pre-retrofit and post-retrofit) responses were received. This represented a response rate of $57 \%$ of eligible full-time building occupants.

\subsubsection{Statistical Analysis}

Occupants were asked several questions regarding work space satisfaction including three questions specifically dealing with lighting (see Appendix B for survey instrument).

Results of the statistical analysis for each lighting question are provided below.

\section{"How satisfied are you with the amount of light in your workspace?"}

The scale was $\quad$ Very Dissatisfied $\bigcirc \bigcirc \bigcirc \bigcirc \bigcirc \bigcirc \bigcirc$ Very Satisfied

Responses were coded with $1=$ very dissatisfied, $7=$ very satisfied.

- Mean Scores

○ Before: 5.24

○ After: 5.26

- Paired t-test

- $95 \%$ Confidence Interval of After minus Before

- $(-0.21,0.25)$ 
○ Post-retrofit scores were not significantly lower than pre-retrofit scores ( $\mathrm{p}$-value $=$ 0.5702)

○ Post-retrofit scores were not significantly different from pre- retrofit scores ( $\mathrm{p}$-value $=$ 0.8597)

○ No evidence that scores changed.

- Wilcoxon Signed Rank Test

○ One-Sided p-value $=0.6315$

○ Two-Sided p-value $=0.7386$

$\circ$ No evidence that scores changed.

- Sign Test

○ 47 increases, 42 decreases, 56 unchanged

○ One-Sided p-value $=0.7375$

○ $\quad$ Two-Sided p-value $=0.6718$

$\circ$ No Evidence that scores changed

"How satisfied are you with your visual comfort under this lighting?"

The scale was $\quad$ Very Dissatisfied $\bigcirc \bigcirc \bigcirc \bigcirc \bigcirc \bigcirc \bigcirc$ Very Satisfied

Responses were coded with $1=$ very dissatisfied, $7=$ very satisfied

- Mean Scores

○ Before: 5.04

○ After: 5.06

- Paired t-test

- $95 \%$ Confidence Interval of After minus Before

- $(-0.28,0.31)$

○ Post-retrofit scores were not significantly lower than pre-retrofit scores ( $\mathrm{p}$-value $=$ 0.5367)

- Post-retrofit scores were not significantly different from pre-retrofit scores ( $\mathrm{p}$-value $=$ 0.9266)

- No evidence that scores changed.

- Wilcoxon Signed Rank Test

○ One-Sided p-value $=0.6433$

$\circ \quad$ Two-Sided p-value $=0.7149$

○ No evidence that scores changed.

- Sign Test

○ 50 increases, 44 decreases, 51 unchanged

○ One-Sided p-value $=0.7648$ 
○ Two-Sided p-value $=0.6063$

- No evidence that scores changed.

“Overall, does the lighting quality enhance or interfere with your ability to get your job done?"

The scale was Interferes $\bigcirc \bigcirc \bigcirc \bigcirc \bigcirc \bigcirc \bigcirc$ Enhances

Responses were coded with 1=interferes, $7=$ enhances

- Mean Scores

○ Before: 4.88

○ After: 5.03

- Paired t-test

- $95 \%$ Confidence Interval of After minus Before

- $(-0.15,0.44)$

○ Post-retrofit cores were not significantly lower than pre-retrofit scores ( $p$-value $=0.8357$ )

- Post-retrofit scores were not significantly different from pre-retrofit scores ( $\mathrm{p}$-value $=$ 0.3287 )

○ No evidence that scores changed.

- Wilcoxon Signed Rank Test

○ One-Sided p-value $=0.8368$

○ Two-Sided p-value $=0.3274$

- No evidence that scores changed.

- Sign Test

○ 49 increases, 41 decreases, 55 unchanged

○ One-Sided p-value $=0.8286$

○ $\quad$ Two-Sided p-value $=0.4608$

○ No evidence that scores changed.

\subsubsection{Variables and their Impacts on Responses}

We analyzed the paired (pre-retrofit and post-retrofit) survey responses to see how several variables may have influenced lighting satisfaction. Results are below.

\subsubsection{Age}

Respondents were asked to indicate their age group as 30 or under, 31-50, or over 50. Respondent age group did not appear to be a factor for any questions on the survey. There was no statistically measureable difference in the answers given by respondents in any age group as compared to other age groups. 


\subsubsection{Gender}

Respondent gender was not a statistically significant factor for the lighting questions on the survey. 83 of the respondents identified themselves as females, while 62 indicated male. The average pre-retrofit rating on the lighting questions for the females was 5.00; post-retrofit it was 5.13. The average preretrofit rating on the lighting questions for the males was 5.13; post-retrofit it was 5.10.

\subsubsection{Monitor Type}

Respondents were asked to indicate the type of computer monitor they used, choosing CRT with curved screen, CRT with flat screen, LCD flat screen, laptop, other, or "I do not use a computer in my workspace.” In Building B, the number of respondents reporting each type of monitor was as follows (adds to more than the total responses because some may use more than one type of monitor in their workspace):

CRT with curved screen - 11

CRT with flat screen - 43

LCD flat screen - 86

Laptop - 25

Two measurable differences were found between different monitor groups. First, following the retrofit, CRT flat screen users rated the question, "Overall, does the lighting quality enhance or interfere with your ability to get your job done?" significantly higher than CRT curved screen users. The average rating provided by CRT flat screen users was 5.42 and the average rating of CRT curved screen users was 4.45. Second, there was a significant difference between laptop users and CRT curved screen users in terms of the change in their pre-retrofit and post-retrofit ratings on the question, "How satisfied are you with your visual comfort under this lighting?" Laptop users' ratings changed by +0.64 points, while CRT curved screen users changed by -0.73 .

\subsubsection{Office Type}

\section{Pre-Retrofit:}

- When asked "How satisfied are you with the amount of light in your workspace?" private office respondents answered significantly higher (average rating 6.00) before retrofit than respondents in tall cubicles (5.01).

- When asked "Overall, does the lighting quality enhance or interfere with your ability to get your job done?" private office respondents answered significantly higher (5.83) than respondents in tall cubicles (4.70) and short cubicles (4.81).

\section{Post-Retrofit:}

- On the post-retrofit survey, no statistically significant differences were found between office types on the lighting questions.

\subsubsection{Daylight Availability vs. Occupant Survey Responses}

Twenty of the 145 respondents had access to daylight in their office spaces; 125 did not. Answers were broken out by daylight availability to see if it had any impact on answers (See Table 4.7). 
Table 4.7. Comparison of Survey Responses from Building B Workspaces With and Without Daylight

\begin{tabular}{|l|c|c|c|c|}
\hline Pre-Retrofit Ratings & Sample & Amount of Light & Visual Comfort & Impact on Job \\
\hline & \multicolumn{5}{|c|}{ Average score (scale 1 - 7) } \\
\hline Daylight & 20 & 5.15 & 4.85 & 4.86 \\
\hline No Daylight & 125 & 5.26 & 5.07 & 4.89 \\
\hline Post-Retrofit Ratings & 5.65 & 5.55 & 5.25 \\
\hline Daylight & 20 & 5.2 & 4.98 & 4.99 \\
\hline No Daylight & 125 & 0.5 & 0.7 & 0.4 \\
\hline Change & 20 & -0.06 & -0.1 & 0.1 \\
\hline Daylight & 125 & \multicolumn{5}{|l|}{} \\
\hline No Daylight
\end{tabular}

There were no statistically significant differences when comparing the responses from people who had daylight in their workspaces to those who did not.

\subsubsection{Conclusions}

Statistical analysis of the pre-retrofit and post-retrofit responses from Building B staff determined the following:

- Mean scores on lighting questions were not significantly different after retrofit than before retrofit.

- Age was not a factor for any questions.

- Gender was not a factor for any of the lighting questions.

- Monitor type was a factor in two cases, with CRT flat screen users answering more favorably on the question "Overall, does the lighting quality enhance or interfere with your ability to get your job done?" as compared to CRT curved screen users; and laptop users reporting more improvement in visual comfort compared to CRT curved screen users.

- Reponses from occupants with daylight did not differ significantly from occupants without daylight. 


\subsection{Building C Results}

This chapter provides results of pre- and post-retrofit measurements in Building C, a 67,000-sq ft, two-story office building located in Oxnard, California. Approximately 2,300 overhead lamps were replaced in this building. The original overhead lighting was provided by Philips FO32/741/ECO lamps and electronic instant start ballasts with ballast factor of 0.88 . These were found in predominately $2 \times 4-$ foot, 3-lamp fixtures, which lighted 57 enclosed offices, 168 cubicles, nine conference rooms, and eight hallways (see Figures 5.1 and 5.2 for examples of open office or cubicle areas). Lamps in all fixtures were replaced with new Sylvania FO30/850/XP/SS/ECO lamps. Ballasts were replaced with electronic programmed start ballasts with a ballast factor of 0.71. Results of PNNL's evaluations of lighting energy use consumption, light levels, task lighting use, and occupant satisfaction for Building $\mathrm{C}$ are described below.

The measured connected load for pre-retrofit T8 lamps with standard electronic ballasts was 27.11 W/lamp and the measured connected load for post-retrofit T-8 lamps with low-power factor ballast was 21.56 W/lamp. These results are consistent with the nominal (rated) fixture loads of the pre- and postretrofit technologies. This change corresponds to a $20.5 \%$ reduction in connected load.

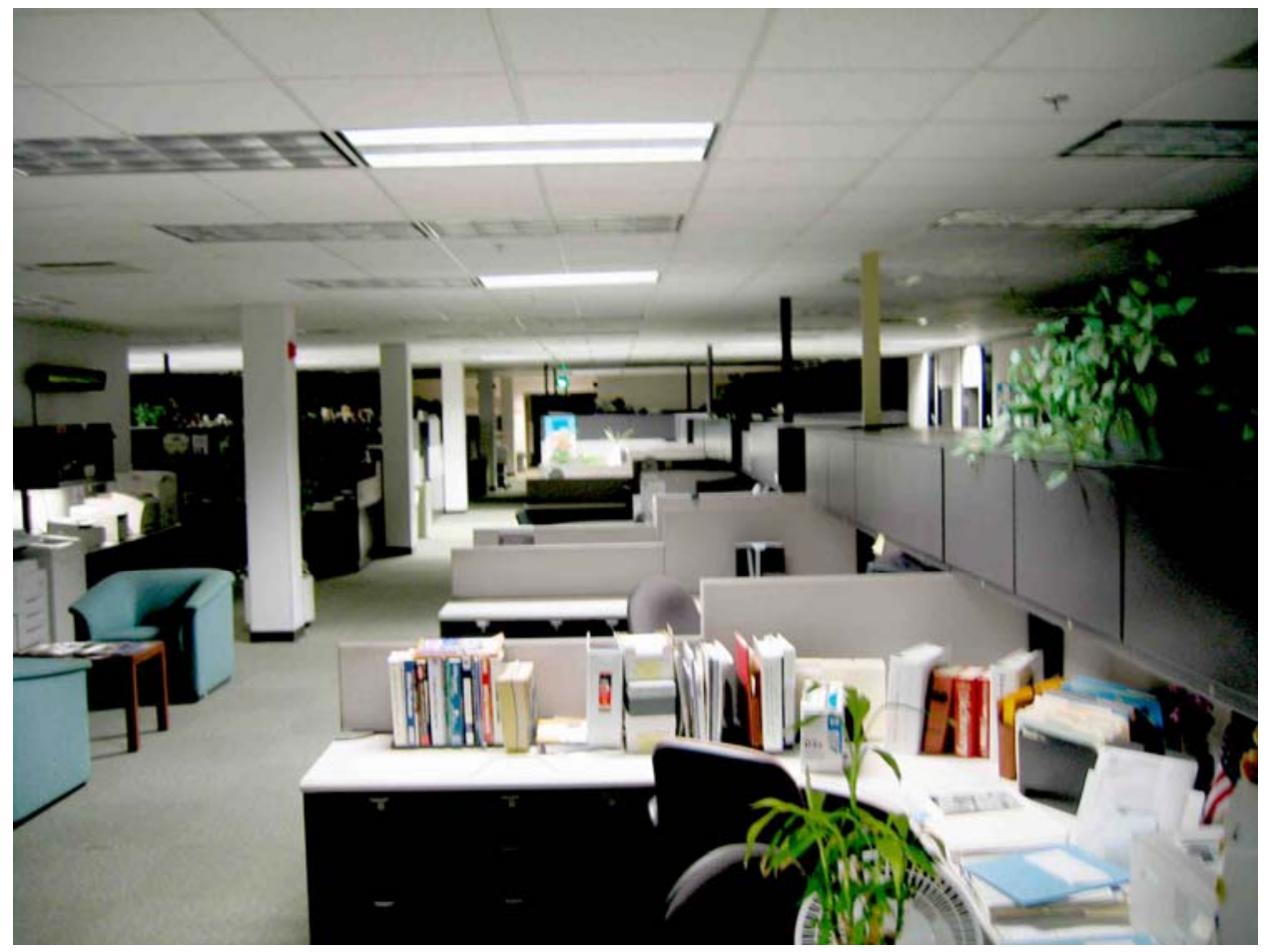

Figure 5.1. Building C Open Office Area, Second Floor, East Wing, Looking East from the Foyer 


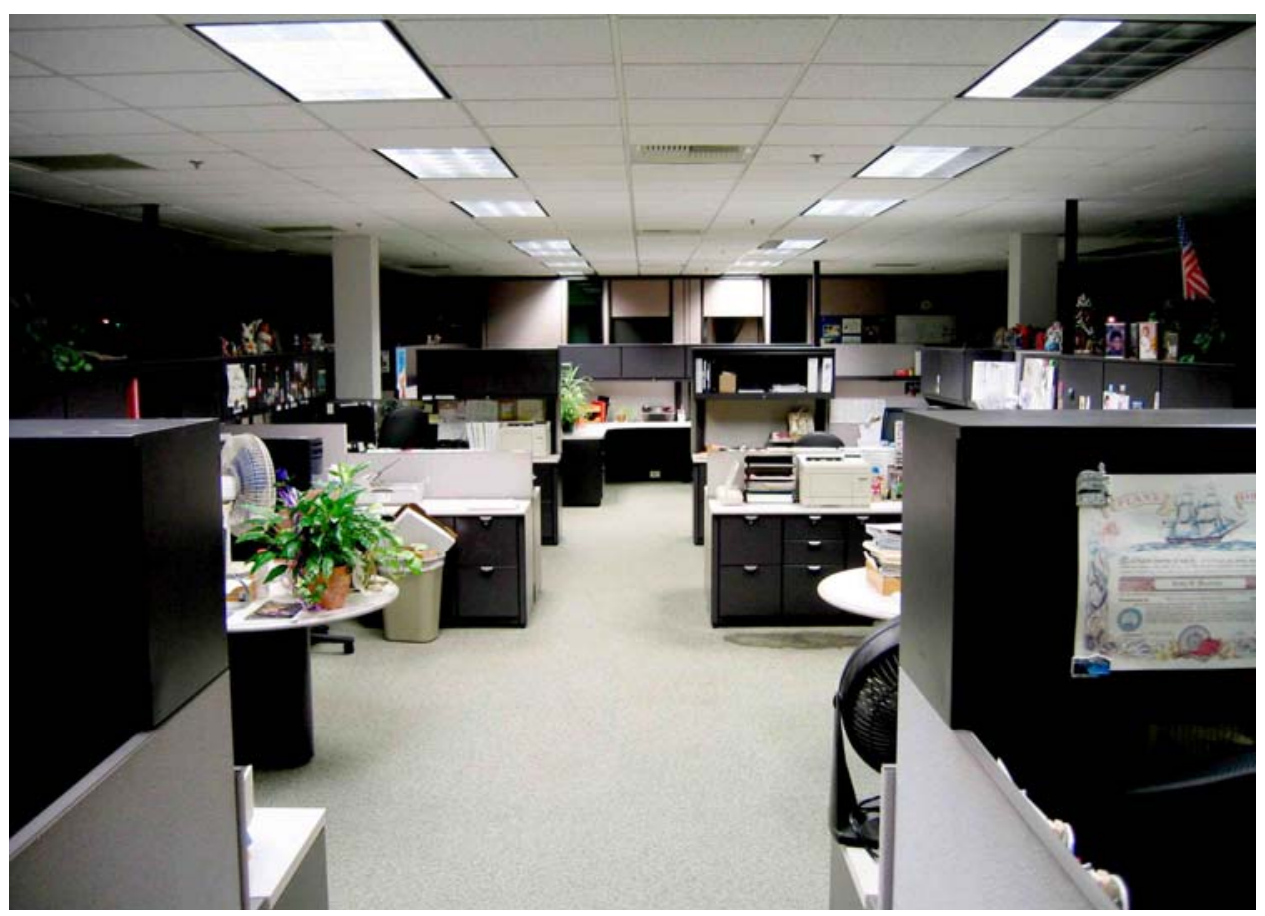

Figure 5.2. Building C Open Office Area, Second Floor, East Wing, Looking South from the North Wall

\subsection{Overhead Lighting Electricity Use}

\subsubsection{Pre- and Post-Retrofit Measurements}

The fixtures affected by the retrofit are powered from twenty-one 277-volt dedicated lighting circuits on the first floor and twenty-four circuits on the second floor. Two end-use metering loggers were installed to monitor these circuits. The second-floor logger installation is shown in Figure 5.3; the firstfloor logger installation is essentially identical. The pre-retrofit study period was September 26 - October 17, 2005, and the post-retrofit period was October 31-November 20, 2005.

A problem with the data collected via the logger installation on the first floor was discovered which made this data unusable. Please see Appendix A, Section A.7 for a full explanation of the issue. The data presented in this section were collected from the data logger installed on the second floor. 


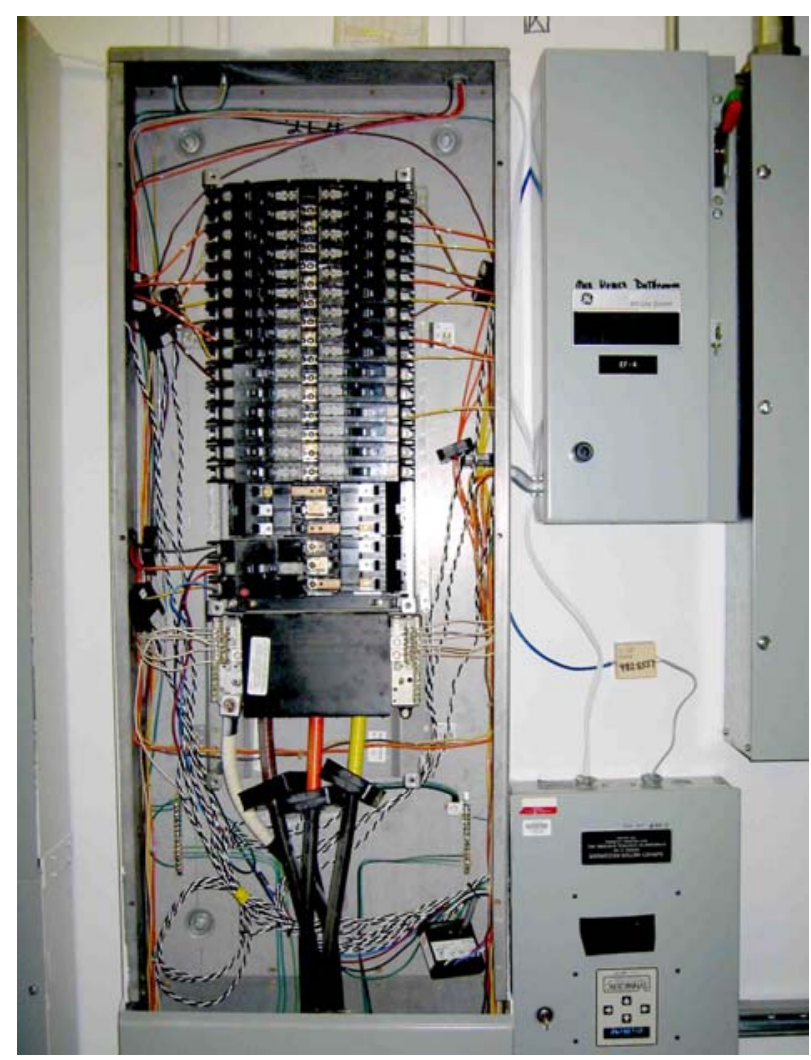

Figure 5.3. Building C - One of Two End-Use Logger Installations, Second Floor, Panel L2A.

\subsubsection{Time Series Lighting Load Data}

The time series data of total lighting power monitored by the second-floor logger is shown in Figure 5.4.

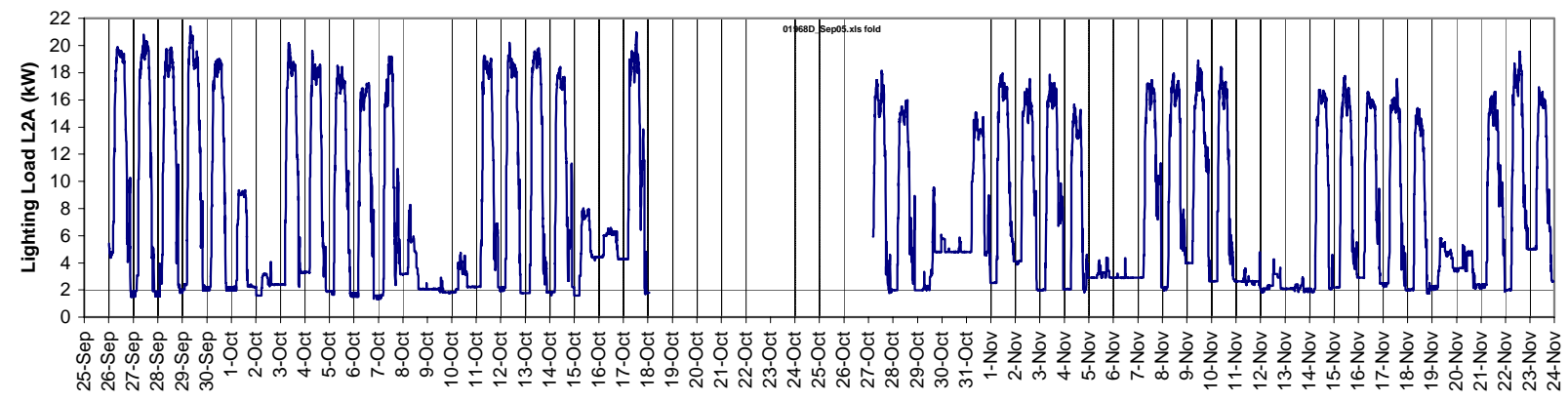

Figure 5.4. Building C Second-Floor Lighting Load, Sept. 26 - Nov. 23, 2005. Retrofit activity took place October 21-29, 2005.

Note: There is a gap in the time series data due to a malfunction on the computer used to download data remotely from the $\mathrm{C} 180$ logger. Fortunately this occurred while the retrofit work was taking place and therefore did not affect the pre-retrofit or post-retrofit data.

Daily lighting load profiles are shown for pre-retrofit weekdays (Sept. 26-Oct. 17) in Figure 5.5 and for post-retrofit weekdays (Oct. 31 - Nov. 22) in Figure 5.6. Each daily load profile is a separate line in Figures 5.5 and 5.6. 


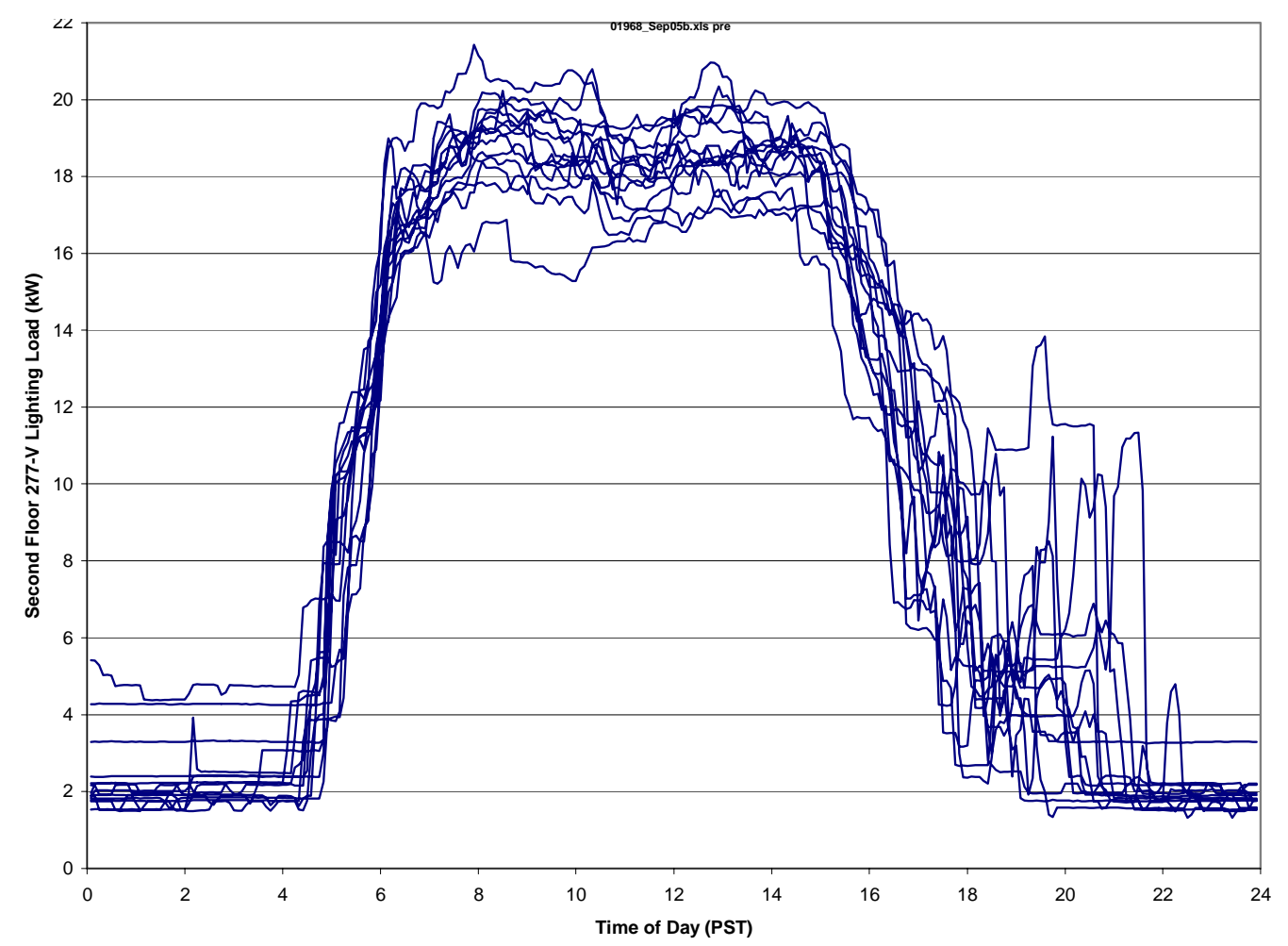

Figure 5.5. Building C Second Floor Pre-Retrofit Weekday Load Profiles, Sept. 26 - Oct. 17, 2005

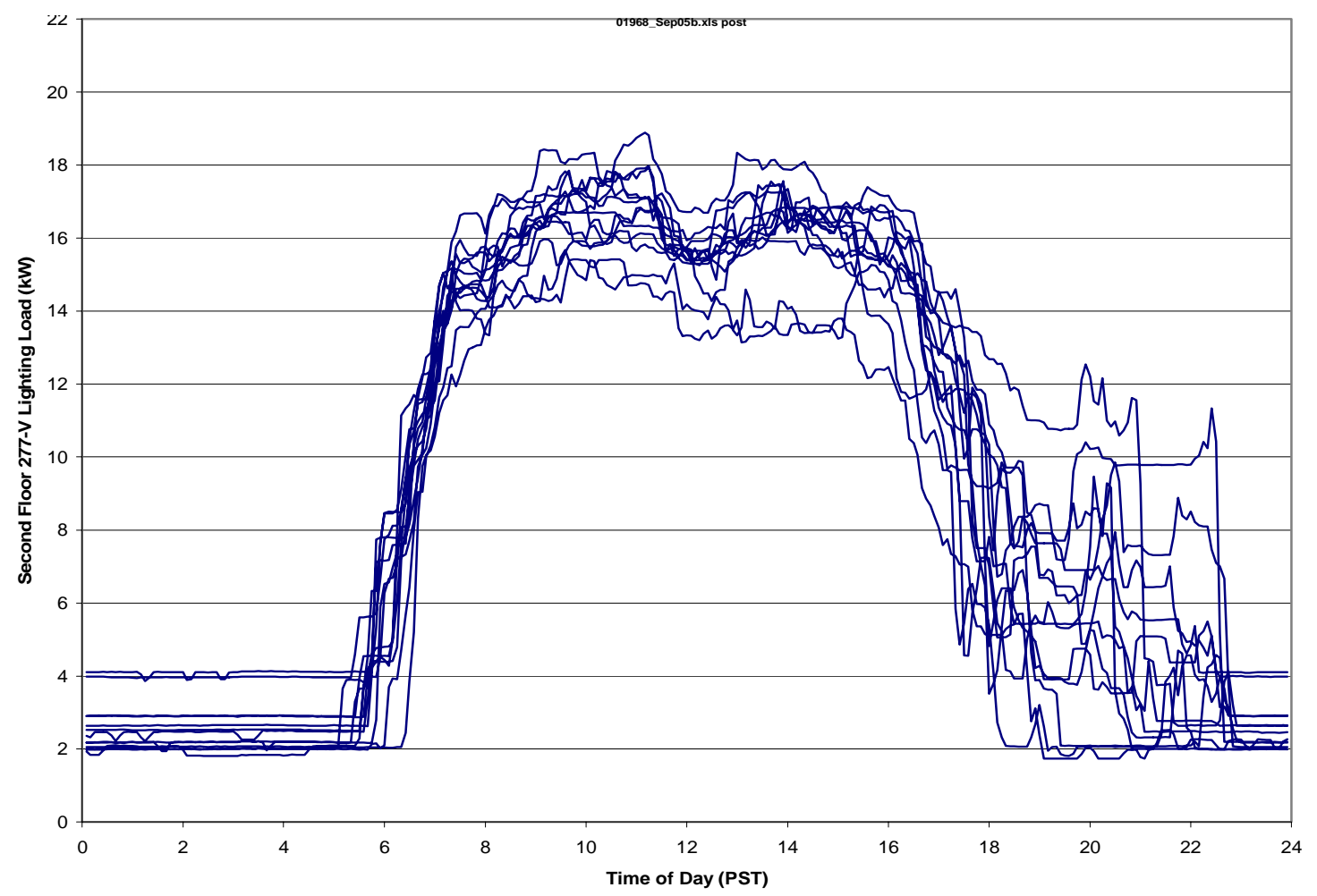

Figure 5.6. Building C Second-Floor Post-Retrofit Weekday Load Profiles, Oct. 31 -Nov. 22, 2005 
Figures 5.5 and 5.6 show variations of up to $20 \%$ (+/- 10\%) among normal workday profiles during the working hours and some Friday load profiles deviate by more than $10 \%$. Also significant are variations in duration of lighting hours. The time for turning off lights at the end of each day varies by zone and it appears that janitors or workers routinely stay past $9 \mathrm{pm}$.

The number of fixtures left on at night (as indicated by the load trajectories in Figures 5.5 and 5.6 is fairly constant. The fact that the retrofit did not change lighting energy use at night indicates one or more of the following: that some of the security lights were not retrofit (observed), that perhaps (not observed) a change was made in security light circuiting to include more tubes or fixtures that cannot be switched off, or that a significant change in nighttime lighting use occurred with the change from daylight-savings to standard time.

Figure 5.7 shows a comparison of the average pre-retrofit load to average post-retrofit load for the periods measured. This graph shows the small increase in average nighttime load in spite of the expected significant uniform decrease in work-hours load.

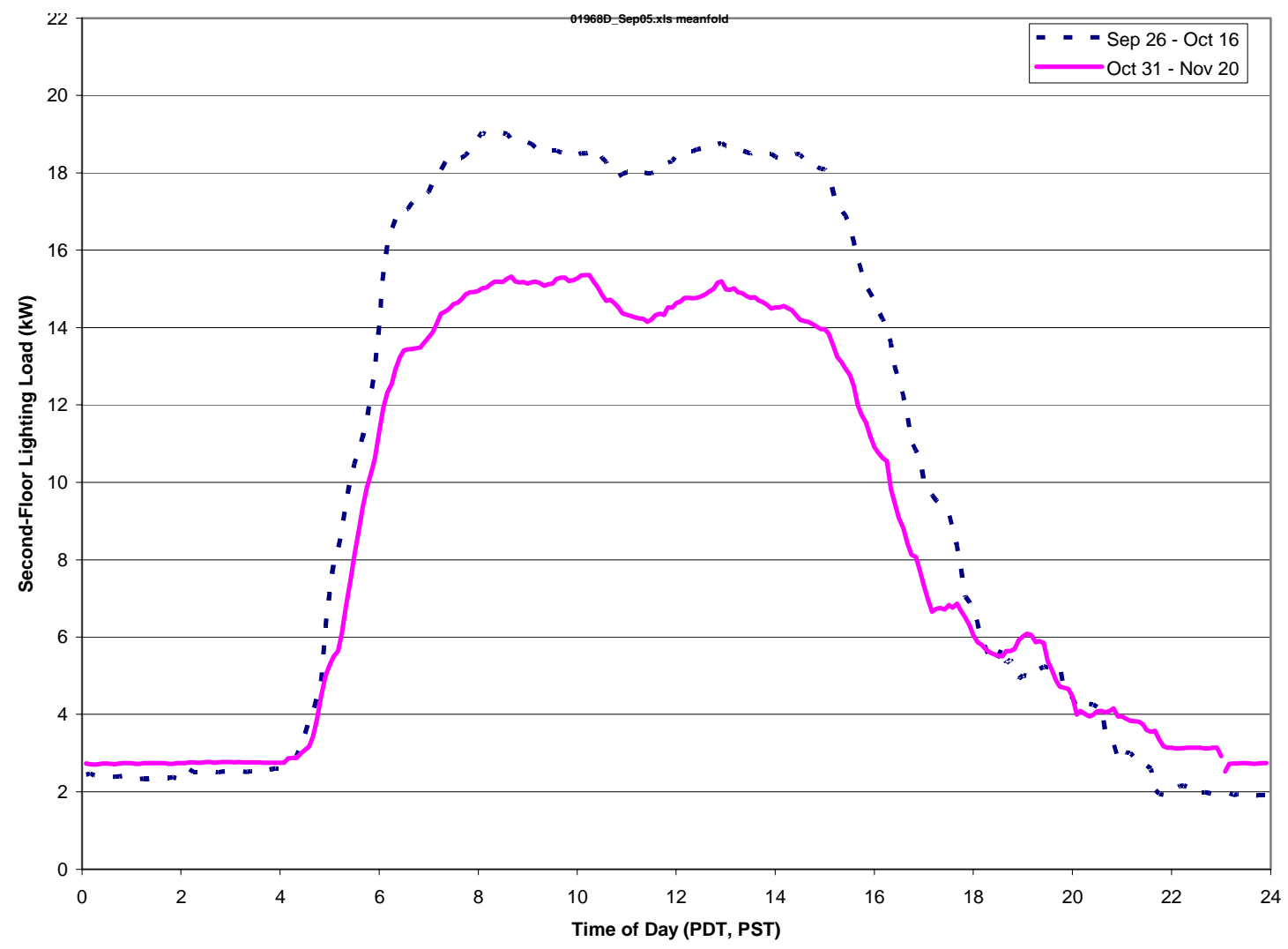

Figure 5.7. Building C Second Floor Mean Pre- and Post-Retrofit Weekday Load Profiles

\subsubsection{Pre- and Post-Retrofit Energy Use}

The observed changes in workhours, weekday, and weekly energy use, expressed as average $\mathrm{kW}$ during two typical pre-retrofit weeks and during two typical post-retrofit weeks, are summarized in Table 5.1. 
Table 5.1. Building C Second Floor Average Pre- and Post-Retrofit Loads

\begin{tabular}{|l|ccc|}
\hline & Weekly $(24 \times 7)$ & Weekday & Workhours \\
\hline Pre-retrofit (average kW) & 10.33 & 10.29 & 17.02 \\
Post-retrofit (average kW) & 8.91 & 8.61 & 13.44 \\
Ratio & 0.862 & 0.836 & 0.789 \\
Change (average kW) & 1.42 & 1.69 & 3.59 \\
Change (\% reduction) & $13.8 \%$ & $16.4 \%$ & $21.1 \%$ \\
\hline
\end{tabular}

The pre-retrofit period is September 28 through October 17 and the post-retrofit period is October 31 through November 22. The two holidays, Columbus Day (Oct. 10) and Veterans Day (Nov. 11), were removed from the analysis.

The observed daily profiles indicate that both the weekly and daily average loads are affected by the seasonal change in time of sunset. This is exacerbated by the change from daylight savings time to standard time on October 30. The mechanism that seems to be at play here is that when leaving work before sunset, occupants tend to turn the lights off, but when leaving work after sunset relatively more occupants leave lights on.

The average weekly load in $\mathrm{kW}$ is the average load for all hours in the week ( $24 \times 7=168$ hours); the average weekday load is the average load for the week days ( $12 \times 5=60$ hours), and the work hours load is the average load for the work hours ( 9 × $5=45$ hours per week). The annual savings based on these observations is $10.33-8.91=1.42$ average $\mathrm{kW}$ or $13.8 \%$. The extrapolation of these numbers to annual energy savings is not entirely reliable because of seasonal affects and other day-to-day changes in building operation. However, we can roughly project savings for the second floor of 8,760 hr/yr * 1.42 average $\mathrm{kW}=12,439 \mathrm{kWh} / \mathrm{yr}$.

\subsubsection{Connected Load Measurements}

The most reliable estimate of annual project energy savings is based on reduction in connected load, which can be measured directly and is not affected by building operational changes or seasonal effects. The reduction in connected load equals average pre-retrofit connected load minus average post-retrofit connected load.

The pre-retrofit connected load, based on five switch circuits of $6,12,24,25$, and 40 tubes, was 27.11 W/lamp. The post-retrofit connected load, based on the same five switch circuits, was 21.56 W/lamp.

Thus, $27.11 \mathrm{~W} / \mathrm{lamp}-21.56 \mathrm{~W} / \mathrm{lamp}=5.56 \mathrm{~W} / \mathrm{lamp}$, which is a $20.5 \%$ reduction in connected load.

The pre-retrofit weekly $\mathrm{kW}(10.33 \mathrm{~kW})$ multiplied by hours in a year ( $8760 \mathrm{hrs})$ multiplied by the observed reduction in connected load (0.205) yields a second-floor savings of $18,550 \mathrm{kWh} / \mathrm{yr}$. Because the first and second floor footprints and functions are identical, the first floor savings will be nearly the same and we can estimate a total project savings of $37,100 \mathrm{kWh} / \mathrm{yr}$. 


\subsubsection{Conclusions}

The change in connected load, determined by one-time measurements at selected light switches, was a 20.5\% load reduction and this is consistent with the nominal fixture loads of the pre- and post-retrofit technologies (change of ballasts to the specified low ballast power). We estimate annual energy savings are approximately $37,000 \mathrm{kWh} / \mathrm{yr}$.

\subsection{Light Levels in the Workspace}

\subsubsection{Pre- and Post-Retrofit Measurements}

Light level measurements were taken in 64 locations in Building C. All readings were taken after sundown in lux with overhead lights on but no task lights on. Pre-retrofit light level readings were made on October 17, 2005. Post-retrofit light level readings were made on December 8, 2005. In both cases, the readings were taken well after dark to avoid daylighting effects. The individual measurements and their associated S/P ratios can be found in Appendix C in Tables C.5 and C.6.

Although these data represent individual spaces, their averages can provide a useful comparison of the resulting change in light levels between pre- and post-retrofit conditions. As discussed in the next section on statistical analysis of these data, there is fairly high confidence that the averages shown in Table 5.2 accurately represent the overall change in test spaces.

Table 5.2. Building C - Average Pre- to Post-Retrofit Light Level and S/P Ratio Changes

\begin{tabular}{|c|c|c|c|c|c|}
\hline \multicolumn{2}{|c|}{ Photopic (lux and \%) } & \multicolumn{2}{|c|}{ Scotopic (lux and \%) } & \multicolumn{2}{c|}{ S/P ratio } \\
\hline Vertical & Horizontal & Vertical & Horizontal & Vertical & Horizontal \\
\hline$-15(-9 \%)$ & $-84(-15 \%)$ & $+21(+8 \%)$ & $+15(+1.7 \%)$ & $+0.29(+19 \%)$ & $+0.31(+19 \%)$ \\
\hline
\end{tabular}

Because of the nature of field measurements, including manual recording and measuring, it is always possible to experience recording errors or other unexpected anomalies in the measurements. Lighting equipment retrofit activities, maintenance, or normal business operation changes can also lead to differences between pre- and post-retrofit conditions that were not expected and that might affect measurement values. This might include addition or removal of lamps, furniture changes or moves, or other occupant changes to their workspace. Because of these possibilities, comparison plots were made of the scotopic versus photopic readings to visually identify S/P ratio outliers that might be mismeasurements or effects from retrofit variations. Figures 5.8 and 5.9 below show these comparisons. For uniform lighting conditions, the plotted points shown in the figures would be expected to form a uniform line with a consistent slope indicating similar S/P ratios for all locations. Those that fall far from this expected line could be considered outliers and potentially suspect.

As expected, the slope represented by the lines in the plots is steeper for the post-retrofit ratios, confirming the increased scotopic content of the post-retrofit lamps. Both charts show fairly uniform slopes for the plotted data, indicating consistent data with few outliers. The data for any outliers in the dataset were carefully considered to determine if they could be specifically identified as bad data points. In these cases the values that were outside of the expected values were either considered within the realm 
of possible data recording or effects from retrofit differences. Because they are so few in number and so small in magnitude, they have a negligible effect on the results.

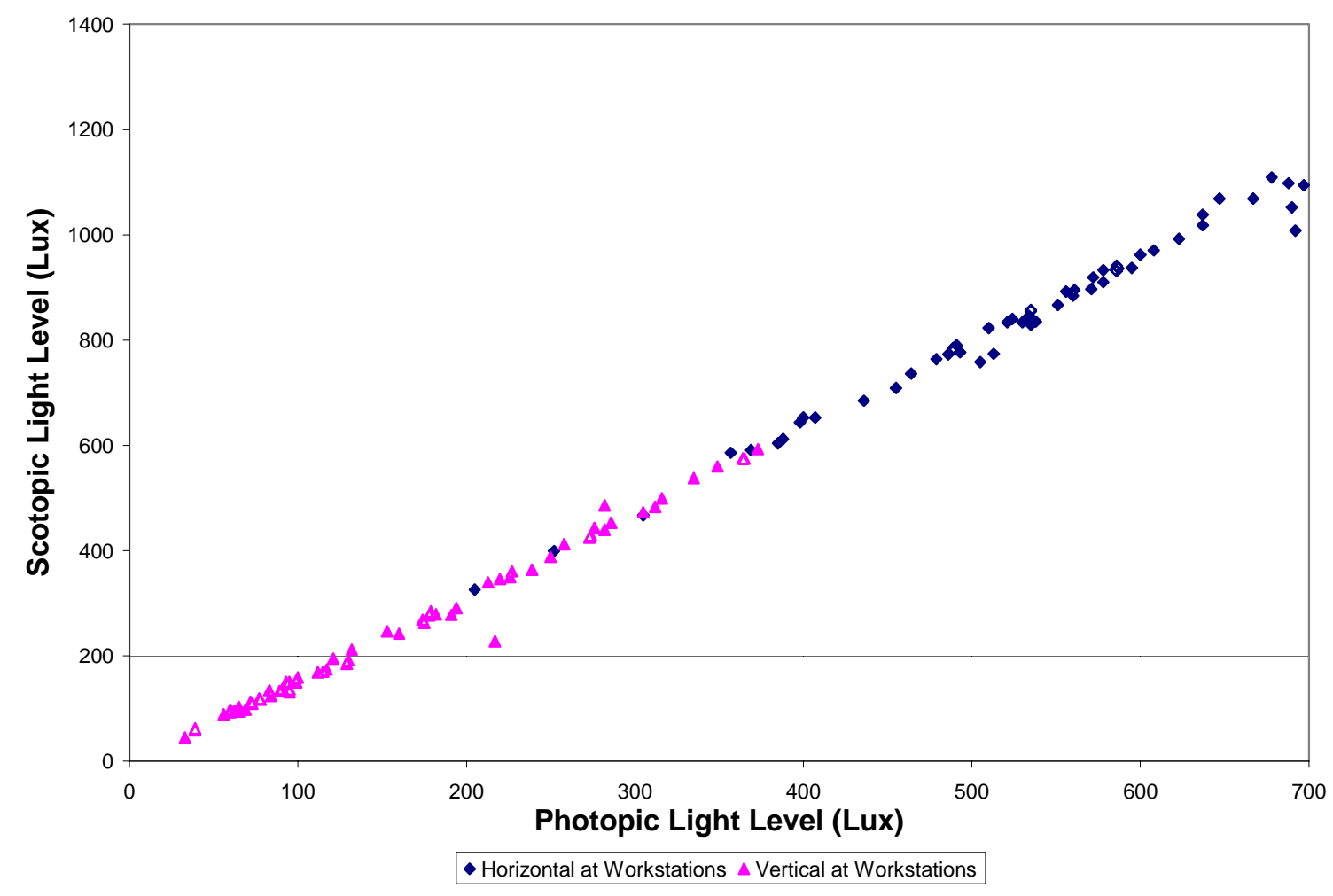

Figure 5.8. Building C - Pre-Retrofit Scotopic/Photopic Ratio Comparison 


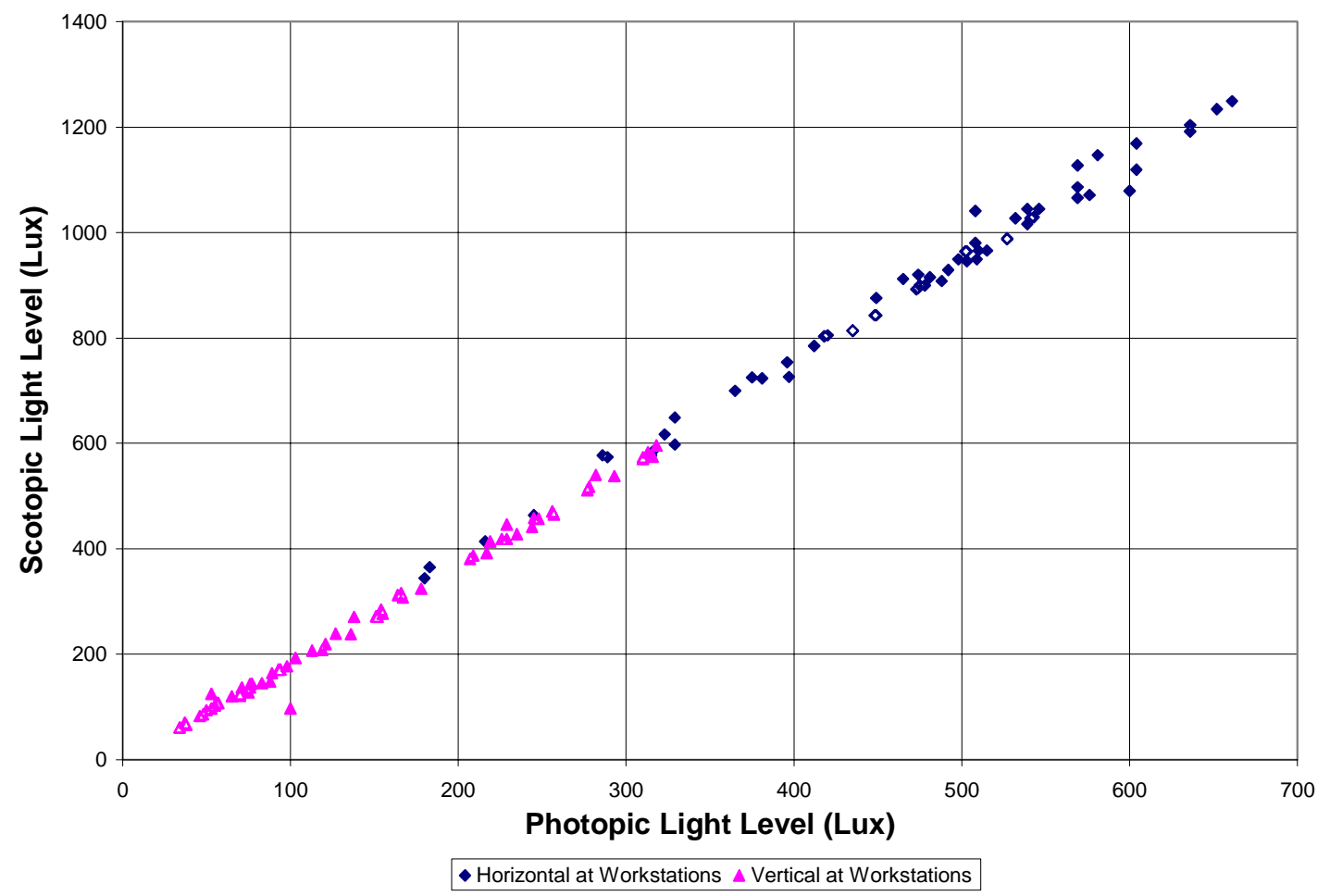

Figure 5.9. Building C - Post-Retrofit Scotopic/Photopic Ratio Comparison

One of the major variables affecting the light level measurements is the varied workspace environment and changing character of the occupied spaces. Workspaces are oriented in different ways in relation to overhead lighting fixtures and partition walls. Materials surrounding desk spaces and posted on walls (personal and business related) are also varied and can have an effect on the horizontal light level readings between spaces and in particular between time periods. This tends to reduce the consistency of the comparison between horizontal values within a specific set of measurements and between pre- and post-retrofit sets. As averaged data, these effects are less noticeable but it is useful to understand this variability. Figures 5.10 and 5.11 present ratios of horizontal to vertical measurements for each location. The cloud of data points shows the extent of the variability. Both of these charts show a subtle slope trend indicating some consistency between vertical and horizontal reading changes but still a fairly wide variation. 


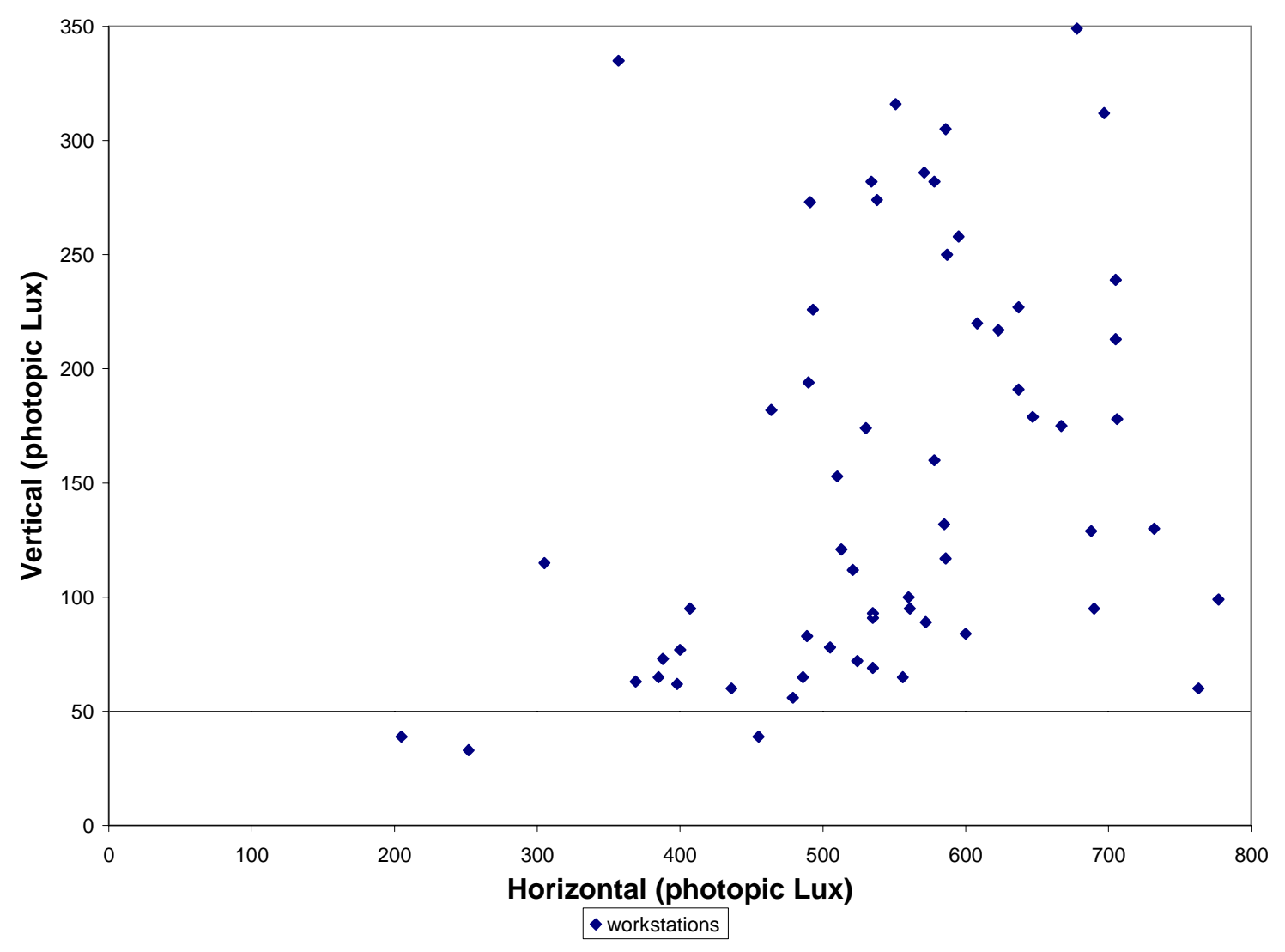

Figure 5.10. Building C - Pre-Retrofit Vertical vs. Horizontal Comparison (Photopic) 


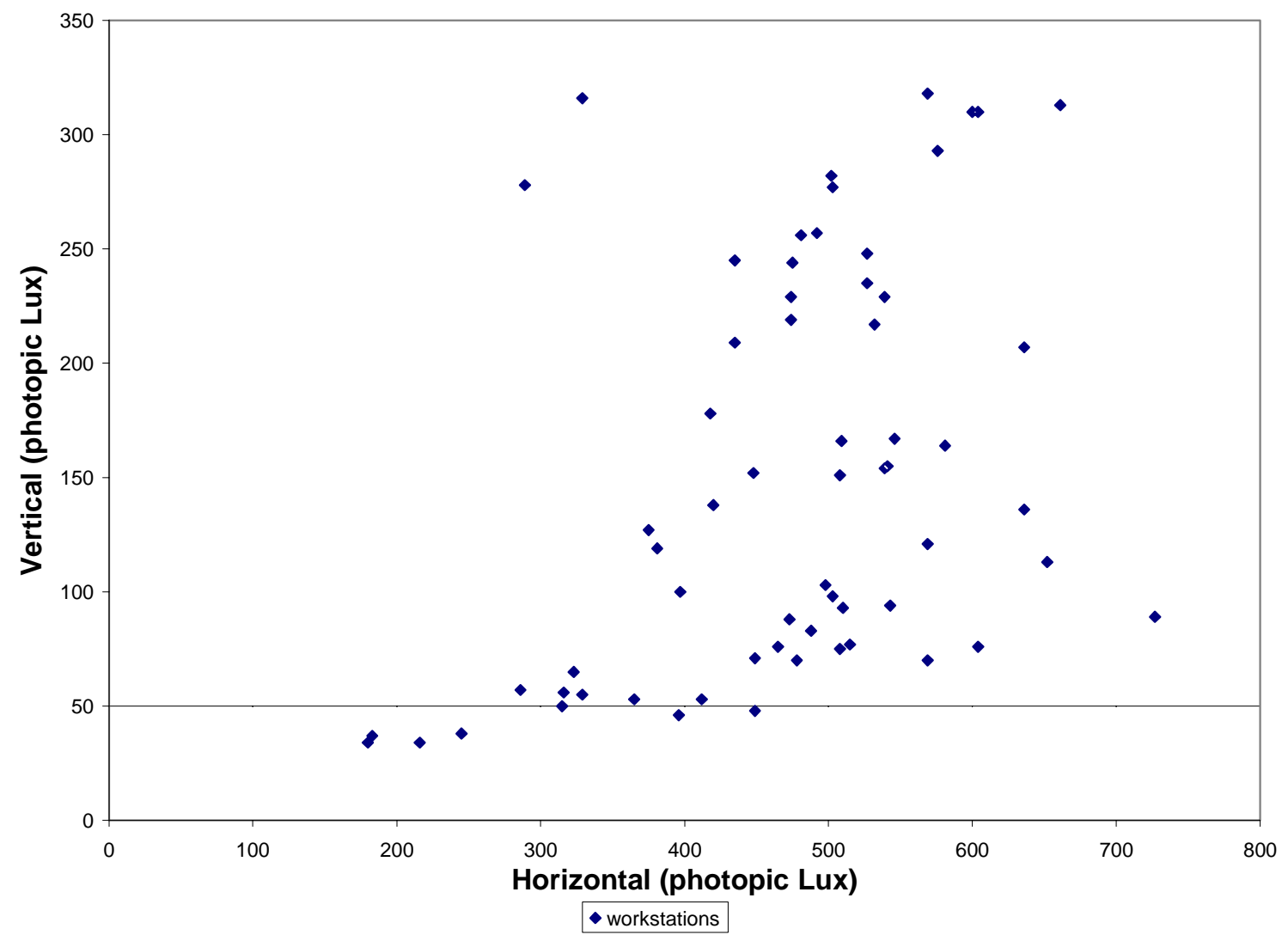

Figure 5.11. Building C - Post-Retrofit Vertical vs. Horizontal Comparison (Photopic)

\subsubsection{Statistical Analysis of Measurements}

While each of the measurements from the 64 office locations is unique, their collective values form a measured comparison of the lighting of the building before and after the retrofit. The averages are shown in Appendix C, Tables C.5 and C.6. They show that, as expected, the S/P ratio increased with the retrofit lighting. The minimums and maximums from Tables C.5 and C.6 show more variability than might be expected given a complete and consistent replacement of all overhead lighting in the measured spaces. However, variables exist in all real-world occupied spaces that affect light level measurements and their comparison. The variability in minimum and maximum values is most likely due to the type of fixtures used in the building. Parabolic fixtures are highly directional and have a sharp cut-off angle. For this reason, illuminance values can differ significantly in open plan offices, depending on the location of the fixture relative to cubicle walls and the height of those walls. Other potential variables that could impact variability in pre- and post-retrofit illuminance measurements including the following:

Material (letters, drawings, pictures, etc.) on the wall that the sensor is aimed towards for the vertical measurements may change over time effecting mostly vertical readings.

- Equipment close to the horizontal measurement point (particularly computer monitors) may be moved, added, or removed, affecting mostly horizontal readings.

- Nearby bookcase contents, plants, notebooks, and other equipment may change quantity or location, causing differences in mostly horizontal measurements. 
To ensure that the variability experienced with these measurements did not adversely affect the usability of the averages as comparison results, a statistical analysis was completed for the 64 sets of office location measurements. The differences between post- and pre-retrofit measurements did not appear to be completely normally distributed. The distributions largely followed a normal distribution except for 1 or 2 observations that were outliers, but these were extreme enough that they suggested these outlier data points were not normally distributed. Therefore the results of the Wilcoxon Signed Rank Test and Sign Test which are more robust when data is not normally distributed are presented here.

\subsubsection{Horizontal Measured Data Analysis}

Results of the analysis are shown in Table 5.3.

Table 5.3. Building C - Horizontal and Vertical Photopic and Scotopic Measured Data Analysis Results

\begin{tabular}{|l|l|l|l|l|}
\hline \multirow{2}{*}{} & \multicolumn{2}{|c|}{ Horizontal } & \multicolumn{2}{c|}{ Vertical } \\
\cline { 2 - 5 } & Photopic & Scotopic & Photopic & Scotopic \\
\hline Mean Before Retrofit (lux) & 558.20 & 886.98 & 165.38 & 256.11 \\
\hline Mean After Retrofit (lux) & 474.09 & 901.75 & 150.75 & 276.77 \\
\hline 2-Sided paired t-test, p-value & $0.0000^{(\mathrm{a})}$ & 0.2896 & 0.0211 & 0.2896 \\
\hline $\begin{array}{l}\text { Wilcoxon Signed Rank test, p- } \\
\text { value }\end{array}$ & 0.0000 & 0.0271 & 0.0001 & 0.1048 \\
\hline Sign Test, p-value= & 0.0000 & 0.2604 & 0.0005 & 0.3135 \\
\hline Change in light level & -84 lux & $+15^{(\text {b) }}$ lux & -15 lux & $+21^{(\text {(c) }}$ lux \\
\hline 95\% confidence interval & $+/-15$ lux & NA & $+/-12$ lux & NA \\
\hline
\end{tabular}

(a) The very small $(0.0000,0.0001) \mathrm{p}$-values for some of the measurements indicate that there is essentially no chance that the observed change in light level is due to random variation.

(b) Appears to be a general increase of 15 lux but this is not statistically significant.

(c) Appears to be a general increase of 21 lux but this is not statistically significant.

Sixty-three of the 64 office spaces had a decrease in horizontal photopic measurements, while 1 office space had an increase. This is significant evidence that more office spaces had a decrease in measurements than an increase. These results indicate high confidence that the average overall decrease in horizontal photopic light level is 84 lux with a $95 \%$ confidence interval of $+/-15$ lux.

Assuming a normal distribution, there is no significant evidence that horizontal scotopic measurements changed. However, note that data was skewed and did not perfectly follow a normal distribution, and therefore the Wilcoxon Signed Rank and Sign Tests are more appropriate. The Wilcoxon Signed Rank test (p-value=0.0271) showed some evidence of a change in horizontal scotopic measurements. However, in the Sign Test, p-value $=0.2604$ with 37 increases, and 27 decreases. These test results provide statistical evidence of an increase in horizontal scotopic light level, indicating a trend toward an overall increase of 15 lux. 


\subsubsection{Vertical Measured Data Analysis}

There is highly significant evidence that vertical photopic measurements decreased (see Table 5.3). Forty-five of the office spaces had a decrease in vertical photopic measurements, 17 had an increase, and 2 were unchanged. These results indicate high confidence that the average overall decrease in vertical photopic light level is 15 lux with a $95 \%$ confidence interval of $+/-12$ lux.

Assuming a normal distribution, there is no evidence that vertical scotopic measurements changed. However, note that data was skewed and did not perfectly follow a normal distribution, and therefore the Wilcoxon Signed Rank and Sign Tests are more appropriate. The Wilcoxon Signed Rank test pvalue $=0.1048$ and the Sign Test $p$-value $=0.3135$. There were 36 increases, 27 decreases, and 1 with no change. These results indicate no statistical evidence of a change but do indicate a definite trend toward an overall increase of 21 lux.

\subsubsection{S/P Ratio Data Analysis}

A statistical analysis of the resulting $\mathrm{S} / \mathrm{P}$ ratios derived from the raw measurement data was also completed as a further verification of the significance of the results. The results are shown in Table 5.4.

Table 5.4. Building C - S/P Ratio Analysis Results

\begin{tabular}{|l|c|c|}
\hline & Vertical & Horizontal \\
\hline Mean Before Retrofit: & 1.54 & 1.59 \\
\hline Mean After Retrofit: & 1.83 & 1.90 \\
\hline 2-Sided paired t-test, p-value $=$ & 0.0000 & 0.0000 \\
\hline Wilcoxon Signed Rank test, p-value= & 0.0000 & 0.0000 \\
\hline Sign Test, p-value= & 0.0000 & 0.0000 \\
\hline Change in S/P ratio & +0.29 & +0.31 \\
\hline 95\% confidence interval & $+/-0.04$ & $+/-0.02$ \\
\hline
\end{tabular}

Assuming a normal distribution, there is highly significant evidence that the vertical S/P ratio increased. However, note that data was skewed and did not perfectly follow a normal distribution, and therefore the Wilcoxon Signed Rank and Sign Tests are more appropriate. The Wilcoxon Signed Rank test $\mathrm{p}$-value $=0.0000$ and the Sign Test $\mathrm{p}$-value $=0.0000$. Sixty-three of the 64 office spaces had an increase in vertical S/P ratio, while 1 office space had a decrease. These results indicate high confidence that the average overall increase in vertical $\mathrm{S} / \mathrm{P}$ ratio is 0.29 with a $95 \%$ confidence interval of $+/-0.04$.

Assuming a normal distribution, there is highly significant evidence that the horizontal S/P ratio increased. However, note that data was skewed and did not perfectly follow a normal distribution, and therefore the Wilcoxon Signed Rank and Sign Tests are more appropriate. The Wilcoxon Signed Rank test $p$-value $=0.0000$ and the Sign Test $p$-value $=0.0000$. All 64 of the office spaces had an increase in horizontal S/P ratio. All results show significant evidence that there was an increase in $\mathrm{S} / \mathrm{P}$ ratio from pre- to post-retrofit. These results indicate high confidence that the average overall increase in horizontal $\mathrm{S} / \mathrm{P}$ ratio is 0.31 with a $95 \%$ confidence interval of $+/-0.02$. 


\subsubsection{Conclusions}

The light level measurements taken in a sample of workstations in Building $\mathrm{C}$ indicate that horizontal photopic light levels decreased by $15 \%$ following the retrofit. Horizontal scotopic light levels did not change, but the S/P ratio increased by $19 \%$.

\subsection{Task Lighting Use}

PNNL monitored task lighting use in a sample of 98 workstations in Building C.

\subsubsection{Pre- and Post-Retrofit Measurements}

To assess pre- and post-retrofit task lighting use, individual lighting data loggers were deployed at a sample of the building's workstations. Figures 5.12 and 5.13 show some of the workstations in Building C. Portable data loggers were installed on or near 98 workstation task lights. The loggers were set to track light level (lumens per square foot) at 5-minute intervals. Data were collected for more than two weeks in both the pre- and post-retrofit periods. The post-retrofit data were collected after the threeweek adaptation period to allow for occupant adjustment to the new overhead lighting.

For statistical testing, only those measurements from Monday through Friday between 5:50 am and $7: 10 \mathrm{pm}$ were used, to capture the full range of business hours. Times after October 29 were adjusted for daylight savings. Fifteen business days were used before retrofit, and ten business days were used after retrofit. In both cases, each day of the week appears the same number of times.

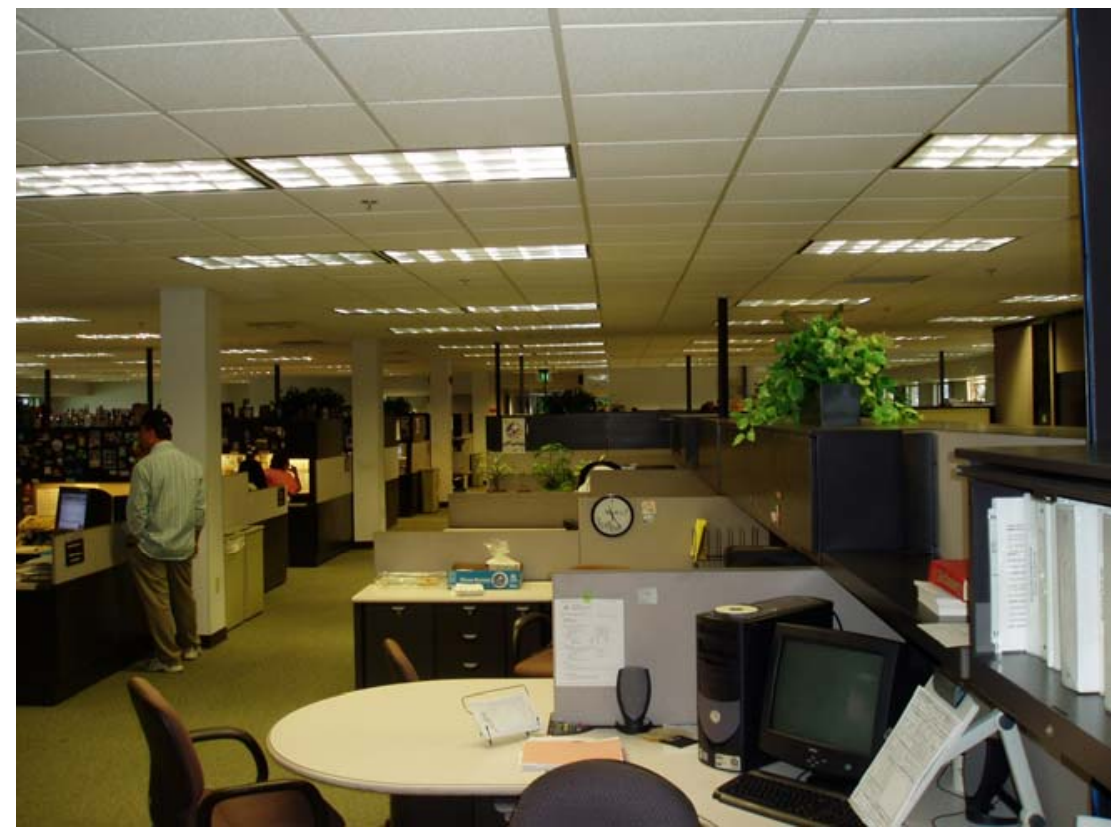

Figure 5.12. Building $\mathrm{C}$ - Workstation within Open Plan Office Area 


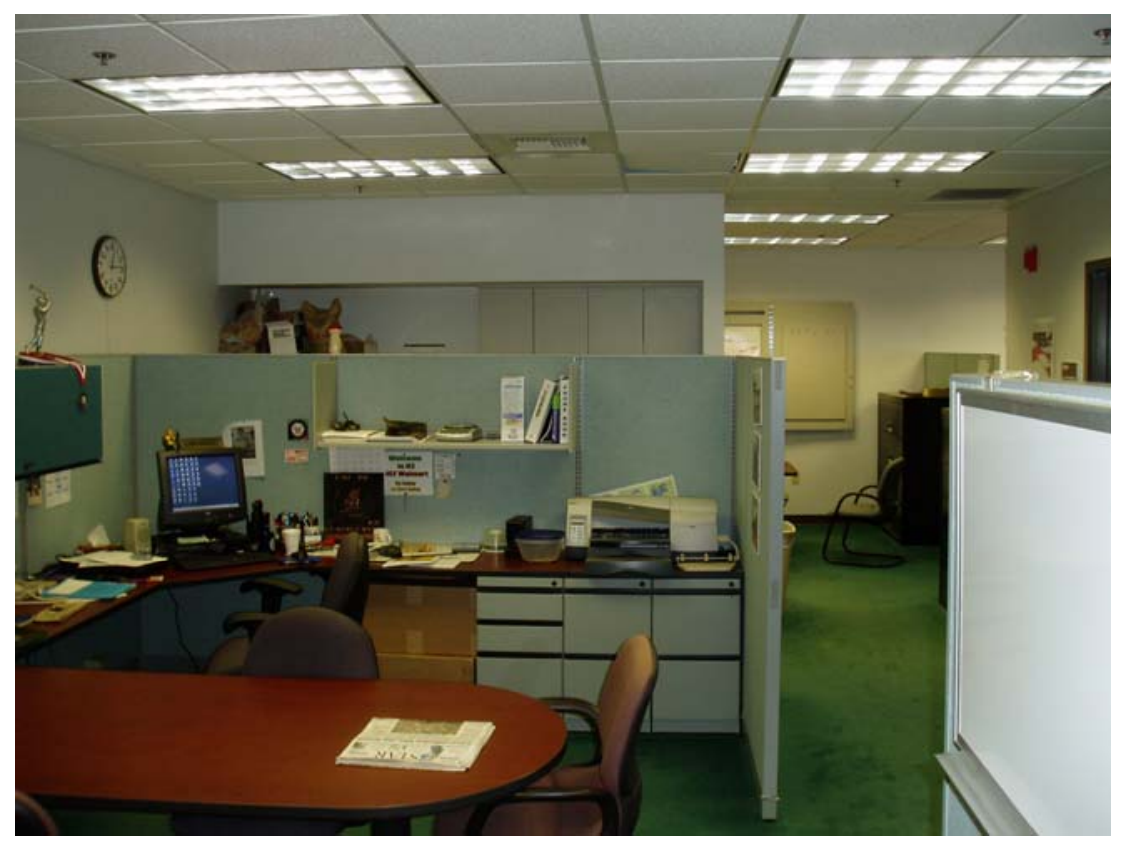

Figure 5.1.3. Building C - Cubicle Workstation

\subsubsection{Measurement Results}

Based on data from the 98 task lighting data loggers, there is no statistical evidence of task lighting usage change after the retrofit. The figures below show percentage of task light use before and after the retrofit. The mean task lighting usage before the retrofit was $14.1 \%$ of weekday business hours. The mean task lighting usage after the retrofit was $12.6 \%$. In absolute terms, there was a decrease in task lighting usage (baseline to retrofit); however, statistically this difference is not significant (see Table 5.5).

Table 5.5. Building C - Comparison of Pre- and Post-Retrofit Task Lighting Usage in Percent of Hours

\begin{tabular}{|l|c|c|c|}
\hline Building & $\begin{array}{c}\text { Mean Task Light } \\
\text { Usage Baseline }^{(\mathrm{a})}\end{array}$ & $\begin{array}{c}\text { Mean Task Light Usage } \\
\text { Retrofit }^{(\mathrm{a})}\end{array}$ & $\begin{array}{c}\text { Statistically } \\
\text { Significant Change }^{(\mathrm{b})}\end{array}$ \\
\hline Building C & $14.1 \%$ & $12.6 \%$ & No \\
\hline
\end{tabular}

(a) Mean task light usage is defined as percentage of task light on-time over the study period from 5:50 am to 7:10 pm on 12 days during both the pre- and post-retrofit periods.

(b) Assumes normal distribution in application of the paired t-test to determine statistical significance.

While the mean on-time decreased in nominal terms for Building $\mathrm{C}$, there is no statistically significant evidence of task lighting usage change after the retrofit. Figure 5.14 below shows the percentage of work hours during which the monitored task lights were in use before and after the retrofit. 


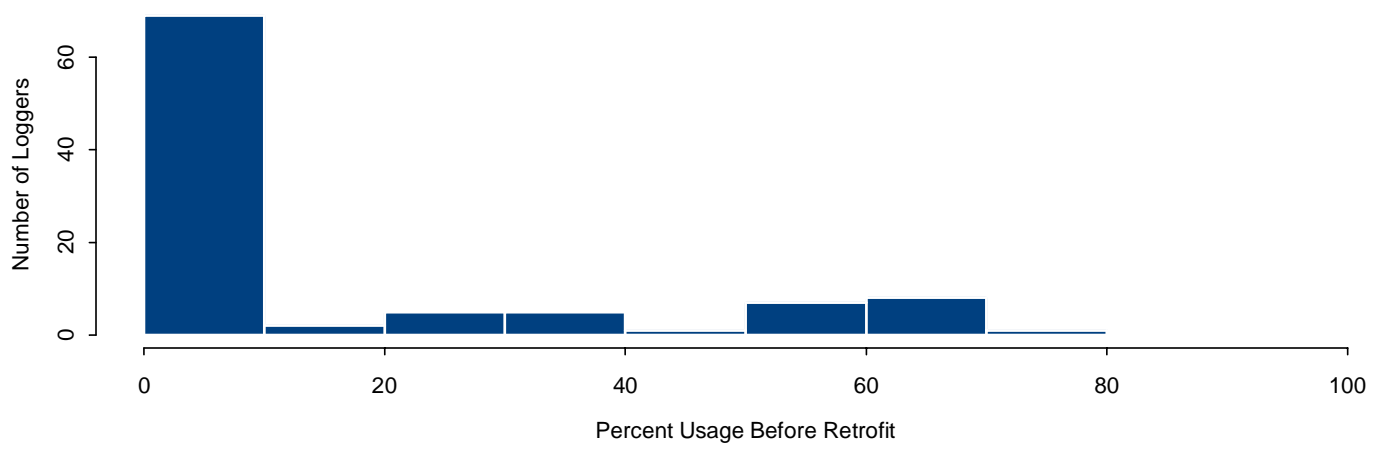

Percent Usage After Retrofit

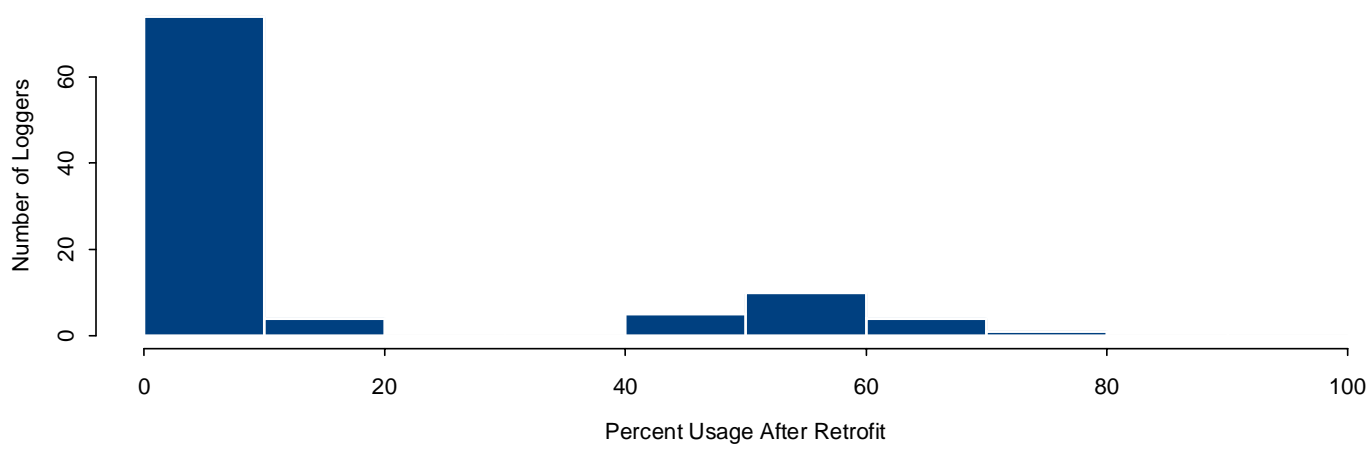

Figure 5.14. Building C - Task Light Usage as a Percent of Business Hours Before and After Retrofit

Percent usage was calculated for each logger before and after retrofit. The difference of After minus Before was calculated. The plotted differences are shown in Figure 5.15, which shows that most loggers had a small change, but several had very large changes. Non-parametric tests will be reported in addition to tests assuming a normal distribution. Non-parametric tests are more valid in this case. 


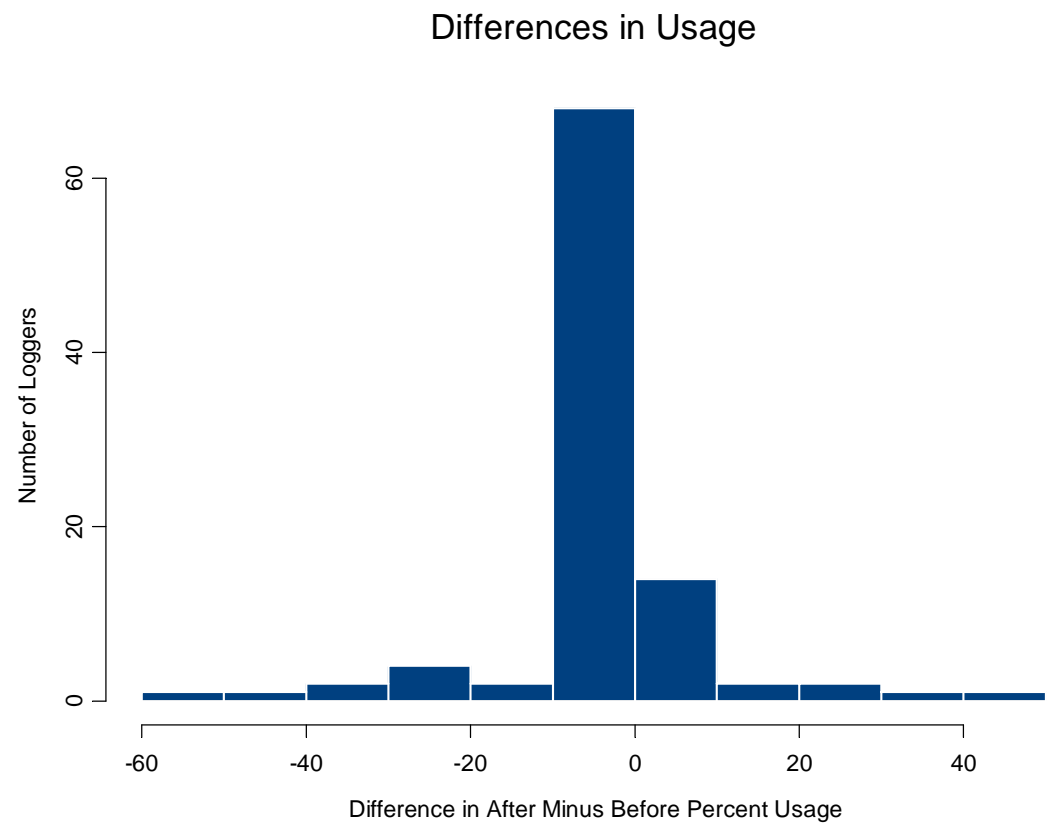

Figure 5.15. Building $C$ - Task Lighting Logger Differences in Usage Before and After Retrofit

\subsubsection{Statistical Analysis}

The results of the parametric and non-parametric tests used in the statistical analysis are given below.

\subsubsection{Paired T-Test}

- Mean usage of task lighting was not significantly different after retrofit (12.6\%) when compared to before retrofit $(14.1 \%)$. Assuming the paired differences are normally distributed, the $95 \%$ confidence limit of the difference is $(-4.1 \%, 1.2 \%)$.

- Out of 48 loggers that showed a change in usage, 20 showed an increase in usage while 28 showed a decrease in usage. This difference is significant within $95 \%$ confidence.

- $\quad$-value $=0.2739$

- Assuming Normality, there is no significant difference.

\subsubsection{Wilcoxon Signed-Rank Test}

(Tests for differences in the ranks of the relative magnitude of the differences.)

- $\quad$ P-value $=0.3064$

- There is no evidence that usage increased or decreased after the retrofit.

\subsubsection{Sign Test}

- $\quad$ P-value $=0.3123$

- 20 had increased usage, 28 had decreased usage, 50 had no change.

- There is no evidence that increases in usage were more or less common than decreases. 


\subsubsection{Reported Task Lighting Use}

In addition to monitoring the frequency of task lighting use at a sample of 98 workstations, all 186 fulltime occupants of the building were asked about frequency of task lighting use as part of the online occupant survey; 88 occupants answered both the pre- and post-retrofit surveys. In Building C, 58 survey respondents indicated on both the pre- and post-retrofit surveys that they had a desk/task light in their workspace. Of these, 8 respondents indicated more frequent desk/task light use after the retrofit than before the retrofit, 7 respondents indicated a decrease, and 43 reported no change in the frequency of desk/task lighting use. Overall, there was no statistically significant change in reported task lighting use following the retrofit. The number of responses to each possible answer is plotted in Table 5.6, comparing before and after retrofit:

Table 5.6. Building C - Comparison of Occupant Responses to Question About Frequency of Task Lighting Use, Pre- and Post-Retrofit. Question: "How often do you use your Desk (Task) light(s) when you are working?" Note: Numbers along main diagonal represent the number of occupants who reported the same frequency of task lighting use pre and post retrofit.

\begin{tabular}{|l|c|c|c|c|c|}
\hline \multicolumn{1}{|c|}{ Prest } & Always & $\begin{array}{c}\text { More than } \\
\text { half of the } \\
\text { time }\end{array}$ & $\begin{array}{c}\text { About half of } \\
\text { the time }\end{array}$ & $\begin{array}{c}\text { Less than } \\
\text { half of the } \\
\text { time }\end{array}$ & Never \\
\hline Always & 19 & & & 1 & \\
\hline $\begin{array}{l}\text { More than } \\
\text { half of the } \\
\text { time }\end{array}$ & 1 & 1 & 2 & 4 & \\
\hline $\begin{array}{l}\text { About half of } \\
\text { the time }\end{array}$ & & & 1 & 14 & \\
\hline $\begin{array}{l}\text { Less than half } \\
\text { of the time }\end{array}$ & & & 1 & 4 & 8 \\
\hline Never & & & & & \\
\hline
\end{tabular}

\subsubsection{Conclusions}

Based on 10-minute light intensity data collected from 98 task lights in Building C over the course of four weeks (two weeks baseline and two weeks retrofit), there is no statistical evidence of task light usage change from before the retrofit to after the retrofit. Further, there was no statistically significant change in reported task lighting use by the occupants. Given these findings, there is no evidence of a take back effect of increased task lighting use to adjust for photopic reductions in the overhead lighting levels.

\subsection{Occupant Ratings of Satisfaction with the Lighting}

Building C management provided a list of 209 names of employees to receive the occupant survey. Of these, 176 were in open plan offices (cubicles) and 33 were in enclosed offices. Six names were removed because the staff members were on-leave or on field assignment during the entire period of the 
pre-retrofit survey, and 17 were removed because the staff had pre-tested the survey. This left a population of 186 full-time staff, including 158 in open plan offices and 28 in enclosed offices, to participate in the pre-retrofit survey.

\subsubsection{Pre- and Post-Retrofit Measurements}

The pre-retrofit survey was administered the week of October 10, 2005, following a three-week adaptation period after the baseline lamp change-out and fixture cleaning. Building staff sent an email message to all full-time staff in the building inviting them to complete the survey.

The survey was sent to 186 full-time staff occupying the building. Follow-up phone calls were made to non-respondents during the week of October 17. By October 21, 133 responses had been received (72\% response rate).

Building occupants were notified after the pre-retrofit survey that the lighting would be retrofitted. Employees were not told that the lamp color would change.

Following a three-week adaptation period after the lighting retrofit, the post-retrofit survey was administered during the week of November 28, 2005. Full-time building occupants again received an email message from Building $\mathrm{C}$ staff inviting them to take the survey.

Follow-up phone calls were completed by PNNL staff during the week of December 5. A total of 85 paired (pre-retrofit and post-retrofit) responses were received. This represented a response rate of $46 \%$ of the eligible full-time building occupants.

\subsubsection{Statistical Analysis}

Respondents were asked the same three questions regarding lighting on both the pre- and postretrofit surveys. Results of the statistical analysis for each lighting question are provided below.

\section{"How satisfied are you with the amount of light in your workspace?"}

The scale was $\quad$ Very Dissatisfied $\bigcirc \bigcirc \bigcirc \bigcirc \bigcirc \bigcirc \bigcirc$ Very Satisfied

Responses were coded with $1=$ very dissatisfied, $7=$ very satisfied

- Mean Scores

○ Before: 5.49

○ After: 5.56

- $\quad$ Paired t-test

○ $95 \%$ Confidence Interval of After minus Before

- $(-0.18,0.32)$

○ Post-retrofit scores were not significantly lower than pre-retrofit scores ( $\mathrm{p}$-value $=$ 0.7131)

- Post-retrofit scores were not significantly different from pre-retrofit scores ( $\mathrm{p}$-value $=$ 0.5738).

○ No evidence that scores changed. 
- Wilcoxon Signed Rank Test

○ One-Sided p-value $=0.8146$

$\circ \quad$ Two-Sided $\mathrm{p}$-value $=0.3732$

- No evidence that scores changed.

- Sign Test

○ 29 increases, 22 decreases, 34 unchanged

○ One-Sided p-value $=0.8688$

○ $\quad$ Two-Sided p-value $=0.4011$

○ No Evidence that scores changed.

"How satisfied are you with your visual comfort under this lighting?"

The scale was $\quad$ Very Dissatisfied $\bigcirc \bigcirc \bigcirc \bigcirc \bigcirc \bigcirc \bigcirc$ Very Satisfied

Responses were coded with $1=$ very dissatisfied, $7=$ very satisfied

- Mean Scores

○ Before: 5.29

○ After: 5.48

- Paired t-test

- $95 \%$ Confidence Interval of After minus Before

- $(-0.08,0.46)$

- Post-retrofit fit scores were not significantly lower than pre-retrofit scores ( $\mathrm{p}$-value $=$ 0.9143).

- Post-retrofit scores were not significantly different from pre-retrofit scores ( $\mathrm{p}$-value $=$ $0.1715)$

- No evidence that scores changed.

- Wilcoxon Signed Rank Test

○ One-Sided p-value $=0.9503$

○ $\quad$ Two-Sided p-value $=0.1003$

○ No evidence that scores changed.

- Sign Test

○ 30 increases, 19 decreases, 36 unchanged

○ One-Sided p-value $=0.9572$

○ Two-Sided p-value $=0.1524$

○ No evidence that scores changed. 
“Overall, does the lighting quality enhance or interfere with your ability to get your job done?"

The scale was Interferes $\bigcirc \bigcirc \bigcirc \bigcirc \bigcirc \bigcirc \bigcirc$ Enhances

Responses were coded with $1=$ interferes, $7=$ enhances

- Mean Scores

○ Before: 5.26

○ After: 5.28

- $\quad$ Paired t-test

- $95 \%$ Confidence Interval of After minus Before

○ $(-0.25,0.25)$

- Post-retrofit scores were not significantly lower than pre-retrofit scores ( $\mathrm{p}$-value $=$ 0.5625)

○ Post-retrofit scores were not significantly different from pre-retrofit scores ( $\mathrm{p}$-value $=$ 0.8360).

- No evidence that scores changed.

- Wilcoxon Signed Rank Test

○ One-Sided p-value $=0.6582$

○ $\quad$ Two-Sided p-value $=0.6871$

○ No evidence that scores changed

- Sign Test

○ 26 increases, 23 decreases, 36 unchanged

○ One-Sided p-value $=0.7159$

○ Two-Sided p-value $=0.7754$

$\circ$ No evidence that scores changed.

\subsubsection{Variables and their Impacts on Responses}

We analyzed the 85 paired (pre-retrofit and post-retrofit) survey responses to see how several variables may have influenced lighting satisfaction. Results are given below.

\subsubsection{Age}

Respondents were asked to indicate their age group as 30 or under, 31-50, or over 50. Respondent age group did not appear to be a factor for any questions on the survey. There was no statistically measureable difference in the answers given by respondents in any age group as compared to other age groups.

\subsubsection{Gender}

Men tended to the answer the question, "How satisfied are you with the amount of light in your workspace?" higher than women after retrofit. Of the 85 respondents, 54 identified themselves as male, while 31 indicated female. The average pre-retrofit rating among the men was 5.65; post-retrofit was 5.80 
for a change of +0.15 . The average pre-retrofit rating among women was 5.23; post-retrofit was 5.16, for a change of -0.06 . The difference in the post-retrofit ratings between men and women was statistically significant.

\subsubsection{Monitor Type}

Respondents were asked to indicate the type of computer monitor they used, choosing CRT with curved screen, CRT with flat screen, LCD flat screen, laptop, other, or "I do not use a computer in my workspace." In Building C, the number of respondents reporting each type of monitor was as follows:

CRT with curved screen -38

CRT with flat screen - 39

LCD flat screen - 3

Laptop - 5

The only measureable differences between monitor groups on the lighting questions were between the LCD users and the CRT users. However, only three respondents indicated LCD use, so this is not considered significant.

\subsubsection{Office Type}

\section{Pre-Retrofit:}

- When asked, "How satisfied are you with the amount of light in your workspace?" private office respondents answered significantly higher (6.06) before retrofit than respondents in tall cubicles (5.06).

- When asked, "How satisfied are you with your visual comfort under this lighting?" private office respondents answered significantly higher (5.88) before retrofit than respondents in open, enclosed shared, or other workspaces (4.64).

- When asked, "Overall, does the lighting quality enhance or interfere with your ability to get your job done?" private office respondents answered significantly higher (5.81) before retrofit than respondents in open, enclosed shared, or other workspaces (4.64).

\section{Post-Retrofit:}

- When asked about their visual comfort, respondents in open, enclosed shared, or other workspaces (1.09) had a significantly higher increase in score than respondents in tall cubicles $(0.00)$.

- No other significant differences were found between different office types on the lighting questions.

\subsubsection{Daylight Availability vs. Occupant Survey Responses}

Twenty-one of the 85 respondents had access to daylight in their office spaces; 64 did not. Answers were broken out by daylight availability to see if it had any impact on answers (See Table 5.7). 
Table 5.7. Comparison of Survey Responses from Building C Workspaces With and Without Daylight

\begin{tabular}{|c|c|c|c|c|}
\hline Pre-Retrofit Ratings & Sample & Amount of Light & Visual Comfort & Impact on Job \\
\hline & & \multicolumn{3}{|c|}{ Average score (scale $1-7$ ) } \\
\hline Daylight & 21 & 5.71 & 5.57 & 5.62 \\
\hline No Daylight & 64 & 5.42 & 5.2 & 5.14 \\
\hline \multicolumn{5}{|l|}{ Post-Retrofit Ratings } \\
\hline Daylight & 21 & 5.48 & 5.33 & 5.14 \\
\hline No Daylight & 64 & 5.59 & 5.53 & 5.33 \\
\hline \multicolumn{5}{|l|}{ Change (post - pre) } \\
\hline Daylight & 21 & -0.24 & -0.24 & -0.48 \\
\hline No Daylight & 64 & 0.17 & 0.32 & 0.19 \\
\hline
\end{tabular}

On the question, "Overall, does the lighting quality enhance or interfere with your ability to get your job done?" the change in mean score for respondents with daylight (-0.48) was significantly different from the change in mean score for respondents without daylight (0.19). We surmise this difference is due to the change to daylight savings time which took place between the pre- and post-retrofit surveys.

\subsubsection{Conclusions}

Statistical analysis of the pre-retrofit and post-retrofit responses from Building C occupants determined the following.

- Mean scores on lighting questions were not significantly different after retrofit than before retrofit.

- Age was not a factor for any lighting questions.

- Men tended to answer "How satisfied are you with the amount of light in your workspace?" higher than women after retrofit.

- Monitor type was not a major factor for any lighting questions. LCD users showed some differences, but this is only three people.

- Respondents in tall cubicles were less satisfied with their lighting than those in private offices before retrofit.

- Respondents in private offices tended to respond with higher scores to the question "Overall, does the lighting quality enhance or interfere with your ability to get your job done?" and "How satisfied are you with your visual comfort under this lighting?" than did respondents in an open space, enclosed but shared, or other office space types collectively.

- On the question, "Overall, does the lighting quality enhance or interfere with your ability to get your job done?" the change in mean score for respondents with daylight (-0.48) was significantly different from the change in mean score for respondents without daylight (0.19). 


\section{Appendix A}

\section{End-Use Logger Description and Configurations}




\section{Appendix A}

\section{End-Use Logger Description and Configurations}

\section{A.1. C180 Logger Description}

The 180-Series electrical measurement modules and loggers are intended to provide accurate acquisition of AC voltage, current, power, and energy levels. The application of modern sampled-data Digital Signal Processing (DSP) technologies to AC measurement requires careful analysis and design to ensure that the reported data is accurate and consistent with the measurements of classical electrodynamic instruments. Hundreds of C180 meters have been used in utility company end-use load study installations where their data is "checksummed" against the standard electromechanical service meter with typical differences of less than $1 \%$. This document explains the basic measurement techniques used in the Series 180 instruments.

BASIC ALGORITHM. For each of its sixteen "virtual wattmeter" channels, a C180 receives two analog signal inputs from external sensors. One signal is a divided-down differential voltage signal, which is proportional to the instantaneous voltage difference between the highside and lowside potential inputs of the "wattmeter," and the other is a low-voltage signal proportional to the instantaneous current flow in the associated current-carrying conductor. Using these two signals, the unit will compute the true RMS voltage, true RMS current, true power (watts), apparent power (volt-amps), integrated energy (kilowatthours), and apparent energy (KVA-hours) of each channel.

In brief, the signal processing sequence is as follows:

1. Both the voltage and current signals are periodically (and simultaneously) sampled and digitized, yielding numeric instantaneous voltage and current sample values.

2. The voltage samples are squared and lowpass filtered to yield a smoothed, mean-square voltage value. The square root of this filtered value is periodically computed and presented as the real-time RMS voltage value.

3. The current samples are squared and lowpass filtered to yield a smoothed, mean-square current value. The square root of this filtered value is periodically computed and presented as the realtime RMS current value.

4. The instantaneous voltage and current samples are independently multiplied to yield a signed instantaneous power product. The power-product samples are lowpass filtered, and the output of this filter is periodically posted as the realtime true power value.

5. The realtime power value from the "power" lowpass filter is time-integrated into a kilowatt-hour (energy) register.

6. The realtime RMS voltage and current values (the output signals of steps 2 and 3 above) are multiplied and presented as the realtime apparent power (KVA) value.

7. The realtime KVA value is time-integrated into the KVAH register. 
This algorithm is accurate without regard to the signal frequency, phase angles, or waveforms. SAMPLING AND FILTERING. The 180-series sampling rate was chosen to ensure accurate measurement of waveforms containing frequency components up to the 50th line harmonic. Advanced signal processing and filtering techniques are used in the Series 180 products to deliver accurate measurements for the ranges of signals found in real AC power systems.

Although Series 180 units are normally used to measure 50 or $60 \mathrm{~Hz}$ AC circuits, the units are capable of accurate measurement of power circuits from DC to more than $100 \mathrm{~Hz}$, if suitable current transducers are provided.

All acquired data is lowpass filtered to smooth instantaneous samples into averaged RMS volts, amps, watts, and KVAs. The digital filters used have a normal bandwidth of 1 Hertz. The filters have a "transitional" transfer function, a compromise between good high-frequency noise rejection and clean, damped step response. For a step change of voltage or current, the realtime RMS values reported by the AT180/V180 will transition (20-80\% levels) in about 400 milliseconds and will settle cleanly without ringing or overshoot. Filtered volts, amps, watts, and other measured parameters are updated at a rate of 32 times per second.

One advantage of digital processing is the wide dynamic range of power measurement it allows. Whereas electromechanical instruments are limited by friction, and analog-multiplier-based electronic wattmeters have inherent offset and drift errors, a digital wattmeter can use autozero and correlation techniques to eliminate offsets, and can use statistical techniques to improve ADC linearity and remove digital quantization effects. The Series 180 products demonstrate power measurement linearity of better than 1 part in 5000, and have virtually unmeasurable "zero power" offsets--below one part in 100,000. This means that a Series 180 instrument can accurately measure power levels that are a small fraction of the full-scale power of the instrumented circuit. The 180-series achieves this wide dynamic range without scale or gain switching.

SOURCES OF ERROR. Several sources of error should be considered in applying the 180 series products. They include the following.

1. CURRENT SENSOR ERRORS. The standard current sensors provided with the Series 180 products are typically accurate to about $0.5 \%$ (amplitude) and 0.5 degrees (phase), so these sensors are the dominant error contributor in a typical system. These sensors, like most current transformers, show increased phase shift at low currents (say, below $10 \%$ of full scale).

2. STRAY PICKUP. Since Series 180 current inputs are usually $333.3 \mathrm{mV}$ AC for full-scale current, low current levels correspond to very low signal levels. A current of $1 \%$ of full scale corresponds to only 3.333 millivolts, and a $1 \%$ error of this voltage is only 33.3 microvolts. The parts-per-million zero offset accuracy of the Series 180 modules can be degraded by microvolt-level hum pickups. To avoid microvoltlevel errors, the following precautions are suggested:

A. Use torroidal (as opposed to removable link) current transformers. Removable-link CTs can pick up signals from current-carrying conductors which are outside the sense loop. If split-core sensors are used, keep them away from other current-carrying lines or transformers.

B. Ensure that current sensor leads are tightly and uniformly twisted, and that the signal leads are not run near or parallel to current-carrying conductors or near transformers. 
C. To avoid ground loops, do not ground CT leads anywhere except at the C760 termination panel.

3. SENSOR OVERLOAD. Measurement errors can result from overload of current signal inputs. If a current sensor is rated at "N" amps, the instantaneous current level through the sensor should not exceed 2(N) amps. Since very distorted waveforms may have high peak-to-average ratios, it may be advisable to use a higher-rated CT to measure currents that may have high peak values.

4. CIRCULATING DC. Current transformers may lose accuracy if the measured current contains a significant DC component, such as that which might be created by a half-wave rectified load or asymmetric SCR circuit. If DC is suspected, it should be measured with a DC ammeter, and CT specifications checked for compatibility. Note that a DC current component contributes no real power so long as the line voltage remains pure AC. 


\section{A.2 C180 Logger Parameter Set, Building A, Panel HA.}

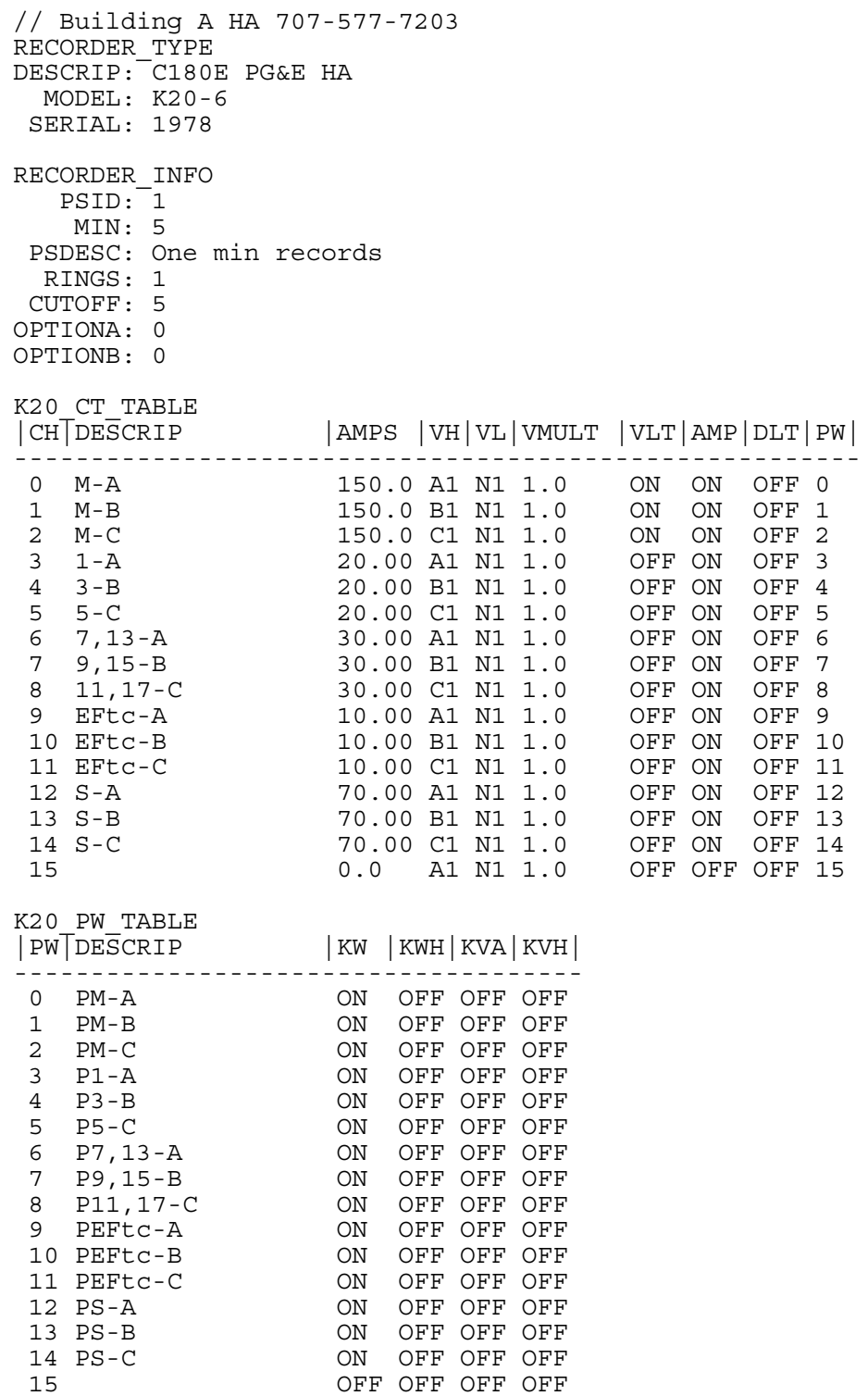

\begin{tabular}{|c|c|c|c|c|c|c|c|c|c|}
\hline $\mathrm{CH}$ & DEESCRIP & |AMPS & VH & VL & VMULT & |VLT & AMP & DLT & PW \\
\hline 0 & $M-A$ & 150.0 & A1 & N1 & 1.0 & ON & ON & OFF & 0 \\
\hline 1 & $M-B$ & 150.0 & B1 & $\mathrm{N} 1$ & 1.0 & ON & $\mathrm{ON}$ & OFF & 1 \\
\hline 2 & $M-C$ & 150.0 & $\mathrm{C} 1$ & N1 & 1.0 & ON & ON & OFF & 2 \\
\hline 3 & $1-\mathrm{A}$ & 20.00 & A1 & N1 & 1.0 & OFF & $\mathrm{ON}$ & OFF & 3 \\
\hline 4 & $3-B$ & 20.00 & B1 & N1 & 1.0 & OFF & $\mathrm{ON}$ & OFF & 4 \\
\hline 5 & $5-C$ & 20.00 & $\mathrm{C} 1$ & N1 & 1.0 & OFF & ON & OFF & 5 \\
\hline 6 & $7,13-\mathrm{A}$ & 30.00 & A1 & N1 & 1.0 & OFF & ON & OFF & 6 \\
\hline 7 & $9,15-B$ & 30.00 & B1 & $\mathrm{N} 1$ & 1.0 & OFF & ON & OFF & 7 \\
\hline 8 & $11,17-\mathrm{C}$ & 30.00 & $\mathrm{Cl}$ & N1 & 1.0 & OFF & ON & OFF & 8 \\
\hline 9 & EFtc $-A$ & 10.00 & A1 & N1 & 1.0 & OFF & ON & OFF & 9 \\
\hline 10 & EFtC-B & 10.00 & B1 & N1 & 1.0 & OFF & ON & OFF & 10 \\
\hline 11 & EFtc-C & 10.00 & $\mathrm{C} 1$ & N1 & 1.0 & OFF & ON & OFF & 11 \\
\hline 12 & $S-A$ & 70.00 & A1 & N1 & 1.0 & OFF & ON & OFF & 12 \\
\hline 13 & $S-B$ & 70.00 & B1 & N1 & 1.0 & OFF & ON & OFF & 13 \\
\hline 14 & $S-C$ & 70.00 & $\mathrm{C} 1$ & N1 & 1.0 & OFF & ON & OFF & 14 \\
\hline 15 & & 0.0 & A1 & N1 & 1.0 & OFF & $\mathrm{OFF}$ & OFF & 15 \\
\hline
\end{tabular}

K20 PW TABLE

| PWTDE $\bar{S}$ CRIP $\quad$ KW $|\mathrm{KWH}| \mathrm{KVA}|\mathrm{KVH}|$

0 PM-A $\quad$ ON OFF OFF OFF

1 PM-B ON OFF OFF OF

OFF OFF OFF

P1-A ON OFF OFF OFF

P3-B ON OFF OFF OFF

P5-C ON OFF OFF OFF

P7, 13-A ON OFF OFF OFF

P9, 15-B ON OFF OFF OFF

P11, 17-C ON OFF OFF OFF

PEFtC-A ON OFF OFF OFF

10 PEFtC-B ON OFF OFF OFF

11 PEFtC-C ON OFF OFF OFF

12 PS-A ON OFF OFF OFF

13 PS-B ON OFF OFF OFF

14 PS-C ON OFF OFF OFF

15

OFF OFF OFF OFF 


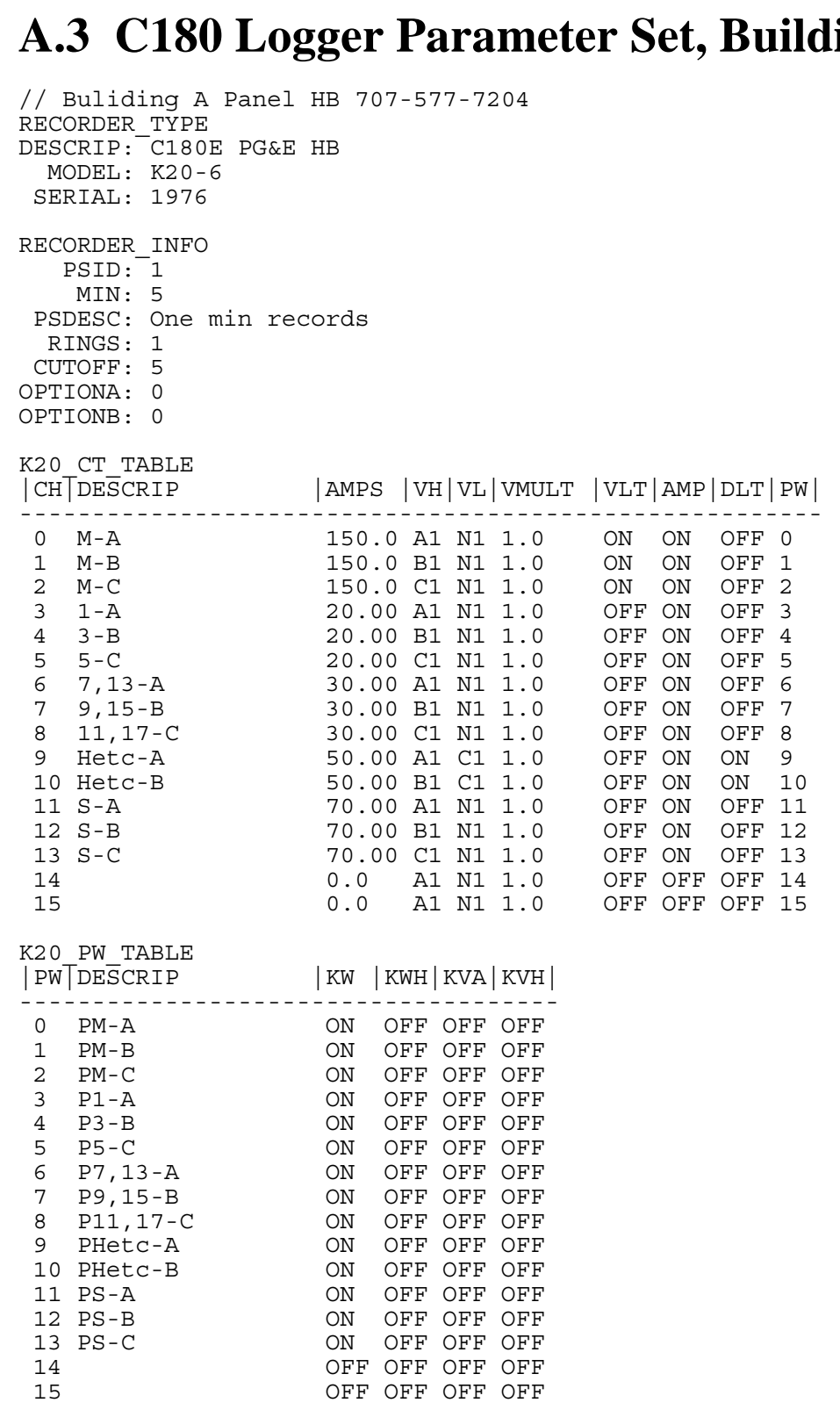




\section{A.4 C180 Logger Parameter Set, Building B, Panel L1.}

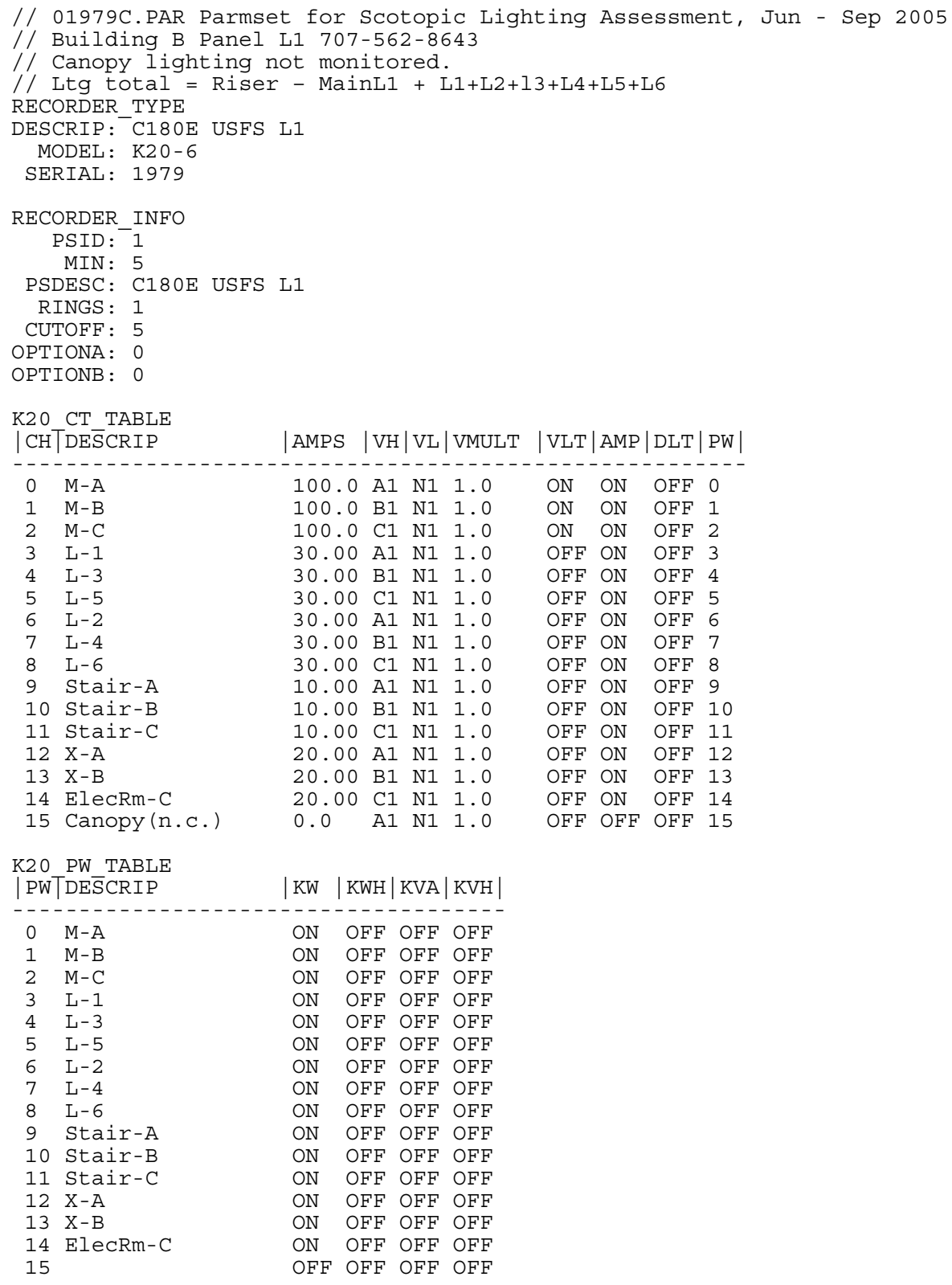

\begin{tabular}{|c|c|c|c|c|c|}
\hline PW & DES $\bar{S}$ CRIP & KW & KWH & KVA & $\mathrm{KVH}$ \\
\hline 0 & $M-A$ & $\mathrm{ON}$ & OFF & OFF & OFF \\
\hline 1 & $M-B$ & $\mathrm{ON}$ & OFF & OFF & $\mathrm{OFF}$ \\
\hline 2 & $M-C$ & ON & OFF & OFF & OFF \\
\hline 3 & $\mathrm{~L}-1$ & ON & OFF & OFF & OFF \\
\hline 4 & $L-3$ & $\mathrm{ON}$ & $\mathrm{OFF}$ & OFF & OFF \\
\hline 5 & $L-5$ & $\mathrm{ON}$ & OFF & OFF & OFF \\
\hline 6 & $\bar{L}-2$ & $\mathrm{ON}$ & $\mathrm{OFF}$ & OFF & OFF \\
\hline 7 & $\mathrm{~L}-4$ & $\mathrm{ON}$ & OFF & OFF & OFF \\
\hline 8 & $L-6$ & $\mathrm{ON}$ & OFF & OFF & OFF \\
\hline 9 & Stair-A & $\mathrm{ON}$ & OFF & OFF & OFF \\
\hline 10 & Stair-B & ON & OFF & OFF & OFF \\
\hline 11 & Stair-C & $\mathrm{ON}$ & OFF & OFF & OFF \\
\hline 12 & $X-A$ & $\mathrm{ON}$ & $\mathrm{OFF}$ & OFF & OFF \\
\hline 13 & $X-B$ & $\mathrm{ON}$ & OFF & OFF & OFF \\
\hline 14 & ElecRm-C & ON & OFF & OFF & OFF \\
\hline 15 & & $\mathrm{OFF}$ & OFF & OFF & OFF \\
\hline
\end{tabular}




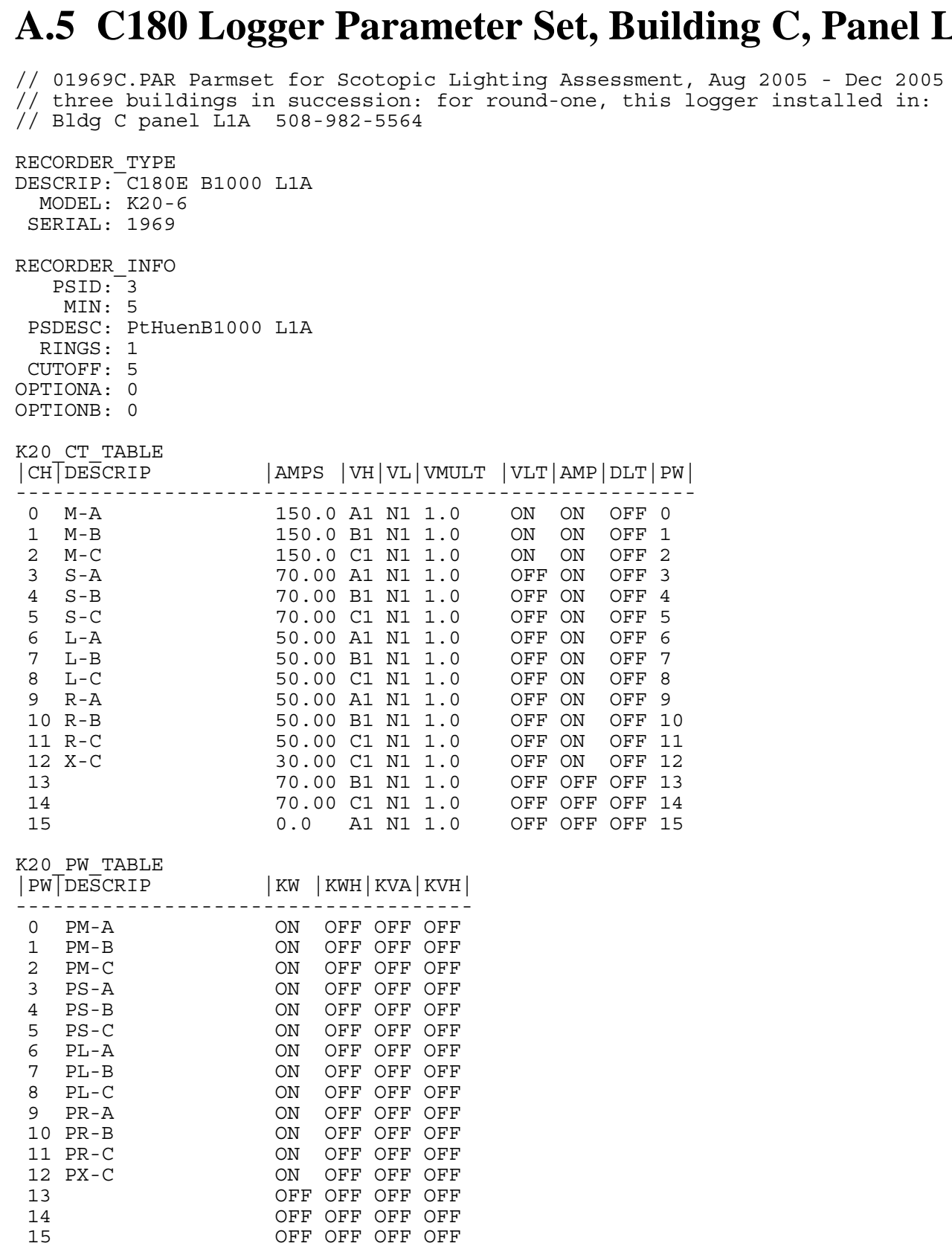




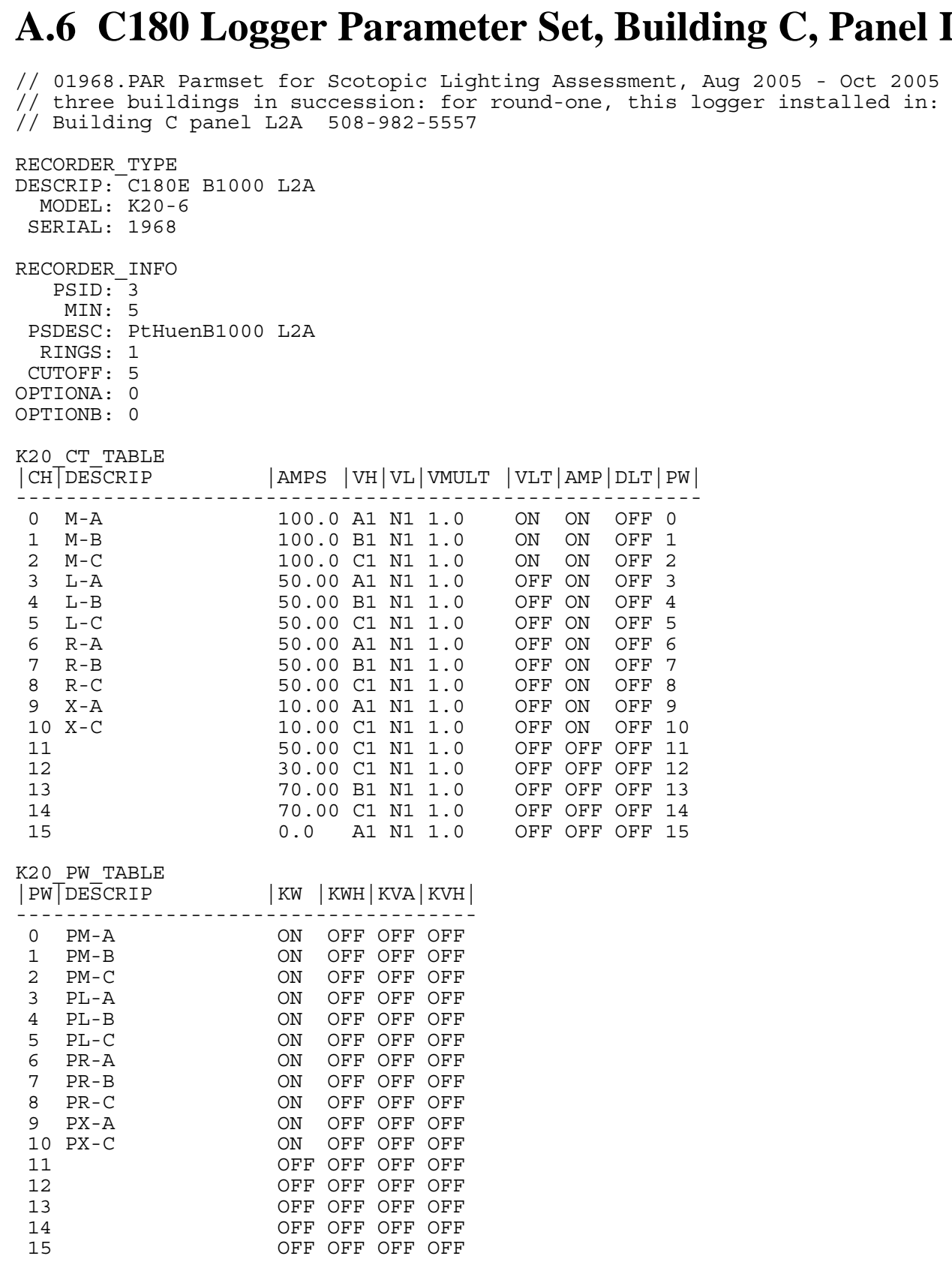




\section{A.7 Sumcheck Analyses}

\section{End-use power channel Sumcheck Results for Building A.}

The most common end-use metering errors result from programming errors (wrong current transformer amp rating) and connection errors (reversed CT, transposed channels, missed circuits). To catch these errors it is customary to perform a panel-level energy balance or "checksum." This is accomplished by instrumenting the feed into a panel as well as all of its load circuits as indicated in the logger parameter set appendices. The checksum analysis performed on the two end-use metering loggers installed in Building A indicated that there were no installation errors. The checksum deviations over a range of loads indicate the following uncertainties for the two lighting panel HA in the ESE wing and panel HB in the WNW wing.

The HA error band is $+/-50 \mathrm{~W}+(+0 \%$ to $-0.5 \%) *$ Reading

The HB error band is $+/-50 \mathrm{~W}+(+0 \%$ to $-0.3 \%) *$ Reading

The error bands are in the range expected for the type of metering equipment installed. The 50W error band represents $0.04 \%$ of the $125 \mathrm{~kW}$ full-scale mains reading.

\section{End-use power channel Sumcheck Results for Building B.}

Building B lighting was monitored at a single point in the main electrical room. Although sumchecking is not possible in this situation, the risk of logger and CT installation error is also relatively low because it is the simplest type of research metering installation.

\section{End-use power channel Sumcheck Results for Building C.}

The checksum analysis performed on both loggers installed at Building $\mathrm{C}$ initially indicated that there were no installation errors. Figure A.1 shows the standard checksum plot for lighting panel L1A.

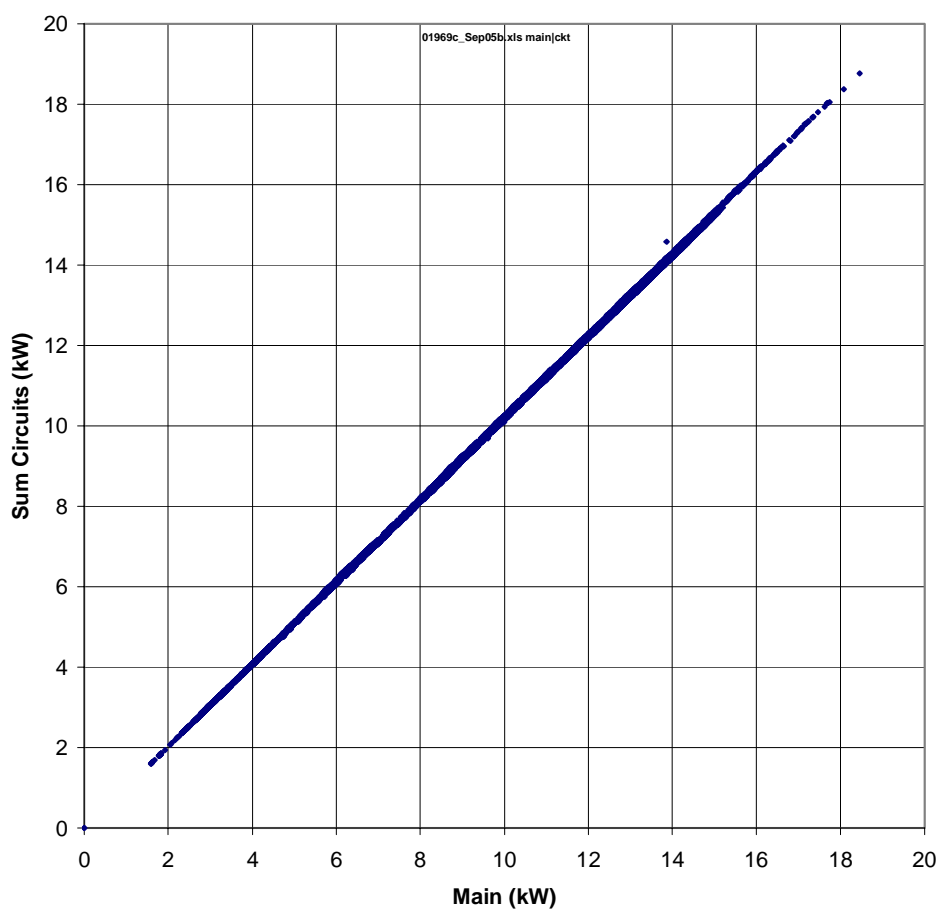

Figure A.1. Panel L1A Checksum Plot 
However there were some indications of problems when data from the first-floor connected load step-change test was performed. The CT and PT connections and logger programming were rechecked on a return site visit October 17 and no errors were found. However the first-floor data continued to look slightly suspicious.

Further analysis performed after the retrofit indicated larger, possibly significant errors for the firstfloor end-use metering logger. Further checksum analysis was performed. The checksum residuals for panel L1A are shown in Figure A.2 and the residual for panel L2A are shown in Figure A.3. The residual for panel L2A behave as expected: the absolute error increases with panel total power but with diminishing slope. The same information is represented a different way by the percent error, which decreases with panel total power. The residuals from panel L1A do not exhibit this expected behavior. The absolute error increases more or less linearly with panel total power.

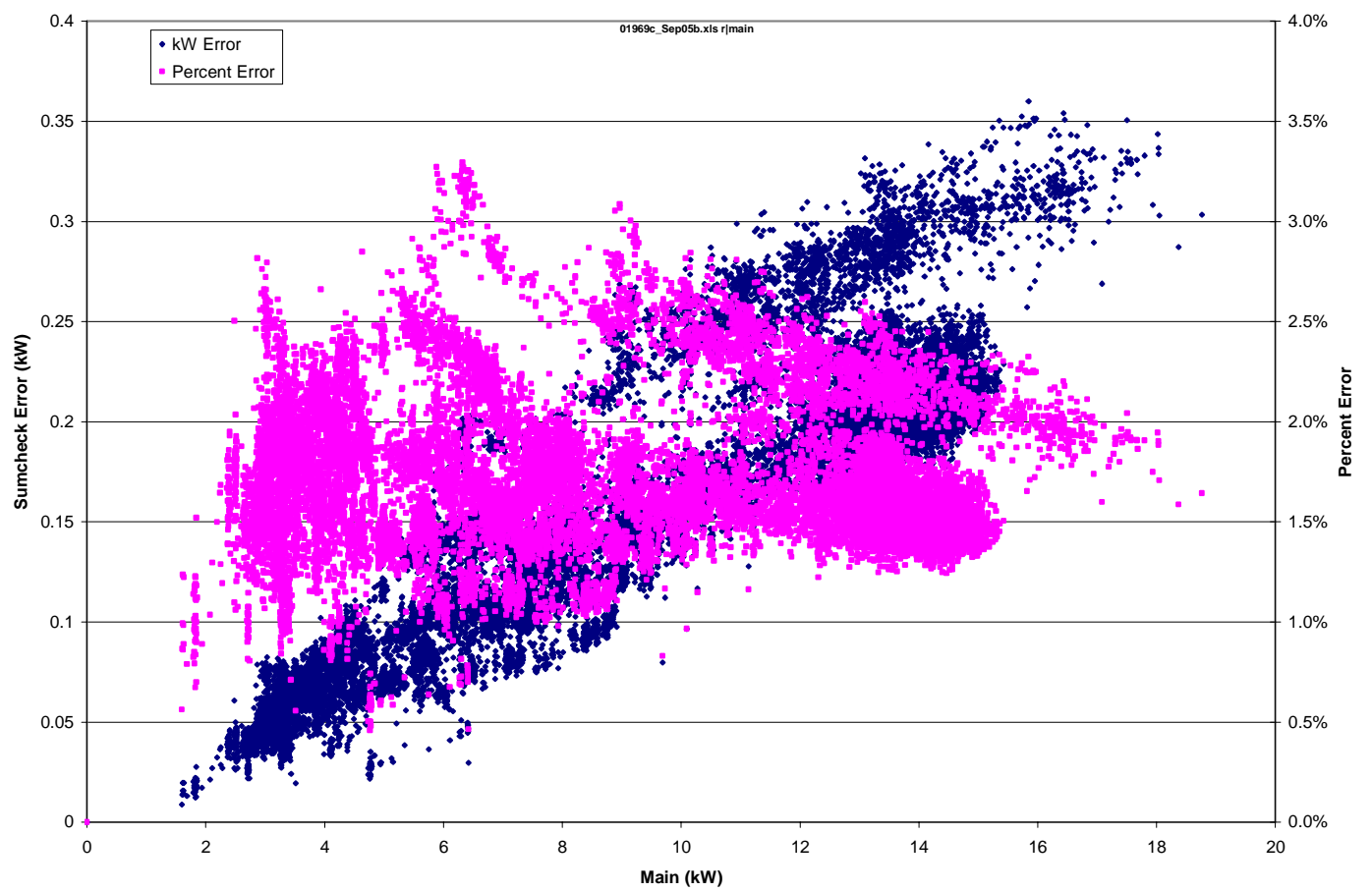

Figure A.2. Panel L1A Checksum Residuals 


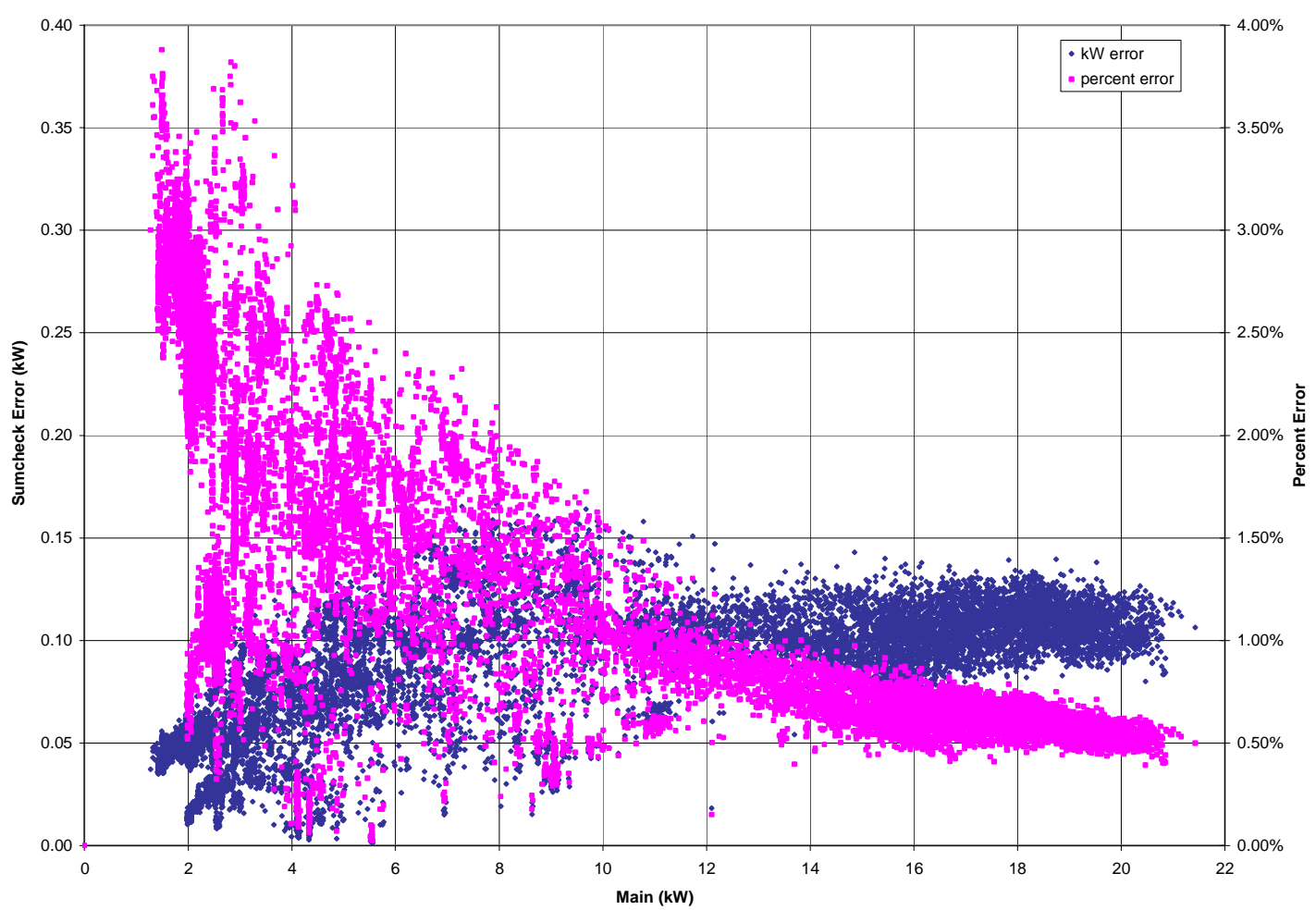

Figure A.3. Panel L2A Checksum Residuals

The checksum is not an absolute test of accuracy. Certain faults, such as PT phase errors, affect both the mains and circuit power calculations in a similar way. A marginal checksum error can indicate more significant absolute errors on all channels or even larger errors on some individual channels. Errors that are sensitive to phase, if present, are likely to be different in magnitude for the pre- and post-retrofit condition because the retrofit changed the magnitude and phase of harmonics in lighting circuits. The Second floor errors were found to be acceptable and the first floor errors marginal as summarized below.

L1A checksum error: $10 \mathrm{~W}+1.5 \% * \mathrm{Rdg}$.

L2A checksum error: $40 \mathrm{~W}+0.4 \% * \mathrm{Rdg}$.

Note that $40 \mathrm{~W}$ represents less than $.05 \%$ of full scale; it is the $1.5 \%$-of-reading error observed in L1A data that is marginal.

Since the questionable checksum behavior was not observed until after the retrofit and the preretrofit harmonics were never measured, there is no way to correct the pre-retrofit data even if the exact cause of the error could be determined. We therefore have used only the second-floor time series data to verify the second-floor one-time connected-load measurements. The first-floor connected load measurements were verified by taking one-time measurements on a large group of light fixtures serving an open office space as well as on a small group in a conference room. 


\section{A.8 Power Multimeter Description}

The Fluke 43B Power Quality Analyzer is intended to measure signals associated with 50- and 60$\mathrm{Hz}$ power systems. It can measure true rms voltage and current and calculates real and reactive power at fundamental $(60 \mathrm{~Hz})$ and harmonic $(120,180,240, \ldots \mathrm{Hz})$ frequencies with sufficient bandwidth to measure up to the $51^{\text {st }}$ harmonic as well as the ability to measure any dc components of voltage and current. Figure A.4 is a photo of the meter in use. The meter's performance specifications are provided below. For complete description see http://us.fluke.com/usen/products/Fluke+43B.htm.

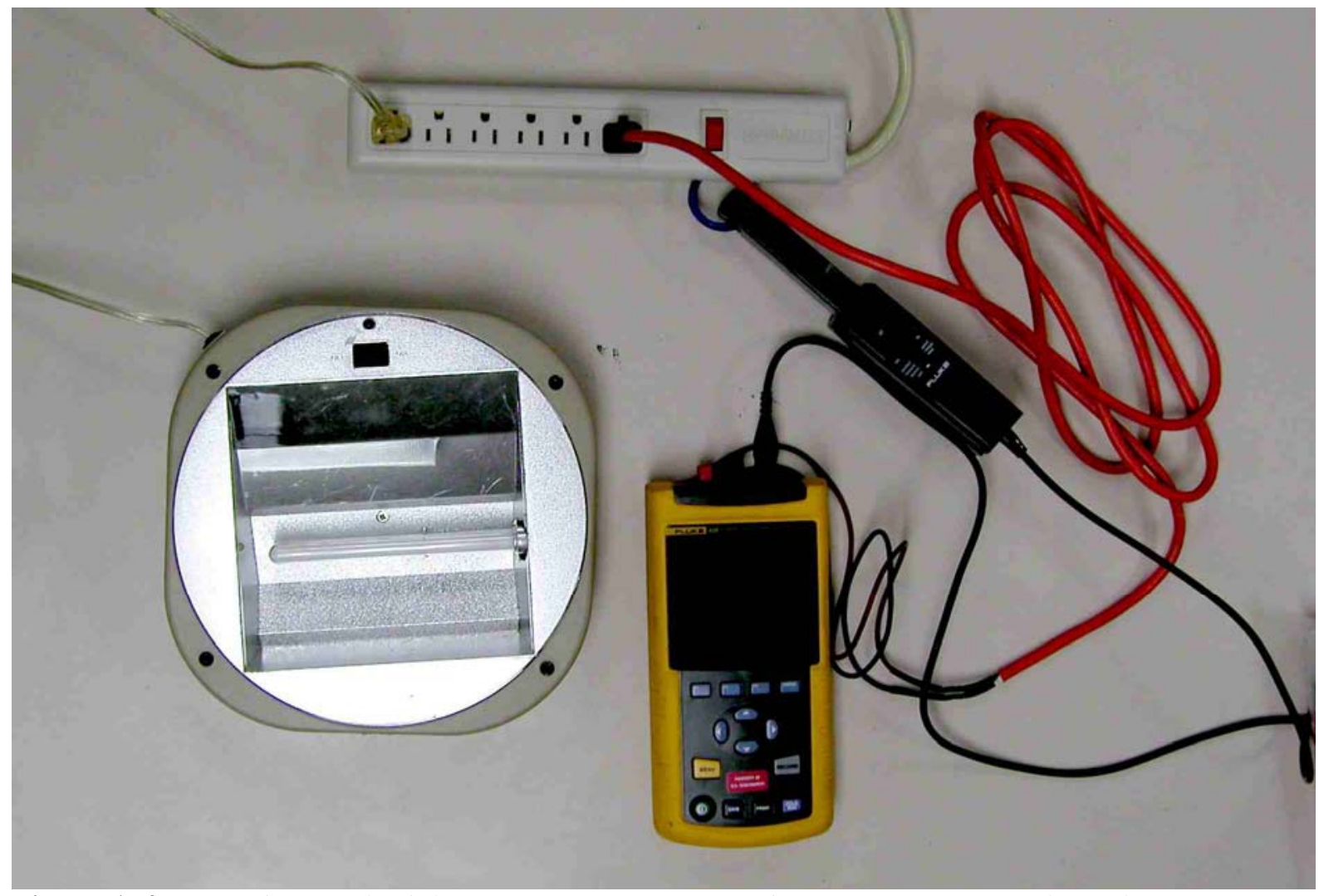

Figure A.4. One-Time Task Light Power Measurement Using 100A Current Probe and 10-Turn "Amplifier"

$\begin{array}{ll}\begin{array}{l}\text { General } \\ \text { Input impedance } \\ \text { Voltage rating }\end{array} & 1 \mathrm{M} \Omega, 20 \mathrm{pF} \\ & 600 \mathrm{~V} \mathrm{rms}, \mathrm{CAT} \mathrm{III} \\ \begin{array}{l}\text { True-rms voltage }(\mathbf{a c}+\mathbf{d c}) \\ \text { Ranges: }\end{array} & 5.000 \mathrm{~V}, 50.00 \mathrm{~V}, 500.0 \mathrm{~V}, 1250 \mathrm{~V} * \\ \text { Accuracy: } & \pm(1 \%+10 \text { counts }) \\ \begin{array}{l}\text { True-rms current }(\mathbf{a c}+\mathbf{d c}) \\ \begin{array}{l}\text { Ranges: } \\ \text { Accuracy: }\end{array}\end{array} \\ \begin{array}{l}\text { Frequency } \\ \text { Ranges: }\end{array} & \begin{array}{l}50.00 \mathrm{~A}, 500.0 \mathrm{~A}, 5.000 \mathrm{kA}, 50.00 \mathrm{kA}, 1250 \mathrm{kA} \\ \text { Accuracy: }\end{array} \\ \end{array}$


CF Crest factor

Ranges:

Accuracy:

Watts, VA, VAR

Ranges:

Accuracy:

Accuracy:

\section{PF Power Factor}

Range:

Accuracy:

DPF Displacement Power Factor

Range:

Accuracy:

Range:

Accuracy:

H2 Frequency Fundamental

Ranges:

Accuracy:

Harmonics (V, I, f)

Ranges:

Accuracy:

Fundamental:

2 to 31 st harmonic:

32 to 51 st harmonic:

\section{Frequency Fundamental}

Ranges:

Accuracy:

Phase

Range:

Accuracy:

Range:

Accuracy:

K-factor (Current and Power)

Range:

Accuracy:

THD Total Harmonic Distortion

Range:

Accuracy:

\section{Transient Capture}

Minimum pulse width:

Useful bandwidth input 1:

Number of transients:

Voltage threshold settings:

Reference signal:

Vpeak min, Vpeak max at cursor:
$1.0-10.0$

$\pm(5 \%+1$ count $)$

1-phase and balanced delta loads

$250 \mathrm{~W}-1.56 \mathrm{GW}$

$\pm(4 \%+4$ counts $)$ Fundamental Power

$\pm(2 \%+6$ counts $)$ Total Power

$0-1.0$

$\pm 0.04$

$0.25-0.9$

$\pm 0.04$

$0.90-1.0$

$\pm 0.03$

40.0 to $70.0 \mathrm{~Hz}$

$\pm(0.5 \%+2$ counts $)$

Fundamental to 51st harmonic

$\mathrm{VA} \pm(3 \%+2$ counts $) \mathrm{W} \pm(5 \%+2$ counts $)$

$\mathrm{VA} \pm(5 \%+3$ counts $) \mathrm{W} \pm(10 \%+10$ counts $)$

$\mathrm{VA} \pm(15 \%+5$ counts $) \mathrm{W} \pm(30 \%+5$ counts $)$

$40 \mathrm{~Hz}$ to $70 \mathrm{~Hz}$

$\pm 0.25 \mathrm{~Hz}$

V, A (between Fundamental \& Harmonics)

$\pm 3^{\circ}$ to $\pm 15^{\circ}$

W (Current Harmonics wrt Voltage Fundamental)

$\pm 5^{\circ}$ to $\pm 15^{\circ}$

1.0 to 30.0

$\pm 10 \%$

$0.00-99.99$

$\pm(3 \%+8$ counts $)$

$40 \mathrm{~ns}$

$\mathrm{DC}$ to $1 \mathrm{MHz}$

40

$20 \%, 50 \%, 100 \%, 200 \%$ above or below reference sinewave based on initial measured Vrms, frequency $10 \mathrm{~V}, 25 \mathrm{~V}, 50 \mathrm{~V}, 125 \mathrm{~V}, 250 \mathrm{~V}, 500 \mathrm{~V}, 1250 \mathrm{~V}$ Accuracy: $\pm 5 \% \mathrm{FS}$ 
Appendix B

Occupant Lighting Satisfaction Survey Instrument 


\section{Web-Based Occupant Survey}

The complete survey is shown below, with explanation and commentary in italics.

\section{Screen 1}

Occupant Survey

Thank you for your participation in this survey. The survey is being administered by an independent party. Information you provide will be held confidential and only aggregate totals of survey responses will be provided to your management. Your name and office location are requested in order for the independent party to follow up with you, if necessary. Your specific responses will not be identified, published or provided to your management. Completing the survey should take less than five minutes. Thanks for your time!

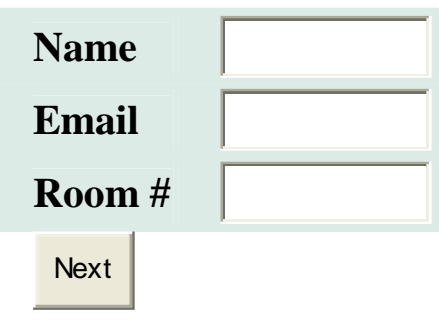

\section{System Requirements:}

Internet Explorer 5.0 or later

Netscape 6.0 or later

Firefox or other Mozilla browsers

Safari or Internet Explorer for Mac OS

Opera 5.0 or later

\section{Questions/feedback:}

Please email Survey Technical Support if you have questions or problems completing the survey. 


\section{Screen 2}

1. Which of the following best describes your personal workspace?

$O$ Enclosed office, private

Enclosed office, shared with other people

Cubicles with partitions above standing eye level

O Cubicles with partitions below standing eye level

Workspace in open office with no partitions

O Other (fill-in textbox)

Question 1 was used to categorize responses by type of work space. Responses from workers in enclosed offices may differ from those in open-plan office lay-outs, such as cubicles. Within cubicle areas, partition height may impact light levels on the work surfaces.

2. What kind of computer monitor do you use in your workspace?

O CRT (cathode ray tube) with curved screen

$\mathrm{O}$ CRT with flat screen

O LCD (liquid crystal display) flat screen

O Lap-top

O Other (fill-in textbox)

I do not use a computer in my workspace

Question 2 was used to check for potential differences in lighting satisfaction related to type of computer monitor used. Older-style cathode ray tube (CRT) monitors with curved screens are more reflective than newer-style flat screen monitors, potentially increasing glare.

\section{$\underline{\text { Screen } 3}$}

3. How satisfied are you with the comfort of your office furnishings (chair, desk, computer, equipment, etc.)?

Very Dissatisfied $\bigcirc \bigcirc \bigcirc \bigcirc \bigcirc \bigcirc \bigcirc$ Very Satisfied

4. Overall, do your office furnishings enhance or interfere with your ability to get your job done?

Interferes $\bigcirc \bigcirc \bigcirc \bigcirc \bigcirc \bigcirc \bigcirc$ Enhances

Questions 3 and 4 were intended to identify any issues with office furnishings that could impact overall satisfaction with the work environment.

5. How satisfied are you with the temperature in your workspace?

Very Dissatisfied $\bigcirc \bigcirc \bigcirc \bigcirc \bigcirc \bigcirc \bigcirc$ Very Satisfied

6. Overall, does your thermal comfort in your workspace enhance or interfere with your ability to get your job done?

Interferes $\bigcirc \bigcirc \bigcirc \bigcirc \bigcirc \bigcirc \bigcirc$ Enhances

Questions 5 and 6 were intended to identify any issues related to thermal comfort that could impact overall satisfaction with the work environment. 


\section{Screen 4}

7. Which of the following controls do you have for the lighting in your workspace? (check all that apply)

$\begin{array}{ll}\square & \text { Light switch } \\ \square & \text { Light dimmer } \\ \square & \text { Windows, blinds or shades } \\ \square & \text { Desk (task) light } \\ \square & \text { Bi-level switching (separate switches operating lights independently) } \\ \square & \text { Automatic occupancy sensor } \\ \square & \text { None of the above } \\ \square & \text { Other: }\end{array}$

Question 7 gathered information needed to help explain occupant satisfaction or dissatisfaction with the lighting in their workspace. Respondents who checked "Desk (task) light" were prompted with a follow-on question shown below under Screen 5.

\section{Screen 5}

(This screen appears ONLY if occupant has checked that they have a Desk (Task) Light) How often do you use your Desk (Task) light(s) when you are working?

$\square \quad$ Never
$\square \quad$ Less than half of the time
$\square \quad$ About half of the time
$\square \quad$ More than half of the time
$\square$ Always

This question was intended to help identify differences in task lighting usage following the retrofit. This self-reported information about task lighting use was compared to the measurement data on task lighting use obtained through individual data loggers placed on a sample of task lights.

\section{How satisfied are you with the amount of light in your workspace? \\ Very Dissatisfied $\bigcirc \bigcirc \bigcirc \bigcirc \bigcirc \bigcirc \bigcirc$ Very Satisfied \\ 9. How satisfied are you with your visual comfort under this lighting? \\ Very Dissatisfied $\bigcirc \bigcirc \bigcirc \bigcirc \bigcirc \bigcirc \bigcirc$ Very Satisfied}

10. Overall, does the lighting quality enhance or interfere with your ability to get your job done?

Interferes $\bigcirc \bigcirc \bigcirc \bigcirc \bigcirc \bigcirc \bigcirc$ Enhances

Questions 8, 9, and 10 were intended to gather occupant opinions about the lighting in their workspace. Respondents who selected any of the three circles at the negative end of the scale on any of the three lighting questions were queried with a follow-on question: 
Screen 6

You have indicated some level of dissatisfaction with the lighting in your workspace.

Which of the following contribute to your dissatisfaction? (check all that apply)

$\square \quad$ Too dim

$\square \quad$ Too bright

$\square \quad$ Not enough daylight

$\square \quad$ Too much daylight

$\square \quad$ Not enough electric lighting

$\square \quad$ Too much electric lighting

$\square \quad$ Electric lighting flickers

$\square \quad$ Electric lighting is an undesirable color

No task lighting

Reflections in the computer screen

$\square$ Shadows on the workspace

$\square$ Other:

(fill-in textbox)

\section{Final Screen}

13. Please describe any other issues related to lighting that are important to you. (fill-in textbox)

14. What is your age group?

O 30 or under

O $31-50$

O Over 50

15. What is your gender?

O Female

O Male 


\section{Appendix C}

\section{Overhead Light Level Measurement Data}




\section{Appendix C}

\section{Overhead Light Level Measurement Data}

Table C.1. Building A Pre-Retrofit Photopic and Scotopic Measurements (Lux) and S/P Ratio

\begin{tabular}{|l|c|c|c|c|c|c|}
\hline \multirow{2}{*}{ Location } & \multicolumn{3}{|c|}{ Vertical } & \multicolumn{3}{c|}{ Horizontal } \\
\cline { 2 - 7 } & Photopic & Scotopic & $\begin{array}{c}\text { S/P } \\
\text { Ratio }\end{array}$ & Photopic & Scotopic & $\begin{array}{c}\text { S/P } \\
\text { Ratio }\end{array}$ \\
\hline 145A & 150 & 193 & 1.29 & 438 & 575 & 1.31 \\
\hline 146C & 78 & 101 & 1.29 & 430 & 566 & 1.32 \\
\hline 147A & 195 & 244 & 1.25 & 510 & 659 & 1.29 \\
\hline 147D & 162 & 211 & 1.30 & 434 & 569 & 1.31 \\
\hline 147E & 176 & 224 & 1.27 & 477 & 620 & 1.30 \\
\hline 145B & 108 & 138 & 1.28 & 403 & 531 & 1.32 \\
\hline 147C & 77 & 96 & 1.25 & 350 & 450 & 1.29 \\
\hline 129 & 295 & 359 & 1.22 & 592 & 754 & 1.27 \\
\hline $161 \mathrm{~B}$ & 158 & 198 & 1.25 & 496 & 644 & 1.30 \\
\hline 162B & 228 & 293 & 1.29 & 504 & 654 & 1.30 \\
\hline 184D & 222 & 273 & 1.23 & 481 & 624 & 1.30 \\
\hline 184B & 143 & 180 & 1.26 & 417 & 545 & 1.31 \\
\hline 158 & 253 & 301 & 1.19 & 536 & 680 & 1.27 \\
\hline 183A & 114 & 141 & 1.24 & 479 & 629 & 1.31 \\
\hline 126C & 101 & 125 & 1.24 & 392 & 512 & 1.31 \\
\hline 178K & 290 & 404 & 1.39 & 527 & 710 & 1.35 \\
\hline 190F & 180 & 229 & 1.27 & 474 & 622 & 1.31 \\
\hline 190A & 204 & 256 & 1.25 & 478 & 613 & 1.28 \\
\hline 190E & 78 & 93 & 1.19 & 396 & 512 & 1.29 \\
\hline 191B & 157 & 200 & 1.27 & 421 & 450 & 1.07 \\
\hline Hall at 193A & 185 & 239 & 1.29 & 221 & 291 & 1.32 \\
\hline Conf 179 [A] & 222 & 272 & 1.23 & 825 & 1064 & 1.29 \\
\hline Conf 179 [B] & 226 & 276 & 1.22 & 784 & 1015 & 1.29 \\
\hline $\begin{array}{l}\text { Average } \\
\text { (offices only) }\end{array}$ & 168 & 213 & $\mathbf{1 . 2 6}$ & 462 & 596 & $\mathbf{1 . 2 9}$ \\
\hline $\begin{array}{l}\text { Minimum } \\
\text { (offices only) }\end{array}$ & 77 & 93 & $\mathbf{1 . 1 9}$ & 350 & 450 & $\mathbf{1 . 0 7}$ \\
\hline \begin{tabular}{l} 
Maximum (offices only) \\
\hline
\end{tabular} & 295 & 404 & $\mathbf{1 . 3 9}$ & 592 & 754 & $\mathbf{1 . 3 5}$ \\
\hline
\end{tabular}


Table C.2. Building A Post-Retrofit Photopic and Scotopic Measurements (Lux) and S/P Ratio

\begin{tabular}{|l|c|c|c|c|c|c|}
\hline \multirow{2}{*}{\begin{tabular}{l} 
Location \\
\cline { 2 - 7 }
\end{tabular}} & Photopic & Scotopic & $\begin{array}{c}\text { S/P } \\
\text { Ratio }\end{array}$ & Photopic & Scotopic & $\begin{array}{c}\text { S/P } \\
\text { Ratio }\end{array}$ \\
\hline 145A & 138 & 245 & 1.78 & 366 & 662 & 1.81 \\
\hline 146C & 70 & 120 & 1.71 & 364 & 661 & 1.82 \\
\hline 147A & 153 & 258 & 1.69 & 421 & 764 & 1.81 \\
\hline 147D & 123 & 211 & 1.72 & 354 & 649 & 1.83 \\
\hline 147E & 143 & 252 & 1.76 & 390 & 703 & 1.80 \\
\hline 145B & 99 & 171 & 1.73 & 333 & 603 & 1.81 \\
\hline 147C & 70 & 123 & 1.76 & 330 & 599 & 1.82 \\
\hline 129 & 204 & 347 & 1.70 & 436 & 779 & 1.79 \\
\hline 161B & 118 & 206 & 1.75 & 391 & 720 & 1.84 \\
\hline 162B & 175 & 311 & 1.78 & 414 & 749 & 1.81 \\
\hline 184D & 179 & 308 & 1.72 & 413 & 750 & 1.82 \\
\hline 184B & 113 & 192 & 1.70 & 370 & 673 & 1.82 \\
\hline 158 & 186 & 299 & 1.61 & 425 & 762 & 1.79 \\
\hline 183A & 66 & 116 & 1.76 & 370 & 669 & 1.81 \\
\hline 126C & 76 & 133 & 1.75 & 296 & 536 & 1.81 \\
\hline 178K & 167 & 287 & 1.72 & 378 & 682 & 1.80 \\
\hline 190F & 123 & 222 & 1.80 & 348 & 626 & 1.80 \\
\hline 190A & 154 & 273 & 1.77 & 367 & 674 & 1.84 \\
\hline 190E & 55 & 89 & 1.62 & 308 & 559 & 1.81 \\
\hline 191B & 115 & 198 & 1.72 & 335 & 613 & 1.83 \\
\hline Hall at 193A & 152 & 268 & 1.76 & 184 & 328 & 1.78 \\
\hline Conf 179 [A] & 180 & 303 & 1.68 & 656 & 1170 & 1.78 \\
\hline Conf 179 [B] & 181 & 309 & 1.71 & 621 & 1130 & 1.82 \\
\hline $\begin{array}{l}\text { Average } \\
\text { (offices only) }\end{array}$ & 126 & 218 & $\mathbf{1 . 7 3}$ & 370 & 672 & $\mathbf{1 . 8 1}$ \\
\hline $\begin{array}{l}\text { Minimum } \\
\text { (offices only) }\end{array}$ & 55 & 89 & $\mathbf{1 . 6 1}$ & 296 & 536 & $\mathbf{1 . 7 9}$ \\
\hline $\begin{array}{l}\text { Maximum } \\
\text { (offices only) }\end{array}$ & 204 & 347 & $\mathbf{1 . 8 0}$ & 436 & 779 & $\mathbf{1 . 8 4}$ \\
\hline
\end{tabular}


Table C.3. Building B Pre-Retrofit Photopic and Scotopic Data (Lux) and S/P Ratio

\begin{tabular}{|c|c|c|c|c|c|c|}
\hline \multirow[b]{2}{*}{ Location } & \multicolumn{3}{|c|}{ Vertical } & \multicolumn{3}{|c|}{ Horizontal } \\
\hline & Photopic & Scotopic & $\begin{array}{l}\text { S/P } \\
\text { Ratio }\end{array}$ & Photopic & Scotopic & $\begin{array}{l}\text { S/P } \\
\text { Ratio }\end{array}$ \\
\hline N370 Hall E under & 253 & 309 & 1.22 & 375 & 465 & 1.24 \\
\hline N370 Hall between & 293 & 360 & 1.23 & 460 & 569 & 1.24 \\
\hline N370 Hall Center under & 289 & 357 & 1.24 & 482 & 615 & 1.28 \\
\hline N370 Hall between & 170 & 202 & 1.19 & 603 & 756 & 1.25 \\
\hline N370 Hall under & 188 & 222 & 1.18 & 662 & 835 & 1.26 \\
\hline N370 Hall W between & 144 & 170 & 1.18 & 668 & 845 & 1.26 \\
\hline 384 & 58 & 76 & 1.31 & 322 & 399 & 1.24 \\
\hline 422 & 120 & 146 & 1.22 & 382 & 439 & 1.15 \\
\hline 351 & 67 & 87 & 1.30 & 420 & 522 & 1.24 \\
\hline 315 & 289 & 380 & 1.31 & 528 & 662 & 1.25 \\
\hline 299 & 191 & 237 & 1.24 & 622 & 776 & 1.25 \\
\hline 287 & 91 & 114 & 1.25 & 309 & 416 & 1.35 \\
\hline 293 & 192 & 238 & 1.24 & 600 & 766 & 1.28 \\
\hline 310 & 176 & 212 & 1.20 & 585 & 759 & 1.30 \\
\hline 228 & 241 & 296 & 1.23 & 601 & 771 & 1.28 \\
\hline 232 & 120 & 170 & 1.42 & 531 & 717 & 1.35 \\
\hline 207 & 142 & 179 & 1.26 & 421 & 539 & 1.28 \\
\hline 344 & 100 & 148 & 1.48 & 465 & 593 & 1.28 \\
\hline 262 & 127 & 159 & 1.25 & 690 & 887 & 1.29 \\
\hline 374 & 178 & 216 & 1.21 & 225 & 289 & 1.28 \\
\hline 260 & 114 & 142 & 1.25 & 454 & 585 & 1.29 \\
\hline 249 & 256 & 314 & 1.23 & 388 & 494 & 1.27 \\
\hline 277 & 51 & 62 & 1.22 & 329 & 413 & 1.26 \\
\hline 341 & 201 & 241 & 1.20 & 490 & 629 & 1.28 \\
\hline 285 & 217 & 270 & 1.24 & 444 & 559 & 1.26 \\
\hline 264 & 183 & 246 & 1.34 & 508 & 650 & 1.28 \\
\hline 427 & 130 & 157 & 1.21 & 403 & 511 & 1.27 \\
\hline 258 & 206 & 256 & 1.24 & 562 & 706 & 1.26 \\
\hline 332 & 230 & 306 & 1.33 & 509 & 646 & 1.27 \\
\hline 259 & 97 & 119 & 1.23 & 515 & 614 & 1.19 \\
\hline 224 & 178 & 224 & 1.26 & 554 & 714 & 1.29 \\
\hline 363 & 127 & 159 & 1.25 & 352 & 441 & 1.25 \\
\hline 297 & 158 & 188 & 1.19 & 523 & 664 & 1.27 \\
\hline 209 & 206 & 245 & 1.19 & 354 & 439 & 1.24 \\
\hline 244 & 85 & 103 & 1.21 & 386 & 482 & 1.25 \\
\hline 416 & 196 & 247 & 1.26 & 637 & 811 & 1.27 \\
\hline 296 & 35 & 44 & 1.26 & 187 & 232 & 1.24 \\
\hline 283 & 53 & 69 & 1.30 & 337 & 425 & 1.26 \\
\hline 275 & 284 & 364 & 1.28 & 508 & 663 & 1.31 \\
\hline 303 & 125 & 161 & 1.29 & 308 & 386 & 1.25 \\
\hline 269 & 133 & 168 & 1.26 & 678 & 857 & 1.26 \\
\hline 320 & 264 & 336 & 1.27 & 456 & 581 & 1.27 \\
\hline 392 & 227 & 285 & 1.26 & 646 & 822 & 1.27 \\
\hline 240 & 93 & 117 & 1.26 & 350 & 423 & 1.21 \\
\hline
\end{tabular}




\begin{tabular}{|l|r|r|r|r|r|r|}
\hline & \multicolumn{3}{|c|}{ Vertical } & \multicolumn{3}{|c|}{ Horizontal } \\
\cline { 2 - 8 } Location & & & \multicolumn{1}{l|}{ S/P } & & & \multicolumn{1}{l|}{ S/P } \\
\hline 210 & Photopic & Scotopic & Ratio & Photopic & Scotopic & Ratio \\
\hline 408 & 153 & 192 & 1.25 & 503 & 626 & 1.24 \\
\hline 308 & 179 & 220 & 1.23 & 696 & 891 & 1.28 \\
\hline 340 & 120 & 150 & 1.25 & 612 & 785 & 1.28 \\
\hline 257 & 118 & 150 & 1.27 & 558 & 727 & 1.30 \\
\hline 225 & 94 & 121 & 1.29 & 635 & 822 & 1.29 \\
\hline 220 & 191 & 251 & 1.31 & 531 & 704 & 1.33 \\
\hline 218 & 185 & 227 & 1.23 & 333 & 412 & 1.24 \\
\hline 343 & 138 & 170 & 1.23 & 643 & 823 & 1.28 \\
\hline 272 & 113 & 148 & 1.31 & 234 & 311 & 1.33 \\
\hline 289 & 69 & 89 & 1.29 & 366 & 475 & 1.30 \\
\hline Average (offices only) & 139 & 182 & 1.31 & 260 & 357 & 1.37 \\
\hline Minimum (offices only) & 151.8 & 191.4 & $\mathbf{1 . 2 6}$ & 468.4 & 596.2 & $\mathbf{1 . 2 7}$ \\
\hline Maximum (offices only) & 35 & 44 & $\mathbf{1 . 1 9}$ & 187 & 232 & $\mathbf{1 . 1 5}$ \\
\hline
\end{tabular}

Table C.4. Building B Post-Retrofit Photopic and Scotopic Data (Lux) and S/P Ratio

\begin{tabular}{|l|r|r|r|r|r|r|}
\hline & \multicolumn{3}{|c|}{ Vertical } & \multicolumn{3}{|c|}{ Horizontal } \\
\cline { 2 - 8 } Location & & & \multicolumn{1}{l|}{ S/P } & & & \multicolumn{1}{l|}{ S/P } \\
\hline N370 Hall E under & 122 & 207 & 1.70 & 420 & 765 & 1.82 \\
\hline N370 Hall between & 201 & 359 & 1.79 & 339 & 612 & 1.81 \\
\hline N370 Hall Center under & 103 & 74 & 0.72 & 463 & 852 & 1.84 \\
\hline N370 Hall between & 183 & 321 & 1.75 & 262 & 471 & 1.80 \\
\hline N370 Hall under & 134 & 225 & 1.68 & 470 & 859 & 1.83 \\
\hline N370 Hall W between & 212 & 375 & 1.77 & 342 & 625 & 1.83 \\
\hline 384 & 36 & 64 & 1.78 & 203 & 371 & 1.83 \\
\hline 422 & 73 & 129 & 1.77 & 263 & 472 & 1.79 \\
\hline 351 & 40 & 76 & 1.90 & 282 & 508 & 1.80 \\
\hline 315 & 151 & 299 & 1.98 & 376 & 688 & 1.83 \\
\hline 299 & 121 & 228 & 1.88 & 439 & 805 & 1.83 \\
\hline 287 & 60 & 108 & 1.80 & 219 & 412 & 1.88 \\
\hline 293 & 143 & 251 & 1.76 & 426 & 795 & 1.87 \\
\hline 310 & 119 & 220 & 1.85 & 390 & 729 & 1.87 \\
\hline 228 & 144 & 259 & 1.80 & 382 & 712 & 1.86 \\
\hline 232 & 87 & 151 & 1.74 & 395 & 745 & 1.89 \\
\hline 207 & 71 & 117 & 1.65 & 286 & 520 & 1.82 \\
\hline 344 & 84 & 166 & 1.98 & 294 & 550 & 1.87 \\
\hline 262 & 126 & 221 & 1.75 & 382 & 725 & 1.90 \\
\hline 374 & 107 & 184 & 1.72 & 148 & 270 & 1.82 \\
\hline 260 & 94 & 168 & 1.79 & 357 & 660 & 1.85 \\
\hline 249 & 192 & 343 & 1.79 & 289 & 531 & 1.84 \\
\hline 277 & 31 & 54 & 1.74 & 221 & 409 & 1.85 \\
\hline 341 & 129 & 225 & 1.74 & 327 & 612 & 1.87 \\
\hline 285 & 148 & 273 & 1.84 & 307 & 556 & 1.81 \\
\hline
\end{tabular}




\begin{tabular}{|c|c|c|c|c|c|c|}
\hline \multirow[b]{2}{*}{ Location } & \multicolumn{3}{|c|}{ Vertical } & \multicolumn{3}{|c|}{ Horizontal } \\
\hline & Photopic & Scotopic & $\begin{array}{l}\mathrm{S} / \mathrm{P} \\
\text { Ratio }\end{array}$ & Photopic & Scotopic & $\begin{array}{l}\text { S/P } \\
\text { Ratio }\end{array}$ \\
\hline 264 & 110 & 209 & 1.90 & 373 & 692 & 1.86 \\
\hline 427 & 97 & 172 & 1.77 & 298 & 520 & 1.74 \\
\hline 258 & 146 & 262 & 1.79 & 387 & 706 & 1.82 \\
\hline 332 & 164 & 292 & 1.78 & 355 & 649 & 1.83 \\
\hline 259 & 72 & 128 & 1.78 & 347 & 629 & 1.81 \\
\hline 224 & 161 & 300 & 1.86 & 446 & 835 & 1.87 \\
\hline 363 & 95 & 174 & 1.83 & 276 & 553 & 2.00 \\
\hline 297 & 83 & 143 & 1.72 & 255 & 467 & 1.83 \\
\hline 209 & 171 & 310 & 1.81 & 237 & 446 & 1.88 \\
\hline 244 & 73 & 126 & 1.73 & 336 & 609 & 1.81 \\
\hline 416 & 107 & 195 & 1.82 & 442 & 819 & 1.85 \\
\hline 296 & 32 & 60 & 1.88 & 166 & 316 & 1.90 \\
\hline 283 & 83 & 140 & 1.69 & 235 & 430 & 1.83 \\
\hline 275 & 137 & 249 & 1.82 & 204 & 373 & 1.83 \\
\hline 303 & 88 & 161 & 1.83 & 265 & 492 & 1.86 \\
\hline 269 & 87 & 147 & 1.69 & 430 & 837 & 1.95 \\
\hline 320 & 138 & 240 & 1.74 & 292 & 523 & 1.79 \\
\hline 392 & 174 & 318 & 1.83 & 523 & 956 & 1.83 \\
\hline 240 & 60 & 109 & 1.82 & 204 & 390 & 1.91 \\
\hline 210 & 132 & 236 & 1.79 & 296 & 559 & 1.89 \\
\hline 408 & 92 & 169 & 1.84 & 510 & 958 & 1.88 \\
\hline 308 & 85 & 160 & 1.88 & 423 & 778 & 1.84 \\
\hline 340 & 88 & 157 & 1.78 & 387 & 722 & 1.87 \\
\hline 257 & 54 & 101 & 1.87 & 381 & 722 & 1.90 \\
\hline 225 & 125 & 221 & 1.77 & 370 & 707 & 1.91 \\
\hline 220 & 163 & 297 & 1.82 & 261 & 492 & 1.89 \\
\hline 218 & 94 & 166 & 1.77 & 488 & 909 & 1.86 \\
\hline 343 & 59 & 119 & 2.02 & 157 & 275 & 1.75 \\
\hline 272 & 98 & 184 & 1.88 & 290 & 535 & 1.84 \\
\hline 289 & 114 & 205 & 1.80 & 123 & 245 & 1.99 \\
\hline Average (offices only) & 104.9 & 189.5 & 1.81 & 321.3 & 596.2 & 1.86 \\
\hline Minimum (offices only) & 31 & 54 & 1.65 & 123 & 245 & 1.74 \\
\hline Maximum (offices only) & 192 & 343 & 2.02 & 523 & 958 & 2.00 \\
\hline
\end{tabular}

Table C.5. Building C Pre-Retrofit Photopic and Scotopic Data (Lux) and S/P ratio

\begin{tabular}{|r|r|r|r|r|r|r|r|}
\hline \multicolumn{2}{|c|}{ Location } & \multicolumn{3}{|c|}{ Vertical } & \multicolumn{3}{|c|}{ Horizontal } \\
\hline Floor & Room Num & & & \multicolumn{1}{l|}{ S/P } & & & \multicolumn{1}{l|}{ S/P } \\
& & Photopic & Scotopic & Ratio & Photopic & Scotopic & Ratio \\
\hline 1 & 4 & 160 & 242 & 1.51 & 578 & 910 & 1.57 \\
\hline 1 & 6 & 312 & 483 & 1.55 & 697 & 1094 & 1.57 \\
\hline 1 & 7 & 65 & 95 & 1.46 & 385 & 604 & 1.57 \\
\hline 1 & 10 & 217 & 228 & 1.05 & 623 & 992 & 1.59 \\
\hline 1 & 12 & 227 & 361 & 1.59 & 637 & 1018 & 1.60 \\
\hline
\end{tabular}




\begin{tabular}{|c|c|c|c|c|c|c|c|}
\hline \multirow{2}{*}{\multicolumn{2}{|c|}{ Floor $\quad \begin{array}{l}\text { Location } \\
\text { Room Num }\end{array}$}} & \multicolumn{3}{|c|}{ Vertical } & \multicolumn{3}{|c|}{ Horizontal } \\
\hline & & Photopic & Scotopic & $\begin{array}{l}\text { S/P } \\
\text { Ratio }\end{array}$ & Photopic & Scotopic & $\begin{array}{l}\text { S/P } \\
\text { Ratio }\end{array}$ \\
\hline 1 & 14 & 84 & 124 & 1.48 & 600 & 962 & 1.60 \\
\hline 1 & 15 & 282 & 440 & 1.56 & 578 & 933 & 1.61 \\
\hline 1 & 17 & 250 & 388 & 1.55 & 587 & 936 & 1.59 \\
\hline 1 & 18 & 305 & 473 & 1.55 & 586 & 941 & 1.61 \\
\hline 1 & 20 & 112 & 169 & 1.51 & 521 & 834 & 1.60 \\
\hline 1 & 21 & 282 & 486 & 1.72 & 534 & 846 & 1.58 \\
\hline 1 & 25 & 93 & 151 & 1.62 & 535 & 855 & 1.60 \\
\hline 1 & 27 & 91 & 138 & 1.52 & 535 & 857 & 1.60 \\
\hline 1 & 29 & 274 & 429 & 1.57 & 538 & 835 & 1.55 \\
\hline 1 & 31 & 83 & 135 & 1.63 & 489 & 785 & 1.61 \\
\hline 1 & 32 & 316 & 499 & 1.58 & 551 & 867 & 1.57 \\
\hline 1 & 41 & 69 & 98 & 1.42 & 535 & 829 & 1.55 \\
\hline 1 & 42 & 95 & 131 & 1.38 & 407 & 653 & 1.60 \\
\hline 1 & 43 & 56 & 89 & 1.59 & 479 & 764 & 1.59 \\
\hline 1 & 47 & 95 & 151 & 1.59 & 561 & 895 & 1.60 \\
\hline 1 & 51 & 194 & 291 & 1.50 & 490 & 782 & 1.60 \\
\hline 1 & 53 & 182 & 279 & 1.53 & 464 & 736 & 1.59 \\
\hline 1 & 54 & 65 & 103 & 1.58 & 486 & 773 & 1.59 \\
\hline 1 & 58 & 174 & 269 & 1.55 & 530 & 834 & 1.57 \\
\hline 1 & 59 & 153 & 247 & 1.61 & 510 & 823 & 1.61 \\
\hline 1 & 81 & 239 & 364 & 1.52 & 705 & 1126 & 1.60 \\
\hline 2 & 5 & 100 & 159 & 1.59 & 560 & 884 & 1.58 \\
\hline 2 & 6 & 335 & 538 & 1.61 & 357 & 586 & 1.64 \\
\hline 2 & 7 & 364 & 575 & 1.58 & 692 & 1008 & 1.46 \\
\hline 2 & 8 & 365 & 575 & 1.58 & 770 & 1262 & 1.64 \\
\hline 2 & 9 & 349 & 560 & 1.60 & 678 & 1109 & 1.64 \\
\hline 2 & 11 & 273 & 425 & 1.56 & 491 & 790 & 1.61 \\
\hline 2 & 15 & 373 & 593 & 1.59 & 740 & 1167 & 1.58 \\
\hline 2 & 20 & 72 & 113 & 1.57 & 524 & 840 & 1.60 \\
\hline 2 & 25 & 132 & 212 & 1.61 & 585 & 934 & 1.60 \\
\hline 2 & 27 & 60 & 93 & 1.55 & 436 & 685 & 1.57 \\
\hline 2 & 28 & 65 & 102 & 1.57 & 556 & 892 & 1.60 \\
\hline 2 & 29 & 60 & 98 & 1.63 & 763 & 1213 & 1.59 \\
\hline 2 & 30 & 73 & 109 & 1.49 & 388 & 612 & 1.58 \\
\hline 2 & 31 & 286 & 453 & 1.58 & 571 & 897 & 1.57 \\
\hline 2 & 32 & 78 & 117 & 1.50 & 505 & 758 & 1.50 \\
\hline 2 & 36 & 130 & 192 & 1.48 & 732 & 1164 & 1.59 \\
\hline 2 & 37 & 33 & 45 & 1.36 & 252 & 399 & 1.58 \\
\hline 2 & 38 & 226 & 350 & 1.55 & 493 & 777 & 1.58 \\
\hline 2 & 41 & 39 & 59 & 1.51 & 455 & 709 & 1.56 \\
\hline 2 & 44 & 89 & 133 & 1.49 & 572 & 919 & 1.61 \\
\hline 2 & 45 & 258 & 412 & 1.60 & 595 & 937 & 1.57 \\
\hline 2 & 46 & 220 & 346 & 1.57 & 608 & 970 & 1.60 \\
\hline
\end{tabular}




\begin{tabular}{|c|c|c|c|c|c|c|c|}
\hline \multicolumn{2}{|c|}{ Location } & \multicolumn{3}{|c|}{ Vertical } & \multicolumn{3}{|c|}{ Horizontal } \\
\hline Floor & Room Num & Photopic & Scotopic & $\begin{array}{l}\text { S/P } \\
\text { Ratio }\end{array}$ & Photopic & Scotopic & $\begin{array}{l}\text { S/P } \\
\text { Ratio }\end{array}$ \\
\hline 2 & 50 & 179 & 285 & 1.59 & 647 & 1069 & 1.65 \\
\hline 2 & 51 & 39 & 62 & 1.59 & 205 & 326 & 1.59 \\
\hline 2 & 55 & 63 & 96 & 1.52 & 369 & 591 & 1.60 \\
\hline 2 & 56 & 117 & 174 & 1.49 & 586 & 931 & 1.59 \\
\hline 2 & 60 & 62 & 95 & 1.53 & 398 & 644 & 1.62 \\
\hline 2 & 62 & 115 & 170 & 1.48 & 305 & 467 & 1.53 \\
\hline 2 & 67 & 175 & 263 & 1.50 & 667 & 1069 & 1.60 \\
\hline 2 & 68 & 191 & 278 & 1.46 & 637 & 1038 & 1.63 \\
\hline 2 & 69 & 99 & 150 & 1.52 & 777 & 1248 & 1.61 \\
\hline 2 & 74 & 121 & 195 & 1.61 & 513 & 774 & 1.51 \\
\hline 2 & 79 & 178 & 277 & 1.56 & 706 & 1128 & 1.60 \\
\hline 2 & 80 & 276 & 443 & 1.61 & 968 & 1524 & 1.57 \\
\hline 2 & 82 & 77 & 119 & 1.55 & 400 & 653 & 1.63 \\
\hline 2 & 85 & 213 & 340 & 1.60 & 705 & 1159 & 1.64 \\
\hline 2 & 92 & 129 & 185 & 1.43 & 688 & 1098 & 1.60 \\
\hline 2 & 94 & 95 & 137 & 1.44 & 690 & 1052 & 1.52 \\
\hline \multicolumn{2}{|c|}{ Average } & 165.4 & 256.1 & 1.54 & 558.2 & 887.0 & 1.59 \\
\hline \multicolumn{2}{|c|}{ Minimum } & 33 & 45 & 1.05 & 205 & 326 & 1.46 \\
\hline \multicolumn{2}{|c|}{ Maximum } & 373 & 593 & 1.72 & 968 & 1524 & 1.65 \\
\hline
\end{tabular}

Table C.6. Building C Post-Retrofit Photopic and Scotopic Data (Lux) and S/P Ratio

\begin{tabular}{|r|r|r|r|r|r|r|r|}
\hline \multicolumn{2}{|c|}{ Location } & \multicolumn{3}{|c|}{ Vertical } & \multicolumn{3}{|c|}{ Horizontal } \\
\hline Floor & Room Num & Photopic & Scotopic & \multicolumn{1}{l}{$\begin{array}{l}\text { R/P } \\
\text { Ratio }\end{array}$} & Photopic & Scotopic & \multicolumn{1}{l|}{ Ratio } \\
\hline 1 & 4 & 152 & 271 & 1.78 & 448 & 843 & 1.88 \\
\hline 1 & 6 & 293 & 538 & 1.84 & 576 & 1071 & 1.86 \\
\hline 1 & 7 & 65 & 120 & 1.85 & 323 & 617 & 1.91 \\
\hline 1 & 10 & 166 & 316 & 1.90 & 509 & 949 & 1.86 \\
\hline 1 & 12 & 164 & 312 & 1.90 & 581 & 1147 & 1.97 \\
\hline 1 & 14 & 88 & 148 & 1.68 & 473 & 892 & 1.89 \\
\hline 1 & 15 & 229 & 446 & 1.95 & 474 & 920 & 1.94 \\
\hline 1 & 17 & 219 & 414 & 1.89 & 474 & 895 & 1.89 \\
\hline 1 & 18 & 248 & 457 & 1.84 & 527 & 987 & 1.87 \\
\hline 1 & 20 & 103 & 193 & 1.87 & 498 & 949 & 1.91 \\
\hline 1 & 21 & 282 & 540 & 1.91 & 502 & 964 & 1.92 \\
\hline 1 & 25 & 57 & 107 & 1.88 & 286 & 577 & 2.02 \\
\hline 1 & 27 & 37 & 70 & 1.89 & 183 & 365 & 1.99 \\
\hline 1 & 29 & 277 & 511 & 1.84 & 503 & 964 & 1.92 \\
\hline 1 & 31 & 71 & 137 & 1.93 & 449 & 876 & 1.95 \\
\hline 1 & 32 & 256 & 471 & 1.84 & 481 & 915 & 1.90 \\
\hline 1 & 41 & 75 & 128 & 1.71 & 508 & 1041 & 2.05 \\
\hline 1 & 42 & 53 & 125 & 2.36 & 365 & 700 & 1.92 \\
\hline
\end{tabular}




\begin{tabular}{|c|c|c|c|c|c|c|c|}
\hline \multirow[b]{2}{*}{ Floor } & \multirow{2}{*}{$\begin{array}{l}\text { Location } \\
\text { Room Num }\end{array}$} & \multicolumn{3}{|c|}{ Vertical } & \multicolumn{3}{|c|}{ Horizontal } \\
\hline & & Photopic & Scotopic & $\begin{array}{l}\text { S/P } \\
\text { Ratio }\end{array}$ & Photopic & Scotopic & $\begin{array}{l}\text { S/P } \\
\text { Ratio }\end{array}$ \\
\hline 1 & 43 & 76 & 143 & 1.88 & 465 & 912 & 1.96 \\
\hline 1 & 47 & 98 & 177 & 1.81 & 503 & 946 & 1.88 \\
\hline 1 & 51 & 209 & 387 & 1.85 & 435 & 813 & 1.87 \\
\hline 1 & 53 & 127 & 239 & 1.88 & 375 & 725 & 1.93 \\
\hline 1 & 54 & 244 & 442 & 1.81 & 475 & 900 & 1.89 \\
\hline 1 & 58 & 257 & 465 & 1.81 & 492 & 929 & 1.89 \\
\hline 1 & 59 & 178 & 324 & 1.82 & 418 & 803 & 1.92 \\
\hline 1 & 81 & 207 & 381 & 1.84 & 636 & 1192 & 1.87 \\
\hline 2 & 5 & 316 & 575 & 1.82 & 329 & 649 & 1.97 \\
\hline 2 & 6 & 278 & 518 & 1.86 & 289 & 574 & 1.99 \\
\hline 2 & 7 & 318 & 596 & 1.87 & 569 & 1127 & 1.98 \\
\hline 2 & 8 & 310 & 574 & 1.85 & 604 & 1169 & 1.94 \\
\hline 2 & 9 & 310 & 570 & 1.84 & 600 & 1079 & 1.80 \\
\hline 2 & 11 & 245 & 458 & 1.87 & 435 & 814 & 1.87 \\
\hline 2 & 15 & 313 & 583 & 1.86 & 661 & 1249 & 1.89 \\
\hline 2 & 20 & 70 & 125 & 1.79 & 478 & 900 & 1.88 \\
\hline 2 & 25 & 83 & 145 & 1.75 & 488 & 908 & 1.86 \\
\hline 2 & 27 & 46 & 83 & 1.80 & 396 & 754 & 1.90 \\
\hline 2 & 28 & 48 & 86 & 1.79 & 449 & 843 & 1.88 \\
\hline 2 & 29 & 76 & 137 & 1.80 & 604 & 1119 & 1.85 \\
\hline 2 & 30 & 56 & 108 & 1.93 & 316 & 585 & 1.85 \\
\hline 2 & 31 & 235 & 428 & 1.82 & 527 & 989 & 1.88 \\
\hline 2 & 32 & 94 & 171 & 1.82 & 543 & 1029 & 1.90 \\
\hline 2 & 36 & 113 & 207 & 1.83 & 652 & 1234 & 1.89 \\
\hline 2 & 37 & 34 & 61 & 1.79 & 216 & 414 & 1.92 \\
\hline 2 & 38 & 138 & 271 & 1.96 & 420 & 805 & 1.92 \\
\hline 2 & 41 & 53 & 97 & 1.83 & 412 & 785 & 1.91 \\
\hline 2 & 44 & 77 & 144 & 1.87 & 515 & 966 & 1.88 \\
\hline 2 & 45 & 229 & 419 & 1.83 & 539 & 1016 & 1.88 \\
\hline 2 & 46 & 155 & 277 & 1.79 & 541 & 1027 & 1.90 \\
\hline 2 & 50 & 154 & 285 & 1.85 & 539 & 1045 & 1.94 \\
\hline 2 & 51 & 34 & 61 & 1.79 & 180 & 344 & 1.91 \\
\hline 2 & 55 & 50 & 94 & 1.88 & 315 & 577 & 1.83 \\
\hline 2 & 56 & 93 & 171 & 1.84 & 510 & 966 & 1.89 \\
\hline 2 & 60 & 55 & 103 & 1.87 & 329 & 598 & 1.82 \\
\hline 2 & 62 & 38 & 66 & 1.74 & 245 & 464 & 1.89 \\
\hline 2 & 67 & 121 & 219 & 1.81 & 569 & 1066 & 1.87 \\
\hline 2 & 68 & 217 & 392 & 1.81 & 532 & 1027 & 1.93 \\
\hline 2 & 69 & 89 & 164 & 1.84 & 727 & 1372 & 1.89 \\
\hline 2 & 74 & 119 & 208 & 1.75 & 381 & 723 & 1.90 \\
\hline 2 & 79 & 136 & 238 & 1.75 & 636 & 1204 & 1.89 \\
\hline 2 & 80 & 226 & 419 & 1.85 & 817 & 1562 & 1.91 \\
\hline 2 & 82 & 100 & 97 & 0.97 & 397 & 726 & 1.83 \\
\hline
\end{tabular}




\begin{tabular}{|c|c|c|c|c|c|c|c|}
\hline \multicolumn{2}{|c|}{ Location } & \multicolumn{3}{|c|}{ Vertical } & \multicolumn{3}{|c|}{ Horizontal } \\
\hline Floor & Room Num & Photopic & Scotopic & $\begin{array}{l}\text { S/P } \\
\text { Ratio }\end{array}$ & Photopic & Scotopic & $\begin{array}{l}\text { S/P } \\
\text { Ratio }\end{array}$ \\
\hline 2 & 85 & 167 & 308 & 1.84 & 546 & 1045 & 1.91 \\
\hline 2 & 92 & 151 & 272 & 1.80 & 508 & 980 & 1.93 \\
\hline 2 & 94 & 70 & 121 & 1.73 & 569 & 1086 & 1.91 \\
\hline \multicolumn{2}{|c|}{ Average } & 150.8 & 276.8 & 1.83 & 474.1 & 901.8 & 1.90 \\
\hline \multicolumn{2}{|c|}{ Minimum } & 34 & 61 & 0.97 & 180 & 344 & 1.80 \\
\hline \multicolumn{2}{|c|}{ Maximum } & 318 & 596 & 2.36 & 817 & 1562 & 2.05 \\
\hline
\end{tabular}


Appendix D

\section{Task Lighting Data Logger Specifications for the} HOBO ${ }^{\circ}$ Data Loggers 


\section{Appendix D: \\ Task Lighting Data Logger Specifications for the HOBO ${ }^{\circ}$ Data Loggers}

Based upon application, users can choose single-, two-, or four-channel models to measure temperature, relative humidity, light intensity, or external inputs.

External sensors or input cables allow the H8 loggers to measure external temperature, AC current, or accept $\mathrm{mA}$ and voltage inputs from third-party sensors.

\section{Family Features \& Specifications}

- 8-bit resolution

- Record $8 \mathrm{~K}$ readings (4 channel external records $32 \mathrm{~K}$ readings)

- Programmable start time/date

- Programmable sampling rate (0.5 second to 9 hours)

- Blinking LED confirms operation

- Memory modes: Stop when full, Wrap-around when full

- User-replaceable battery lasts 1 year (typical)

- Battery level indication at launch

- Non-volatile memory retains data even if battery fails

- $\quad$ NIST-Traceable temperature accuracy certification available

- Compliance certificate available

- Readout and relaunch with optional HOBO Shuttle

- Size/Weight: 6.0 x 4.8 x $1.9 \mathrm{~cm}(2.4$ x 1.9 x 0.8")/approx. 29 gms ( 1 oz.)

- Detailed specifications for H8 loggers

- Light Intensity Measurement Range: 2 to 600 footcandles (lumens/ $/ \mathrm{ft}^{2}$ ) typical; max. value varies from 300 to 900 footcandles. 


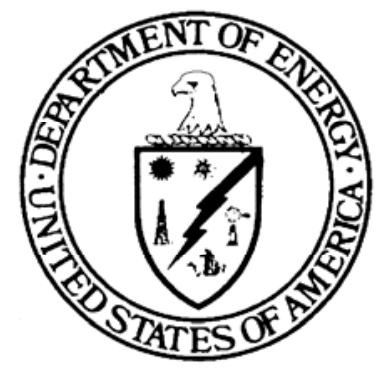

U.S. Department of Energy

Office of Energy Efficiency and Renewable Energy 